UNIVERSIDADE DE SÃO PAULO

FACULDADE DE ODONTOLOGIA

\title{
ESTUDO DA ALTERAÇÃO DA PRECISÃO DE MONTAGEM DO MODELO SUPERIOR EM ARTICULADOR SEMI-AJUSTÁVEL POR MEIO DO ARCO FACIAL SIMPLES
}

ROGÉRIO RIBAS DA COSTA

\begin{abstract}
Dissertação apresentada à Faculdade de Odontologia da Universidade d e São Paulo, para concorrer ao Título de Mestre, pelo Curso de Pós-Graduação em Odontologia. Área de Concentração: Prótese Dental
\end{abstract}


Data da Defesa: 02/07/1998.

BANCA EXAMINADORA

Prof. Dr. ARTEMIO LUIZ ZANETTI

Julgamento: Assinatura:

Prof $^{\text {a. }}$ Dr $^{\text {a. }}$ DALVA CRUZ LAGANÁ

Julgamento: Assinatura:

Prof. Dr. RICARDO TATSUO INOUE

Julgamento: Assinatura: 
UNIVERSIDADE DE SÃO PAULO

FACULDADE DE ODONTOLOGIA

\title{
ESTUDO DA ALTERAÇÃO DA PRECISÃO DE MONTAGEM DO MODELO SUPERIOR EM ARTICULADOR SEMI-AJUSTÁVEL POR MEIO DO ARCO FACIAL SIMPLES
}

\author{
ROGÉRIO RIBAS DA COSTA
}

\begin{abstract}
Dissertação apresentada à Faculdade de Odontologia da Universidade d e São Paulo, para concorrer ao Título de Mestre, pelo Curso de Pós-Graduação em Odontologia. Área de Concentração: Prótese Dental
\end{abstract}

Orientador

Prof. Dr. Artemio Luiz Zanetti

Co-orientador

Prof. Dr. Ricardo Tatsuo Inoue 


\section{Catalogação-na-Publicação}

Serviço de Documentação Odontológica

Faculdade de Odontologia da Universidade de São Paulo

Costa, Rogério Ribas da

Estudo da alteração da precisão de montagem do modelo superior em articulador semi-ajustável por meio do arco facial simples / Rogério Ribas da Costa ; orientador Artemio Luiz Zanetti, co-orientador Ricardo Tatsuo Inoue. -- São Paulo, 1998.

94p. : il.

Tese (Mestrado - Curso de Pós-Graduação em Odontologia. Área de Concentração em Prótese Dental) -- Faculdade de Odontologia da Universidade de São Paulo.

1. Articulador - Prótese dentária 2. Montagem no articulador 


\section{À Paula Cezar Ribas da Costa,}

pelo seu amor e imensa paciência.

Aos meus queridos filhos Marcelo e Bruno, pelo amor, carinho e compreensão que tiveram quando não pude estar presente.

Aos meus queridos pais, Roseny e Rosária, meus primeiros mestres, por todo amor que sempre me dedicaram e, especialmente, por terem me ensinado e incentivado a estudar.

Aos meus familiares, irmãos, cunhados, sobrinhos e tios pelo interesse e incentivo recebidos. 
Ao Prof. Dr. Artemio Luiz Zanetti, pela sua amizade, apoio, incentivo e inesgotável compreensão sempre que foram precisos e que tantas vezes foram demonstrados e ainda, pelo seu valioso ensino, estimulo e orientação, essenciais não somente para a concretização deste trabalho, mas também para a minha carreira profissional e universitária. 
Ao Prof. Dr. Ricardo Tatsuo Inoue, meu co-orientador, por toda sua dedicação, incentivo, colaboração e pela sincera amizade, essenciais para a elaboração deste trabalho. 
À srta. Joelma Moraes de Oliveira, pela sua dedicação e inesgotável paciência durante esses 10 anos de assistência no consultório e, também, pelo seu valioso auxilio prestado ao longo deste trabalho, principalmente em todo material fotográfico. 


\section{AGRADECIMENTOS}

A Prof ${ }^{\text {a. }}$ Dra.- Dalva Cruz Lagana, pelos conselhos e orientações recebidos ao longo de minha vida académica.

Ao Prof. Dr. Eduardo Elviro Froner, pela colaboração e incentivo sempre presentes.

A Prof ${ }^{\text {a. }}$ Ana Cristina Aurora Rosa Perasso Guariglia, pela sua sincera amizade e conselhos imprescindíveis.

Ao Prof. Dr. José Virgílio de Paula Eduardo, pelo incentivo e compreensão essenciais para este trabalho.

A todos meus colegas da equipe do Departamento de Prótese Dental da Faculdade de Odontologia da Universidade Cidade de São Paulo, pela sincera amizade, companheirismo e incentivo recebidos.

Ao Prof. Dr. Hamilton Navarro, pela sua amizade e incentivo desde o inicio de minha carreira.

A todos colegas do Departamento de Prótese Dental da Faculdade de Odontologia da Universidade de São Paulo pelo companheirismo e apoio.

Ao Jurandir Mariano de Oliveira pela dedicação no trabalho de diagramação das fotografias.

A Fundação de Amparo a Pesquisa do Estado de São Paulo FAPESP - pela concessão da bolsa de estudo.

Ao Sr. Sérgio Miglioli pela dedicação no trabalho de impressão.

Aos pacientes pela confiança depositada em meu atendimento. 


\section{SUMÁRIO}

p.

\section{RESUMO}

1. INTRODUÇÃO ............................................................ 1

2. REVISTA DA LITERATURA ............................................ 3

2.1 Articuladores

2.1.1 Histórico ........................................................................... 3

2.1.2 Considerações gerais ........................................................ 8

2.1.3 Classificação ............................................................... 12

2.1.3.1 Articuladores simples ou não ajustáveis ............................... 15

2.1.3.2 Articuladores semi-ajustáveis ......................................... 16

2.1.3.3 Articuladores totalmente ajustáveis ................................ 21

2.2. Arco Facial

2.2.1 Considerações gerais ...................................................... 23

2.2.2 Tipos de dispositivos ................................................... 31

2.2.2.1 Arco facial simples ................................................. 32

2.2.2.2 Arco facial cinemático .................................................... 34

2.2.2.3 Arco facial pantográfico ................................................ 35

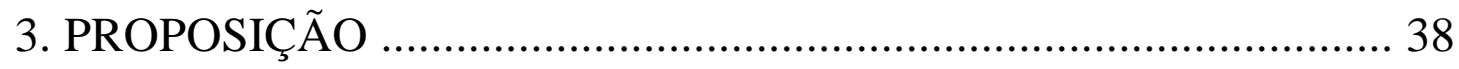

4. MATERIAIS E MÉTODO ..................................................... 39

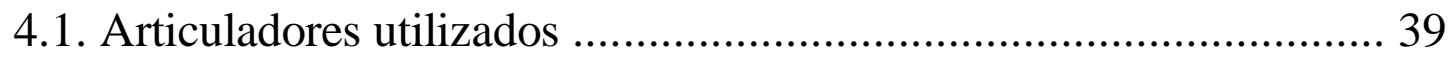

4.2. Método de moldagem e obtenção dos modelos de gesso ............... 41

4.3. Método de registro do arco facial e montagem no articulador ........ 42

4.4. Método de avaliação da montagem do arco facial do articulador .... 47

5. RESULTADOS ................................................................ 59

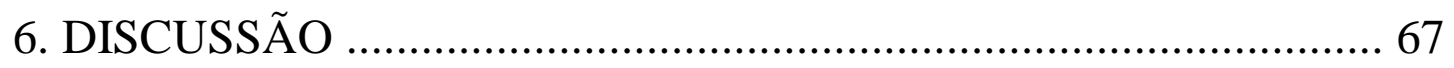

7. CONCLUSÕES ........................................................... 79

REFERÊNCIAS BIBLIOGRÁFICAS ....................................... 83

SUMMARY 


\section{LISTA DE FIGURAS}

p.

Figura 1 - Detalhe de um articulador do tipo arcon 39

Figura 2 - Articuladores utilizados: (a) Whip-Mix 8500; (b) Dent-Flex 10600; (c) Gnatus 8600; (d) Bio Art WM-LS; (e) Bio Art 4000 40

Figura 3 - Observar a correta posição de descanso do arco sobre a mesa de trabalho, enquanto se prepara o articulador para recebê-lo. A banda elástica é colocada nesta fase

Figura 4 - Ajuste dos guias do movimento lateral com angulação negativa para facilitar o manuseio do ramo superior do articulador (seta). 45

Figura 5 - Arco facial montado no ramo superior e apoiado sobre o ramo inferior do articulador 46

Figura 6 - Localização dos pinos metálicos utilizados para a mensuração na região do $1^{\circ}$ molar superior esquerdo. Observar os pinos metálicos utilizados neste procedimento (setas)

Figura 7 - Localização dos pinos metálicos utilizados para a mensuração na região do $2^{\circ}$ molar superior esquerdo. Observar os pinos metálicos utilizados neste procedimento 48

Figura 8 - Detalhe do paquímetro digital 49

Figura 9 - Colocação de 1 elástico passando ao redor das duas metades do arco facial e pela haste vertical do suporte geral do arco facial do articulador Whip-Mix 50

Figura 10 - Colocação de 1 elástico passando pelos ramos superior e inferior do articulador Dent-Flex 10600 51 Figura 11 - Colocação de 3 elásticos no articulador Gnatus 8600, sendo 2 passando pelo lado direito e esquerdo do pino incisal no ramo superior e pelo parafuso da mesa incisal no ramo inferior e outro passando pelos parafusos de aperto condilar direito e esquerdo 
Figura 12 - Colocação de 2 elásticos no articulador Bio Art WM-LS, sendo 1 pelo lado esquerdo do pino incisal e parafuso da mesa incisal e outro passando pelos parafusos de aperto condilar direito e esquerdo 52 Figura 13 - Colocação de 1 elástico no articulador Bio Art 4000, passando pelo arco facial e pelo ramo inferior do mesmo 53 Figura 14 - Detalhe do suporte anterior do arco facial: (a) presilha em alumínio com parafuso de pressão; (b) haste com rosca interna; (c) parafuso extensor com rosca sem fim 54

Figura 15 - Colocação do suporte do arco facial na linha mediana da borda anterior do mesmo 55

Figura 16 - Ajuste da altura do suporte anterior do arco facial 56

Figura 17 - Suporte anterior do arco facial instalado 57 Figura 18 - O suporte anterior do arco facial deve ser ajustado de modo que nenhuma parte do arco encoste no ramo inferior do articulador 58 Figura 19 - inclinação da presilha inferior favorecendo o aumento do efeito de alavanca (seta) 60 Figura 20 - Efeito de alavanca ocasionado pelo apoio das presilhas do arco facial sobre a mesa incisal do articulador 73 Figura 21 - O desenho da aleta e a posição em que é apoiada sobre a mesa incisal, favorece o aumento do efeito de alavanca no articulador Bio Art 4000 (seta)

Figura 22 - Recorte da presilha inferior voltado para a direita do paciente. Neste caso as presilhas se aproximam da haste vertical do arco facial (seta) 76

Figura 23 - Recorte da presilha inferior voltado para a esquerda do paciente. Neste caso as presilhas se afastam da haste vertical do arco facial, aumentando o efeito de alavanca (seta) 76 Figura 24 - Detalhe da união universal do articulador Dent-Flex 10600 (seta) e do posicionamento do cabo do garfo de mordida acima do suporte horizontal do arco facial, diferentemente dos demais articuladores analisados 77 Figura 25 - Detalhe do posicionamento do cabo do garfo de mordida abaixo do suporte horizontal do arco facial, encontrado na maioria dos articuladores analisados 78 


\section{LISTA DE TABELAS}

p.

TABELA 5.1.a: Comparação (em mm) entre a montagem do modelo de gesso com e sem apoio das presilhas sobre a mesa incisal, na região do $1^{\circ}$ molar superior esquerdo, para análise da amplitude do momento de rotação do modelo 61

TABELA 5.1.b: Comparação (em $\mathrm{mm}$ ) entre a montagem do modelo de gesso com e sem apoio das presilhas sobre a mesa incisal, na região do $2^{\circ}$ molar superior esquerdo, para analise da amplitude do momento de rotação do modelo 62

TABELA 5.2.a: Comparação (em $\mathrm{mm}$ ) entre a montagem do modelo de gesso com e sem apoio das presilhas sobre a mesa incisal na região do $2^{\circ}$ molar superior direito, para analisar a diferença de deslocamento do modelo em ambos os lados 63

TABELA 5.2.b: Comparação (em mm) entre a montagem do modelo de gesso com e sem apoio das presilhas sobre a mesa incisal, na região do $2^{\circ}$ molar superior esquerdo, para analisar a diferença de deslocamento do modelo em ambos os lados 64

TABELA 5.3: Comparação (em $\mathrm{mm}$ ) entre a montagem com apoio das presilhas na mesa incisal, sem e com elástico para a contenção do ramo superior. A região analisada é a do $2^{\circ}$ molar superior direito e esquerdo ..... 65

TABELA 5.4: Comparação (em $\mathrm{mm}$ ) entre a montagem sem o apoio das presilhas na mesa incisal e com o apoio da presilha inferior com o recorte voltado para a direita e, depois, com a mesma voltada para a esquerda do paciente 66 


\section{RESUMO}

\section{ESTUDO DA ALTERAQAO DA PRECISAO DE MONTAGEM DO MODELO SUPERIOR EM ARTICULADOR SEMI-AJUSTAVEL POR MEIO DO ARCO FACIAL SIMPLES.}

$\mathrm{O}$ articulador é um dos principais instrumentos utilizados para o diagnostico, planejamento e reabilitação oral dos pacientes.

Os fatores associados com a escolha desse tipo de instrumento são múltiplos e, talvez, o mais importante esteja relacionado com a filosofia do desenvolvimento e correção criteriosa da oclusão, principio básico e fundamental que determina a construção de uma prótese dentaria, seja ela fixa, removível ou total.

Por meio de uma técnica correta de montagem, os articuladores representam a maneira pela qual os modelos de gesso do paciente são montados de modo semelhante a posição tridimensional das arcadas do paciente, em relação a base do crânio e ao eixo de rotação dos côndilos mandibulares.

Zanetti \& Ribas (1997), estudando um novo método para simplificação e maior precisão de montagem, por meio de um sistema de transferência e fixação dos modelos de gesso superiores em articuladores semi ajustáveis com o arco facial arbitrário simples, verificaram a existência de alterações posicionais quando, durante esses procedimentos de montagem, o arco facial é apoiado sobre a mesa incisal do articulador.

$\mathrm{O}$ presente estudo analisa a origem dessas alterações em vários articuladores disponíveis em nosso mercado e apresenta um novo dispositivo para ser usado com o arco facial simples, a fim de evitar os efeitos deletérios que tais erros poderiam causar desde a análise oclusal até a confecção de próteses dentais. 


\section{INTRODUÇÃO}

Para uma criteriosa análise da oclusão do paciente, de modo a obter um correto diagnóstico, planejamento e execução de qualquer tratamento odontológico, é preciso que os modelos de gesso estejam precisamente montados num articulador, numa relação espacial similar a posição tridimensional das arcadas do paciente em relação à base do crânio e ao eixo de rotação dos côndilos da mandíbula.

Desde a primeira tentativa de se imitar o relacionamento maxilomandibular por Phillip Pfaff em 1756, os pesquisadores em Odontologia tem procurado aperfeiçoar as formas de transferir, de maneira correta e precisa, os modelos de gesso obtidos por meio da moldagem das arcadas dentárias dos pacientes.

Para que o articulador exerça sua finalidade, a transferência das informações posicionais da arcada do paciente é feita pelo arco facial.

Quando esta transferência, os registros e a montagem são acompanhados de precisão, os modelos montados em relação central permanecerão nesta posição mesmo quando a dimensão vertical for alterada no articulador.

Dos diversos tipos de articuladores existentes, iremos avaliar em particular a precisão de montagem dos modelos semi-ajustáveis do tipo arcon encontrados em nosso mercado, produzidos a partir do modelo 8500 da Whip-Mix Co., que foi desenvolvido pelo Dr. Charles Stuart em 1967 
baseado numa versão modificada de seu articulador totalmente ajustável e que, sem dúvida nenhuma, são os mais utilizados na Odontologia.

A maioria dos pesquisadores acreditam que os articuladores mais complicados e, inquestionavelmente mais precisos, deveriam ser reservados para a pesquisa e, possivelmente, para o uso em paciente com uma capacidade de adaptação precária para um desajuste mínimo no sistema mastigador.

No entanto Zanetti \& Ribas (1997), estudando um novo método para simplificação e maior precisão de montagem do modelo de gesso da arcada superior em articuladores, por meio de moldeiras de transferência, utilizaram vários articuladores do tipo semi-ajustável e verificaram a existência de alterações posicionais durante os procedimentos para montagem do modelo de gesso no articulador.

Com o intuito de verificar tais problemas na metodologia de transferência dos registros da arcada superior do paciente para o articulador, preocupamo-nos em estudar e avaliar algumas marcas de articuladores semi-ajustáveis que utilizam o arco facial simples, buscando verificar a origem destes erros durante os procedimentos de montagem do modelo de gesso superior e analisar uma nova técnica de montagem que possa resolvê-los, evitando as previsíveis imprecisões no relacionamento maxilomandibular de uma simples análise oclusal, bem como os efeitos deletérios que poderiam causar na confecção de uma prótese dental, seja ela fixa, removível ou total. 


\section{REVISTA DA LITERATURA}

Diversos estudos já foram realizados sobre articuladores com o objetivo de avaliar seus fundamentos.

Teórica e didaticamente dividiremos estes estudos em duas partes. A primeira parte irá tratar da revisão de informações básicas necessárias para a avaliação de conceitos relativos aos articuladores. A segunda parte será dedicada aos conceitos e métodos de montagem utilizando o arco facial.

\subsection{Articuladores}

\subsubsection{Histórico}

O desenvolvimento e a evolução dos articuladores, assim como, qual foi o primeiro articulador construído com a finalidade de auxiliar na reabilitação de arcadas parcialmente edentadas, é um assunto bastante controvertido na literatura. Existe uma vasta quantidade de trabalhos, feitos por centenas de pesquisadores, que vem tentando desde o século XVIII interpretar os complexos movimentos mandibulares e entender o trabalho e a função da articulação temporomandibular.

A história da evolução dos articuladores pode ser contada de várias maneiras: por meio do desenvolvimento mecânico que tiveram; do relato histórico de cada inventor ou contribuidor e, ainda, por meio dos registros ilustrativos de cada instrumento. Mesmo não sendo o objetivo do presente 
estudo esgotar o assunto referente a história dos articuladores, torna-se importante faze-lo de maneira sucinta, apenas para poder entender o grau de precisão dos articuladores de hoje.

Neste propósito, seguiremos a ordem cronológica da evolução dos articuladores, procurando, o máximo possível, manter o posicionamento cronológico dos relatos históricos de cada autor que os descreveram.

Mitchell \& Wilkie (1978), afirmaram que o desenvolvimento do articulador teve início com Pfaff em 1756. Seu dispositivo chamava-se oclusor de gesso. Uma extensão distal do modelo mandibular era escavada para servir de guia para o modelo maxilar. Estas duas extensões juntas constituem o primeiro articulador, conhecido como oclusor de bloco de gesso. Esta é a única maneira conhecida de relacionar a maxila com a mandíbula que se tem notícia antes de 1805, quando Gariot supostamente descreveu o primeiro articulador mecânico.

Ainda segundo esses autores, a compreensão da necessidade de estudar a relação dos dentes com a articulação temporomandibular numa montagem extra-oral, fez com os pesquisadores e clínicos desenvolvessem um aparelho que pudesse reproduzir tal relacionamento, possibilitando ao profissional não só analisar corretamente a oclusão dos pacientes, como também construir próteses para integrá-las ao sistema estomatognático. Por isso esses instrumentos são também chamados de articuladores anatômicos.

Segundo Huggett \& Harrison (1977), que fizeram uma interessante revisão da literatura intitulada "Antagonizadores 1805 aos Articuladores 1977”, a invenção do articulador é geralmente atribuída a J. B. Gariot por 
volta de 1805 , o qual simplesmente pretendia manter os modelos de gesso em posição durante os procedimentos de montagem dos dentes artificiais.

Nesta época, muitos aparelhos foram criados, poucos dos quais possuem interesse histórico por ilustrar apenas progressos e tendências relacionadas ao desenho dos mesmos. Ainda segundo os autores acima, o termo articulador não foi universalmente usado no início do século XIX, sendo que a palavra antagonizador foi preferida por muitos.

De acordo com Saizar (1958), o primeiro articulador com características mais anatômicas que se tem notícia é o de Evans em 1840.

Segundo Saizar (1958) e Huggett \& Harrison (1977), somente a partir de Bonwill em 1858 foram construídos articuladores de maneira que o ramo inferior servisse de base para apoiar o aparelho sobre a mesa, enquanto apenas o ramo superior era móvel. $\mathrm{O}$ articulador de Bonwill foi o primeiro instrumento no qual foi feita uma tentativa de imitar a articulação temporomandibular e, assim, permitir a reprodução dos movimentos mastigatórios da mandíbula.

Em seu trabalho, Huggett \& Harrison (1977), mostraram que dentro do conceito de articuladores ajustáveis, isto é, os que aceitam ser ajustados com registros tirados do paciente, permitindo o movimento dos modelos de cêntrico à qualquer movimento excêntrico, provavelmente o primeiro aparelho com essas características que se tem notícia seja o de Walker em 1897.

Mostraram também que Hayes em 1899, patenteou um articulador que empregava pelo menos uma nova característica: ele permitia que um 
pino articular movesse para frente e para baixo, numa tentativa de reproduzir os movimentos dos côndilos.

Um bom exemplo de um articulador de movimentos (valores) medianos é o de Gritman de 1899, o qual possuía guias condilares fixados à uma porção móvel superior.

A invenção do arco facial foi o resultado lógico das investigações em relação a natureza dos movimentos mandibulares, pois tornou-se evidente que os modelos de gesso deveriam ocupar a mesma relação com as articulações do articulador da mesma maneira que a maxila e mandíbula ocupam em relação às articulações temporomandibulares. $\mathrm{O}$ arco facial de Snow foi introduzido em 1899.

Em 1910 Gysi tornou-se conhecido porque foi o primeiro a registrar e medir o desvio lateral imediato no movimento de Bennett. Gysi desenvolveu um articulador ajustável que tinha uma inclinação cambiável individualmente e com a forma da trajetória condilar, bem como uma guia incisal variável. Ele reconheceu algumas dificuldades no uso deste instrumento e produziu um segundo articulador com trajetórias condilares médias. Seu primeiro articulador de movimentos medianos, o Gysi Simplex de 1914, permitia ajustes arbitrários.

Uma das maiores inovações na medição mediana dos movimentos mandibulares foi desenhado por Monson em 1918, segundo sua teoria esférica. Segundo estes autores, que estudaram esta evolução dos articuladores, a teoria de Monson tem sido abandonada nos dias de hoje.

Semelhante ao articulador de Gysi, o de Ash em 1920, incluía botões laterais para suportar o arco facial.

No início dos anos 20, Hanau, um engenheiro mecânico, tornou-se interessado em articuladores e desenvolveu seus modelos da série $\mathrm{H}$. 
Tinha ajustes simples e estáveis e era bem construído. Com algumas modificações, ele é utilizado até hoje.

McCollum em 1930, percebeu que o côndilo provavelmente não excursionava em linhas retas e desenvolveu técnicas de registrar graficamente as trajetórias condilares em vários planos.

O articulador de Schroder-Trebitsch foi desenvolvido em 1932. Tinha um eixo condilar complexo e era ajustado por meio de registros intra-orais em cera. $\mathrm{O}$ eixo de abertura deste aparelho simulava a abertura simples de relaxamento.

As placas de curvatura esfero-elipsoidais, as quais foram desenhadas por H. H. Boyle em 1936, ainda são empregadas algumas vezes.

O articulador Dentatus foi construído em 1944. Dentre os articuladores totalmente ajustáveis, é ainda utilizado. É produzido na Suécia e existem 4 tipos disponíveis.

Um dos últimos articuladores gnatológicos desenvolvido nos anos 60, o Denar, foi desenhado por Guichet. Ele é descrito como um simulador de movimento mandibular de precisão, o qual possui total capacidade de reproduzir todos os movimentos mandibulares ou posições das arcadas registradas por qualquer registro de mordida ou por métodos mais sofisticados que utilizam o pantógrafo.

Em 1967 Hickey et al. apresentaram um novo articulador para uso no ensino e para a clínica odontológica em geral, o Whip-Mix 8500, desenvolvido pelo Dr. Charles Stuart, a partir de uma versão modificada de seu articulador totalmente ajustável. 


\subsubsection{Considerações gerais}

Pruden (1960) afirmou que existe a necessidade de se utilizar os modelos de estudo para o diagnóstico e plano de tratamento.

Teteruck \& Lundeen (1966) afirmaram que o uso de um articulador está na dependência de uma precisa transferência feita pelo arco facial.

Segundo Hickey et al. (1967), o articulador é um dos principais instrumentos utilizados na Odontologia para o diagnóstico e plano de tratamento.

Tanaka et al. (1975) afirmaram que o propósito principal do articulador é simular ou reproduzir movimentos selecionados da mandíbula. Também são importantes para o diagnóstico e plano de tratamento. Para os autores, os articuladores semi-ajustáveis são precisos nas posições inicial e terminal dos movimentos mandibulares. Contudo, todos os movimentos intermediários são arbitrários.

Tanaka \& Finger (1978) fizeram uma investigação com três tipos de articuladores semi-ajustáveis. Estes autores também demonstraram as mesmas aplicações dos articuladores semi-ajustáveis e totalmente ajustáveis.

Para Celenza (1979), os articuladores permitem uma análise oclusal, o enceramento de diagnóstico e auxilia na formulação do plano de tratamento. Quanto à reabilitação oral, eles proporcionam um perfeito 
funcionamento fisiológico e uma posição que garanta as funções dentro do limite do movimento dinâmico.

O dicionário de termos odontológicos americano define articulador, segundo Wise (1982), como um "aparelho mecânico que representa a articulação temporomandibular, a maxila e a mandíbula, no qual os modelos de gesso são fixados". Se os modelos forem precisamente montados em articulador, é possível simular certas relações oclusais. A facilidade dos articuladores em reproduzir precisamente estas relações oclusais depende de sua capacidade de ajuste. Segundo o mesmo autor, surgiram os articuladores anatômicos, assim denominados, por serem utilizados para simular o relacionamento funcional existente entre os dentes superiores e inferiores com o eixo de rotação da mandíbula. A facilidade dos articuladores em reproduzir precisamente estes relacionamentos irá depender de seu grau de ajuste.

Ainda segundo este autor, os articuladores são usados para:

1) Diagnóstico: Eles capacitam o profissional a observar as relações oclusais. Além disso, permitem a realização do enceramento de diagnóstico e o reposicionamento dental nos modelos com um certo grau de precisão.

2) Restauração dental: Os articuladores facilitam o desenvolvimento da oclusão e da estética (dá ao operador um melhor senso de perspectiva, prevenindo a construção de restaurações com planos oclusais incorretos).

Segundo Barnett (1984), os articuladores são aparelhos para montagem de modelos de diagnóstico, sendo úteis para a análise oclusal e, 
também, os de trabalho para a construção de próteses dentais. Para este autor, alguns articuladores são capazes de imitar os movimentos mandibulares mais precisamente do que outros, porém todos os articuladores apresentam falhas ao representar os mecanismos funcionais da mandíbula em seu todo. Todavia, o articulador é um auxiliar no estudo da oclusão, contanto que todo cuidado seja tomado nas técnicas de registro, bem como o articulador seja utilizado de acordo com suas instruções de uso. O autor é oportuno quando diz que o articulador é um outro meio auxiliar de diagnóstico, o qual quando combinado com o histórico, as radiografias e o exame clínico do paciente, podem ajudar a produzir um plano de tratamento mais completo.

Carter (1984) é muito oportuno ao afirmar que muitos procedimentos diagnósticos deveriam ser repensados à luz de um conhecimento profundo da articulação temporomandibular.

Segundo Smith (1985), a maior diferença entre os articuladores introduzidos nos últimos 15 anos e aqueles desenvolvidos entre 1899 e 1915, é que estes últimos foram direcionados para o uso em próteses totais, enquanto que os articuladores de hoje são mais direcionados para o uso em prótese fixa. Esta diferença originou uma grande dicotomia entre os tipos de articuladores utilizados em prótese fixa e prótese removível.

Para Zuckerman (1985) os articuladores são programados para duplicar o eixo de rotação da mandíbula do paciente. Quando o registro e a montagem são acompanhados de precisão, os modelos permanecerão em relação cêntrica, mesmo que a dimensão vertical seja alterada no articulador. A precisão depende do método utilizado para a localização da 
posição do eixo terminal de rotação da mandíbula, da precisão dos instrumentos utilizados para o registro dessa posição e da habilidade e experiência do profissional no uso desses instrumentos.

No entender de Elledge et al. (1989), os modelos de diagnóstico fornecem ao profissional uma perspectiva das necessidades dentais do paciente. Para os autores os modelos devem estar precisamente montados num articulador para o estudo das relações oclusais e para permitir a simulação dos movimentos mandibulares.

Segundo Wright, Jr. (1989), os articuladores são utilizados há muitos anos na Odontologia para simular a postura maxilo-mandibular em posição estática e os movimentos funcionais e parafuncionais.

Para Pitchford (1991), espera-se que a posição do modelo de gesso superior esteja na mesma dimensão vertical que o maxilar ocupa em relação ao crânio do paciente.

Para Hayashi et al. (1994), a análise oclusal é um dos mais importantes procedimentos para o diagnóstico da função estomatognática ou para a avaliação de uma prótese dental. E o articulador é o instrumento utilizado para este fim. 


\subsubsection{Classificação}

Devido ao grande número de articuladores existentes, com seus mais variados ajustes, a revista da literatura revelou que muitos tipos de classificações foram propostas, desde que começaram a ser estudados.

Gillis (1926), dividiu os articuladores em adaptáveis ou tipo ajustável e medianos ou tipo fixo.

Boucher (1934) classificou os articuladores em não ajustáveis e ajustáveis. Também subdividiu os ajustáveis em instrumento bidimensional e tridimensional.

Beck (1962) baseou sua classificação no desenho dos instrumentos. Dividiu-os em 3 categorias: (1) instrumento de suspensão, (2) instrumento de eixo e (3) instrumento trípode.

Weinberg (1963b), adotou uma classificação diferente baseada na concepção associada com cada articulador. $\mathrm{Na}$ opinião do autor os articuladores podem ser arbitrários (teoria esférica de Monson, 1922 e de Hall, 1929), posicionais ou estáticos (conceito oclusor trípode de Stansbery, 1929), semi-ajustáveis (concepção do Hanau H) e totalmente ajustáveis (concepção do Hanau cinemático; Gysi Trubyte e McCollum). $\mathrm{O}$ autor avaliou matematicamente a utilização dos diversos tipos de articuladores, justificando com muita propriedade a razão para o estudo matemático da precisão dos articuladores, o qual discutiremos mais adiante. 
Posselt (1968) classificou os articuladores de curso simples, de valor médio e os ajustáveis.

Thomas (1973) tentou simplificar as classificações dos articuladores e os dividiu baseando-se no tipo de registro utilizado: (1) arbitrário (não ajustável), (2) posicional (com e sem eixo de registro estático) e (3) funcionais (com e sem eixo de registro funcional).

Sharry (1974) classificou os articuladores em simples, tipo dobradiça, tipo guia fixa e os ajustáveis.

Heartwell \& Rahn (1974), enfatizaram o papel dos pantógrafos nos registros da articulação temporomandibular e dividiram os articuladores em 2 classes: (1) instrumentos que irão receber e reproduzir pantografia e traçados gráficos e (2) instrumentos que não irão receber pantografia, os quais são subdivididos em 4 tipos: (a) tipo dobradiça, (b) arbitrários, (c) ajustáveis e (d) instrumentos desenhados e usados para a construção de prótese totais.

Para Wise (1982), existem muitos aparelhos que são classificados como articuladores, mas de fato não passam de simples seguradores de modelos, que não simulam os movimentos mandibulares. Para o autor, os modelos podem ser analisados das seguintes formas: (1) articulados na mão; (2) em articuladores simples de planos lineares; (3) em articuladores semi-ajustáveis e (4) em articuladores totalmente ajustáveis.

Segundo Weinberg (1963b), Rihani (1980); Zuckerman (1985) e Todescan et al. (1996), existe uma grande variedade de articuladores 
disponíveis para o uso na Odontologia e são classificados segundo sua capacidade de ajuste. Vão desde simples e arbitrários oclusores ou verticuladores e charneiras, capazes de registrar apenas uma posição oclusal estática (são classificados de não ajustáveis), os semi-ajustáveis que reproduzem os pontos inicial e final dos movimentos mandibulares, até os articuladores totalmente ajustáveis, capazes de reproduzir todos os movimentos mandibulares.

Segundo Henderson \& Steffel (1979), Wise (1982), Shillingburg et al. (1983) e Mohl et al. (1991), os articuladores semi-ajustáveis também podem ser classificados em arcon e não arcon. O termo arcon é uma derivação, preconizada por Bergstrom (1950), das palavras articulação e côndilo. Nos do tipo arcon, os elementos condilares (postes condilares) estão presentes no ramo inferior do instrumento, assim como os côndilos estão unidos à mandíbula. A guia condilar está unida ao ramo superior do articulador, simulando a própria cavidade glenóide. Como exemplo, podese citar: semi-ajustáveis - Dent-Flex, Gnatus e Bio Art, nacionais e o Whip-Mix, Denar Mark II, americanos; totalmente ajustáveis - TT II, nacional e o de Stuart e Denar D4 - A, americanos). Nos articuladores do tipo não arcon, as superfícies articulares da cavidade glenóide estão unidas ao ramo inferior e os elementos condilares (postes condilares) ao ramo superior do articulador. Como exemplo pode-se citar os articuladores Dentatus e o Hanau modelo H.

Para tornar a classificação dos articuladores mais simples na visualização e para evitar confusão por causa de seus sofisticados ajustes, será utilizada a classificação de Rihani (1980), baseada no número de registros usados e dos ajustes necessários para o instrumento aceitar esses 
registros. Esse autor classificou os articuladores, quanto ao grau de precisão, em 3 categorias: (1) simples ou não ajustáveis, (2) semiajustáveis e (3) totalmente ajustáveis.

\subsubsection{Articuladores simples ou não ajustáveis}

Para Barnett (1984) estes são essencialmente mecanismos de eixo simples do tipo abre e fecha (charneira).

Segundo Whitbeck \& Ivanhoe (1985), estes instrumentos permitem que os modelos sejam movimentados apenas verticalmente. São ideais para a estabilização da oclusão pela técnica do eixo funcional, na qual o modelo oponente é relacionado por meio de uma superfície registrada de todos os movimentos funcionais.

Segundo Mohl et al. (1991), comumente esses articuladores também possuem uma parada vertical ajustável, para impedir danos aos modelos e alterações bruscas na dimensão vertical de oclusão. As limitações físicas desse dispositivo excluem seu uso nos procedimentos diagnósticos ou restauradores mais complicados. Por exemplo, se os modelos montados em charneira produzirem uma trajetória de fechamento diferente daquela do paciente, pode ocorrer travamento de vertentes das cúspides nas restaurações colocadas na boca do paciente. Outra desvantagem inerente é que os movimentos laterais não podem ser examinados nesses dispositivos.

Este articulador não permite movimentos excêntricos (lateralidade e protrusão). 
Para Todescan et al. (1996), são instrumentos pequenos que só reproduzem movimentos de dobradiça, ou seja, abrir e fechar (charneira), permitindo que os modelos sejam movimentados verticalmente em arco, onde o centro de rotação é o eixo da charneira.

\subsubsection{Articuladores semi-ajustáveis}

Segundo Hickey et al. (1967), Shillingburg et al. (1983), Whitbeck \& Ivanhoe (1985), Desplats (1986), Johnson \& Stratton (1988), Mohl et al. (1991), a maior falha destes articuladores se refere a não reprodução fiel de todos os movimentos mandibulares, pois, por possuírem as guias condilares, que representam as cavidades glenóides, planas, reproduzem um percurso reto, quando os contornos anatômicos são curvilíneos (Todescan et al., 1996). Além disso o movimento de Bennett é reproduzido nestes articuladores como uma linha de desvio gradual, apesar de que as investigações demonstrem com muita freqüência, que existe neste movimento um considerável componente de desvio lateral imediato da cabeça do côndilo (Hickey et al., 1963; Aull, 1965).

Para Hickey et al. (1967) e Malone \& Koth (1991), mesmo apresentando essas limitações mecânicas em relação a reprodução dos movimentos mandibulares, este articulador, pela sua simplicidade de manuseio, quando usado adequadamente e o profissional conhece essas limitações, o articulador semi-ajustável pode dar informações valiosas para auxiliar no diagnóstico e nas reconstruções oclusais (Mohl et al., 1991) e, por isso, é largamente utilizado no ensino de Odontologia e na 
clínica odontológica, sendo precursor das diversas marcas comerciais de articuladores encontradas em nosso mercado.

Para Bellanti (1973), os articuladores semi-ajustáveis orientam somente o componente lateral do movimento de rotação condilar. Além disso, são capazes de reproduzir a largura intercondilar pequena e média com uma margem de erro não significativa. Porém o ajuste da largura maior parece não permitir adequadamente o alcance possível da variação anatômica do paciente que foi descrita por Aull (1965). O erro incorporado numa largura extrema iria requerer mais do que um ajuste mínimo intra-oral da prótese em movimentos excêntricos. Ainda segundo o autor, os articuladores semi-ajustáveis são capazes de somente reproduzir movimentos simples laterais e são incapazes de reproduzir qualquer variação durante os movimentos protrusivos.

No entender de Whitsett et al. (1977), os articuladores semiajustáveis podem ser utilizados na maioria dos pacientes com múltiplas restaurações ou próteses fixas, onde não exista perda de dimensão vertical e com um mínimo de evidência de problemas oclusais.

Tanaka \& Finger (1978) descreveram o articulador Whip-Mix como sendo do tipo arcon. São construídos com a capacidade de ajustes na distância intercondilar, a qual é semi-ajustável no movimento lateral. Pode ser ajustado em pequeno, médio ou grande, dependendo do registro obtido do paciente. Dentro das guias condilares possuem uma guia condilar horizontal e um ajuste progressivo do desvio lateral imediato. 
Segundo Rihani (1980), são capazes de aceitar pelo menos o uso do arco facial, para montar o modelo superior na relação apropriada com seu eixo de rotação condilar (Mohl et al., 1991), a relação cêntrica e os registros interoclusais protrusivos. Em certos casos essas variáveis são freqüentemente deixadas em posições padrão que representam a média da morfologia no adulto e os registros de mordidas interoclusais não são registrados especificamente. Este último método obviamente é menos preciso do que os registros reais feitos em um determinado paciente. Mas os registros individuais podem estar associados com erros relativamente grandes. Para o autor, em certos centros de estudos, por esse motivo, as vantagens dos registros individuais são questionadas e as angulações médias são utilizadas (mesmo quando são empregados os articuladores semi-ajustáveis).

Gibbs \& Lundeen (1982), Drago \& Rugh (1982) e Mongini (1982) demostraram em seus estudos a importância dos articuladores semiajustáveis do tipo arcon na reabilitação por meio de prótese dental.

Segundo Wise (1982) e Mohl et al. (1991), nos articuladores semiajustáveis, as inclinações condilares são ajustadas utilizando-se, por exemplo, placas de cera chamadas de registro ou placas de mordida, mediante as quais se transfere a posição terminal dos côndilos da mandíbula ao instrumento. Estas placas tem em média de 3 a $5 \mathrm{~mm}$ de espessura, de modo que os dentes dos modelos de gesso superior e inferior ficam separados por esta distância, enquanto forem ajustadas as inclinações condilares. Quando se retiram esses registros, e os dentes são ocluídos, as inclinações condilares permanecem as mesmas. Entretanto, quando os dentes são ocluídos num articulador não arcon, ocorre uma 
alteração no ângulo entre a inclinação da trajetória condilar e o plano oclusal dos dentes da maxila, com o articulador aberto (onde as inclinações do articulador são ajustadas, devido a espessura da placa de mordida) e fechado (como é utilizado).

Por estas características, os articuladores arcon tem tido seu uso difundido devido à sua precisão e facilidade de manipulação para o enceramento oclusal necessário nas restaurações dentais. Porém a posição cêntrica é menos facilmente mantida quando a oclusão de todos os dentes posteriores está sendo manipulada. Estas características fazem-no impopular para a montagem de dentes em próteses totais. Em vista disso, o articulador não arcon tem se tornado mais popular para a confecção de prótese totais. Os articuladores arcon, equipados com dispositivos firmes de fixação cêntrica que impedem o deslocamento posterior, contornam a maioria das objeções.

No entender de Shillingburg et al. (1983), são instrumentos que reproduzem os pontos inicial e final de alguns dos movimentos condilares, sendo que a trajetória entre esses dois pontos é representada por uma linha reta, quando na verdade deveria ser uma trajetória curvilínea. Não reproduz as trajetórias intermediárias.

Estes mesmos autores também mencionam que a distância intercondilar destes instrumentos não é totalmente ajustável. Pode ser ajustada, quando muito, a valores pequenos, médios e grandes ou com valores relativos de 1,2 e 3 . As restaurações feitas com este tipo de articulador necessitarão de algum ajuste na boca, porém este será de pouca importância se a restauração for confeccionada cuidadosamente. Ele pode ser usado na maioria das reconstruções unitárias e prótese parciais fixas. 
Barnett (1984) postulou que os articuladores semi-ajustáveis podem ser ajustados em relação a inclinação da trajetória condilar, da guia incisal e aos movimentos simulados de Bennett (reproduz o desvio lateral imediato como uma linha reta).

Numa pesquisa realizada por Gross \& Gazil em 59 faculdades de Odontologia norte-americanas em 1984 e outra realizada por Smith em 1985, também em 59 faculdades de Odontologia norte-americanas, foi constado que articulador Whip-Mix 8500 é o mais freqüentemente utilizado, sendo inclusive sugerido para o uso na construção de próteses fixas e removíveis. Dos 81 tipos de articuladores utilizados no ensino de Odontologia daquele país, 62 (76,5\%) são do tipo arcon, por permitirem a separação dos ramos superior e inferior.

Para Whitbeck \& Ivanhoe (1985), os articuladores semi-ajustáveis são limitados aos registros posicionais que são feitos para registrar várias posições da mandíbula, porém os movimentos mandibulares entre estas posições não são registrados.

Gross et al. (1990) também verificaram em seus trabalhos que os articuladores semi-ajustáveis são os mais utilizados no ensino da Odontologia em muitos países, sendo que o Whip-Mix 8500 encontra-se entre os modelos mais usados. Embora estes articuladores tenham a maior preferência entre os profissionais, os não arcon demonstraram em vários estudos terem um melhor nível de reprodutibilidade na utilização de registros interoclusais.

Num estudo comparativo da habilidade dos articuladores em reproduzir os movimentos mandibulares, usando um articulador eletrônico 
Cyberhoby (Nippon Avionics, Tokyo, Japan), entre 6 articuladores semiajustáveis arcon e não arcon, foi verificado um maior ângulo entre os arcon em relação ao ângulo formado entre o ramo superior e o plano oclusal, quando comparados ao ângulo formado entre o plano de Frankfort e o plano oclusal do paciente.

O estudo destes autores confirmou os anteriores, que também demonstraram que os articuladores semi-ajustáveis do tipo arcon, que utilizam registros interoclusais, possuem um nível baixo de reprodutibilidade e estão sujeitos a variações dos instrumentos, do operador e dos registros oclusais.

\subsubsection{Articuladores totalmente ajustáveis}

Whitbeck \& Ivanhoe (1985) afirmaram que os articuladores totalmente ajustáveis possuem ajustes variáveis para os movimentos multidirecionais e bordejantes irregulares. Eles são programados por meio de traçados pantográficos. Podem ser utilizados com qualquer teoria oclusal ou esquema oclusal, incluindo as oclusões balanceadas, de função de grupo ou mutuamente protegida. A morfologia oclusal pode ser concebida para permitir que as cúspides, fóssulas e sulcos funcionem eficientemente e harmoniosamente com os movimentos mandibulares. Com este instrumento, tem-se a oportunidade de criar a oclusão fisiológica desejada para as mais complexas restaurações, envolvendo uma ou as duas arcadas, com um mínimo de ajustes intra-orais. 
Segundo Rihani (1980), os articuladores totalmente ajustáveis são instrumentos capazes de registrar os ajustes obtidos pelo arco facial, a relação cêntrica, o registro protrusivo e a distância intercondilar.

Para Shillingburg et al. (1983) e Todescan et al. (1996), esses instrumentos são planejados para reproduzir todas as características dos movimentos excêntricos, inclusive o desvio lateral imediato, o progressivo (ou gradual) e a inclinação e curvatura da trajetória condilar. A distância intercondilar é totalmente ajustável. Quando o eixo terminal de rotação é localizado cinematicamente e são obtidos registros precisos dos movimentos mandibulares, estes podem ser parcialmente reproduzíveis.

Segundo Whitbeck \& Ivanhoe (1985), por meio deste traçado cinemático ou pantográfico, a morfologia oclusal pode ser idealizada para permitir que cúspides, fossas e sulcos funcionem com eficácia e em harmonia com o movimento mandibular. Com esse instrumento tem-se a oportunidade de criar a oclusão fisiológica desejável para os casos mais complexos de restauração dental, com um mínimo de ajuste intra-oral.

No entender de Wise (1982), Ramfjord \& Ash (1983), Shillingburg et al. (1983) e Mohl et al. (1991), estes instrumentos mais complicados e inquestionavelmente mais precisos, contudo, não são necessários no tratamento de todos os pacientes, mas estão reservados aos casos mais complexos e à pesquisa e, possivelmente, para uso em paciente com uma capacidade de adaptação precária para um desajuste mínimo no sistema mastigador. Para usar um articulador totalmente ajustável, é necessário um treinamento especial, exigindo um alto grau de habilidade e mais tempo para ser executada a técnica, além de uma verba considerável. 
Em relação aos tipos de articuladores utilizados pelos cirurgiõesdentistas, Mohamed et al. verificaram, num estudo de 1976 nos Estados Unidos, que aproximadamente $64 \%$ eram do tipo charneira ou articuladores simples, $26 \%$ eram semi-ajustáveis e os restantes $10 \%$ eram totalmente ajustáveis. Verificaram ainda que, quando esses profissionais nem sequer mandavam os modelos articulados e não especificavam o tipo de articulador a ser utilizado, em 78,6\% dos casos os técnicos de laboratório escolhiam os simples ou de charneira, os semi-ajustáveis em $17 \%$ dos modelos e de apenas $1,9 \%$ para os totalmente ajustáveis. Os restantes $2,5 \%$ dos modelos não eram montados.

\subsection{Arco facial}

\subsubsection{Considerações gerais}

Weinberg (1961) avaliou a montagem com arco facial e demonstrou tratar-se de um importante passo na construção de restaurações que requeiram um mínimo de ajuste intra-oral. Ele também mostrou o alto grau de precisão dos arcos faciais arbitrários em pacientes para prótese total.

Para Weinberg (1963b), a utilização apropriada de um articulador anatômico está na dependência do uso de um preciso arco facial.

Weinberg (1963a, 1963b); Whitsett et al. (1977); Shillingburg et al. (1983) e Zuckerman (1985), demonstraram com seus estudos que se os modelos forem montados de tal forma que o articulador feche ao redor de 
um eixo diferente daquele da mandíbula do paciente, os dentes ocluirão no articulador em posição diferente do que na boca do paciente.

Teteruck \& Lundeen (1966) analisaram o uso dos arcos faciais arbitrários de posicionamento no ouvido externo e concluíram ser de razoável precisão. Com uma simples modificação das olivas de plástico, no modelo convencional, eles conseguiram uma eficiência de $75,5 \%$. No estudo destes autores, eles verificaram que 56,4\% dos pontos arbitrários obtidos pelo arco facial de aplicação no meato acústico externo, estavam dentro de um raio de $6 \mathrm{~mm}$ do eixo verdadeiro de rotação da mandíbula. Eles calcularam o epicentro da maior concentração de pontos do eixo verdadeiro e modificaram a posição dos orifícios de montagem das olivas para este novo centro, conseguindo-se esta melhoria na localização do eixo de rotação pelo método arbitrário.

Parel (1972) também verificou que 75,5\% dos eixos de rotação arbitrários estão localizados dentro de um raio de $6 \mathrm{~mm}$ do eixo cinemático real de rotação. Para o autor, quando existir necessidade de alterações na dimensão vertical de oclusão, seria necessário o uso de um arco facial para obter-se resultados mais eficientes e precisos.

Para Jones (1974), os procedimentos necessários para a utilização do arco facial são difíceis de se ensinar, a medida que para se proceder à uma transferência precisa das informações posicionais da maxila do paciente são necessários conhecimentos teóricos e práticos, não somente a respeito do manuseio do dispositivo, mas também no controle do paciente. Daí a necessidade do ensino começar num crânio seco ou manequim 
odontológico e, num segundo estágio, passar para a prática com os próprios colegas de classe e somente depois utilizar no paciente.

Whitsett et al. (1977) afirmaram que o uso dos arcos faciais arbitrários adaptados ao meato acústico externo tem adquirido uma larga aceitação e tem sido largamente utilizados. Afirmam ainda que o primeiro passo para o uso de um arco facial é determinar a localização do eixo de rotação horizontal. Quanto mais precisa for essa localização, mais precisa será a transferência e subseqüente montagem dos modelos maxilares no articulador.

Laing \& Wise (1978) demonstraram que o uso do arco facial da Whip-Mix produz uma localização do eixo de rotação da mandíbula próxima àquela obtida pelo arco cinemático.

Thorp et al. (1978) afirmaram que a necessidade de localizar precisamente o eixo de rotação a fim de capacitar a reprodução precisa do relacionamento oclusal tem sido objeto de discussão por muitos anos. Teoricamente, segundo os autores, a menos que o exato eixo de rotação seja localizado e transferido para o articulador, o espaço interoclusal utilizado para se fazer os registros mandibulares induzirá a erros quando o articulador ocluir. Esse autor citou um trabalho de Weinberg em 1959, no qual apresentou um exemplo geométrico para avaliar o efeito de um erro no eixo de rotação de $5 \mathrm{~mm}$ na parte posterior quando da oclusão dos dentes. $\mathrm{Na}$ experiência de Weinberg, foi verificado que se um registro interoclusal em cera, de $3 \mathrm{~mm}$ de espessura, na região dos segundos molares for removido e o articulador fechado, ocorrerá um erro horizontal de $0,1934 \mathrm{~mm}$ nesta região. 
Kotwal (1979) definiu o arco facial como sendo um dispositivo semelhante a um compasso que é utilizado para registrar o relacionamento da maxila com a articulação temporomandibular. Para este autor, a história do arco facial se iniciou com Bonwill em 1860, Balkwill em 1866 e com Hayes em 1880, o qual construiu um aparelho denominado de compasso curvo. Ainda segundo este autor, o arco facial arbitrário foi primeiramente construído por Snow em 1907 e é essencialmente o mesmo utilizado hoje em dia.

Para este autor, o arco facial permite uma maior precisão do arco de fechamento no articulador quando os registros interoclusais em cera são removidos e os dentes no articulador são ocluídos.

Para Hockel (1980), que é professor do curso de Procedimentos de Reconstrução Gnatológica da Universidade da Califórnia, os gnatologistas acham que o uso do arco facial é essencial para planejar, registrar, avaliar, verificar e corrigir seus empenhos ortopédicos. Para este autor o arco facial é um compasso curvo que utiliza três pontos de referência para estabelecer o plano horizontal na cabeça do paciente. Segundo o autor, a arcada superior e os dentes superiores estão relacionados a este plano.

Beard \& Clayton (1981) afirmaram que o registro do eixo terminal de rotação da mandíbula pode ser transferido para os modelos de gesso montados em articulador e, assim, esses modelos podem ser ocluídos na mesma relação cêntrica encontrada no paciente.

Segundo Wise (1982), o arco facial é usado para registrar: a) a distância das articulações temporomandibulares com os dentes superiores. 
b) o relacionamento entre o eixo do plano orbital (unindo-se ao eixo de rotação da mandíbula com a borda inferior da cavidade orbital, que corresponde ao plano de Frankfort) e ao plano oclusal superior (unindo-se às pontas das cúspides dos dentes).

Para Chow et al. (1985), o relacionamento dos dentes com o eixo intercondilar e o plano horizontal é transferido para o articulador por meio do arco facial. Segundo os autores, na maioria dos articuladores semiajustáveis, o plano horizontal, no qual o modelo de gesso superior é orientado, é o plano de Frankfort ou próximo dele, o plano axio-orbital. Nestes tipos de articuladores, torna-se de grande valia se a orientação dos modelos de gesso estiverem, no aparelho, de acordo com o eixo intercondilar e o plano horizontal da mesma maneira que a maxila se relaciona com estes locais no paciente.

Palik et al. (1985) afirmaram que muitos erros em prótese dental podem ser atribuídos à montagem incorreta dos modelos do paciente. Os autores postularam que os registros do arco facial relacionam o modelo de gesso da maxila aos elementos condilares do articulador da mesma maneira que a maxila do paciente se relaciona com o eixo terminal de rotação de seus côndilos. $\mathrm{O}$ trabalho destes autores demonstrou que o arco facial simples de posicionamento no meato acústico externo consegue relacionar a maxila ao eixo de rotação dos côndilos, em 50\% dos casos, dentro de uma área de $5 \mathrm{~mm}$ aceitáveis.

Para Piehslinger et al. (1985), os modelos de gesso da maxila montados no articulador são de grande importância diagnóstica e prática na Odontologia. Para isso, os modelos da arcada superior necessitam ter a 
mesma relação com o plano axio-orbital do paciente. Para os autores, esta relação pode ser transferida do paciente para o articulador por meio do arco facial. No entender dos mesmos, a localização do eixo de rotação da mandíbula pode ser determinada por vários métodos cinemáticos e arbitrários. Os métodos arbitrários possuem alguma margem de erro, enquanto que o método mais preciso de montagem de modelos de gesso é realizado por meio da localização cinemática do eixo de rotação da mandíbula. No entanto, ponderam os autores, o método arbitrário é o mais utilizado pela sua simplicidade e rapidez de manuseio.

O estudo destes autores avaliaram o efeito da montagem de modelos de gesso sobre o relacionamento maxilo-mandibular. Em relação a mobilidade de periodontal de $0,5 \mathrm{~mm}$ verificada em dentes sadios, o limite para um erro oclusal em prótese fixa não deve exceder a $0,1 \mathrm{~mm}$. Os autores citaram o trabalho de Fox (1965) que afirmou que o limite de erros oclusais permitidos em prótese fixa está entre 0,05 e $0,075 \mathrm{~mm}$.

Winstanley (1985) fez uma revisão da literatura a respeito do eixo de rotação da mandíbula e, no seu entender, o assunto da oclusão e dos movimentos mandibulares, embora tenha sido estudado por muitos anos, ainda não está totalmente compreendido.

Goska \& Christensen (1988) afirmaram em seu trabalho, que o arco facial é utilizado normalmente para a montagem dos modelos de gesso no articulador.

Em 1988, Strohaver \& Ryan já verificaram que na maioria das faculdades de Odontologia, bem como os próprios profissionais, 
indicavam o uso do arco facial quando havia a necessidade de montagem de modelos de gesso em articulador.

Estes autores afirmaram que o arco facial registra o relacionamento entre a maxila e o eixo de rotação da mandíbula, estabelecendo o mesmo relacionamento entre o modelo de gesso superior e o eixo mecânico do articulador. Se o arco facial não for utilizado, as próteses construídas em modelos de gesso não montados em articulador de maneira precisa, podem exibir discrepâncias oclusais facilmente mensuráveis.

Para Malone \& Koth (1991) e Mohl et al. (1991), estas diferenças, entre o posicionamento do modelo superior e o eixo de rotação da mandíbula, podem afetar a colocação das pontas de cúspides, fazendo com que as vertentes de cúspides de restaurações na região posterior contactem ou batam primeiro, quando o paciente fechar a boca e os dentes ocluírem. O uso do arco facial também impede as imprecisões rotacionais no plano horizontal, que podem causar relações oclusais incorretas.

Para Henderson \& Steffel (1979), Zuckerman (1985), Pitchford (1991) e Ellis III et al. (1992), quando o registro e a montagem são acompanhados de precisão, os modelos montados permanecerão na posição de relação cêntrica mesmo quando a dimensão vertical for alterada no articulador. É de suma importância que o ângulo formado entre o plano oclusal e o plano de Frankfort no paciente seja o mesmo que o formado pelo plano oclusal do modelo de gesso superior em relação ao ramo superior do articulador. A idéia de que o pórion e a borda inferior da cavidade orbital formam um plano paralelo ao plano de referência horizontal foi originalmente adotada num congresso de antropologia em 
Frankfort, Alemanha, em 1822, tornando-se conhecido como plano de Frankfort.

Segundo Mohl et al. (1991) e Todescan et al. (1996), o arco facial é o dispositivo, utilizado com os articuladores, que relaciona o modelo de gesso da arcada superior de acordo com o relacionamento espacial da maxila à base do crânio do paciente, portanto, tem a função de transferir as características individuais da arcada dental do paciente para o articulador Essa relação é importante ao se alterar a dimensão vertical de oclusão durante a confecção de próteses dentais. Sabe-se que a mandíbula gira em torno de um eixo terminal de rotação, que passa pelos côndilos.

Segundo estes autores, o arco facial deve transferir o modelo de gesso superior em relação a este eixo, fazendo com que o articulador mecanicamente seja equivalente ao eixo de rotação do paciente. $\mathrm{O}$ eixo terminal de rotação é uma referência importante porque é reproduzível (Posselt, 1968). Isto irá permitir que o plano de oclusão do modelo superior seja corretamente orientado num espaço do articulador, comparável ao observado na maxila em relação ao plano de Frankfort do paciente.

Bowley \& Bowman (1992) também demonstraram a possibilidade de erros oclusais se os modelos de gesso forem montados numa posição diferente daquela que as arcadas ocupam no paciente e poderão afetar o posicionamento oclusal das restaurações construídas desta maneira.

Para se ter uma noção exata da importância da determinação do eixo de rotação da mandíbula e do relacionamento dos modelos de gesso de acordo com este eixo, pode-se citar o trabalho de Dawson de 1995, 
onde ele definiu a relação cêntrica como sendo a precisa localização do eixo condilar horizontal quando os elementos côndilo-disco, apropriadamente alinhados, estão completamente assentados em suas respectivas cavidades articulares. Devido a esta posição do eixo condilar horizontal determinar o relacionamento maxilo-mandibular durante o fechamento da mandíbula, qualquer variação na posição dos côndilos irá alterar o arco de oclusão da mandíbula e, assim, afetar o contato inicial dos dentes da mandíbula contra os dentes da maxila.

No entender de Todescan et al. (1996), para que o arco facial possa permitir ao operador alinhar adequadamente o modelo de gesso superior com o eixo terminal de rotação da mandíbula, são necessários 3 pontos de referência: 2 posteriores (direito e esquerdo) e um anterior, de preferência na face. Este particular relacionamento espacial é muito importante, já que torna possível a fixação do modelo superior no articulador de modo individualizado.

\subsubsection{Tipos de dispositivos}

Segundo Strohaver \& Ryan (1988) o protótipo para todos os arcos faciais conhecidos atualmente surgiu com o dispositivo de Snow patenteado em 1899.

A partir deste, basicamente foram desenvolvidos 2 tipos de arcos faciais: o arbitrário e o cinemático. Enquanto o cinemático é usado para localizar realmente o eixo de rotação da mandíbula, a técnica arbitrária é razoavelmente mais rápida e considerada por muitos pesquisadores como sendo suficientemente precisa para os procedimentos rotineiros. 
Os pantógrafos são arcos faciais cinemáticos mais sofisticados que conseguem registrar os movimentos mandibulares multidirecionais, por meio de vários traçados pantográficos. Dentre estes encontram-se também os pantógrafos eletrônicos e os computadorizados.

Segundo Mohl et al. (1991) e Todescan et al. (1996), existem atualmente vários tipos de arcos faciais: o arco facial simples, o cinemático e o pantográfico. Cada articulador vem normalmente acompanhado de seu arco facial com características próprias.

\subsubsection{Arco facial simples}

Para a aplicação de arcos faciais arbitrários simples, existem diversos métodos de localização dos pontos condilares.

Weinberg (1959), Weinberg (1961), Hart et al. (1983) e Gordon et al. (1984) verificaram a presença de erros oclusais resultantes de erros na localização do eixo de rotação.

Pode ser feita por simples palpação dos côndilos ou baseada no tragus. Neste caso, o ponto é demarcado arbitrariamente, baseado em médias anatômicas, a uma distância entre 11 a $13 \mathrm{~mm}$ anterior ao centro da borda superior do tragus, numa linha que vai do tragus à comissura externa do olho (canthus), segundo Weinberg (1963b). Para Teteruk \& Lundeen (1966) e Todescan et al. (1996), 13 mm é a distância mais comum para este tipo de técnica. Tamaki (1971), utiliza a média de 12 
mm para a localização do côndilo. O terceiro ponto de referência é obtido na face do paciente, por meio de um pino do arco facial.

Teteruck \& Lundeen (1966), Shillingburg et al. (1983) e Todescan et al. (1996), descreveram os arcos faciais arbitrários simples que localizam os côndilos por meio do meato acústico externo, baseado em médias anatômicas.

Para Tanaka et al. (1975), esse tipo de arco facial utiliza o meato acústico externo como um meio de localizar o eixo de rotação arbitrário.

Estes arcos faciais apresentam uma pequena esfera, também chamada de oliva, nas extremidades de cada metade do arco, as quais são introduzidas nos meatos auditivos externos. Nas olivas existem orifícios que são adaptados sobre os pinos existentes nas guias condilares que estão a $6 \mathrm{~mm}$ do verdadeiro eixo terminal de rotação. Este arco facial é o mais utilizado com os articuladores semi-ajustáveis.

Os arcos faciais simples que utilizam o meato acústico externo demonstram ter, segundo Whitsett et al. (1977), relativamente um alto grau de precisão, com 75,5\% de acerto na localização do eixo de rotação.

Para Hockel (1980), o arco facial arbitrário utiliza como pontos de referência posteriores para a determinação do plano horizontal, os meatos acústicos externos como meio de localização do eixo de rotação da mandíbula e, como terceiro ponto, uma distância predeterminada inferiormente ao nasion. 
Walker (1980), no entanto, afirmou que a localização do eixo de rotação arbitrário para a maioria da população não existe e que, a maioria dos eixos recomendados na literatura criam uma margem de erro de aproximadamente $6 \mathrm{~mm}$. Para o autor a colocação da linha tragus-canthus na borda superior do tragus do arco facial irá contribuir para aumentar a imprecisão na maioria dos pacientes.

\subsubsection{Arco facial cinemático}

Para Hockel (1980), o arco facial cinemático utiliza, para a determinação do plano horizontal, dois pontos de referência cinematicamente localizados na posição terminal de rotação da mandíbula e um ponto infra-orbitário do lado direito.

Segundo Stade et al. (1982) o desenvolvimento da técnica de localização cinemática do eixo de rotação da mandíbula é atribuída a McCollum e Stuart em 1955. Eles também demonstraram que os eixos podem estar localizados assimetricamente na cabeça do paciente, o que pode levar a incorreções no uso de arcos faciais convencionais. Isto pode resultar em planos oclusais e incisais inclinados de maneira imprópria. Segundo estes autores, o efeito na oclusão causado por modelos de gesso incorretamente montados em articulador devem ser melhor estudados.

Segundo Todescan et al. (1996), o arco facial cinemático é utilizado para a localização do eixo terminal de rotação da mandíbula e também para transportar e orientar a fixação dos modelos, guardando as mesmas relações da boca com o articulador. O mais convencional é composto por 
dois conjuntos, um correspondente à arcada superior e outro à inferior. Nas extremidades direita e esquerda do arco inferior, ficam os estiletes localizadores ou inscritores e nas extremidades do arco superior, as chamadas bandeiras, onde são registrados os pontos de emergências do eixo terminal de rotação virtual. A fixação do arco facial cinemático à arcada dental se faz, normalmente, por meio de um dispositivo acoplador ou de engate chamado "clutch" semelhante a uma moldeira especial metálica, a qual é desmontável por meio de parafusos.

\subsubsection{Arco facial pantográfico}

Em 1973, Moberg et al. propuseram o uso do pantógrafo como um instrumento para registrar os movimentos da mandíbula e também como um arco facial de precisão para transferência do modelo da maxila para o articulador.

De acordo com Tamaki (1976), o pantógrafo, como também é conhecido, é um dispositivo ainda mais sofisticado que determina as trajetórias sagitais dos côndilos, trajetória incisal, ângulos de Bennett, ângulos de Fisher e a distância intercondilar funcional do paciente, por meio de traçados inscritos sobre plataformas de registro fixadas à porção correspondente à mandíbula e com puas registradoras fixadas no arco superior do instrumento.

Esse dispositivo de precisão foi proposto por McCollum em 1939, com o nome de gnatógrafo. 
Shillingburg et al. (1983), orientaram que para se conseguir uma simulação fiel dos movimentos condilares num articulador, é necessário obter certos traçados, de maneira precisa, das trajetórias que percorrem os côndilos. Isto se pode conseguir com um máximo de precisão mediante o uso de um pantógrafo, que captará todas as características dos movimentos excêntricos da mandíbula, desde sua posição retrusiva até sua posição protrusiva e laterais máximas.

Shillingburg et al. (1983) e Todescan et al. (1996) descreveram o pantógrafo como sendo um dispositivo que, de maneira semelhante ao arco cinemático, possui um conjunto de dois arcos faciais. Um está fixo à arcada superior e o outro à inferior, mediante uma moldeira que se prende aos dentes. Num dos braços são fixadas guias ou puas registradoras e, no outro, oposto às guias, pequenas plataformas onde os registros serão feitos. Nas proximidades do eixo terminal de rotação, de um dos lados do pantógrafo, estão situadas duas plataformas de registro, uma vertical e outra horizontal. Também existem outras duas plataformas na parte anterior do aparelho, uma de cada lado da linha mediana.

Segundo estes autores, a mandíbula é submetida à uma série de movimentos laterais, direito e esquerdo, assim como deslocamentos protrusivos. As guias dos arcos vão registrando as trajetórias seguidas pelos côndilos, em cada um de seus movimentos. Todo o potencial do pantógrafo é obtido quando associado a articuladores totalmente ajustáveis.

Para Anderson et al. (1987), os pantógrafos registram os movimentos mandibulares em três dimensões utilizando um estilete inscritor e mesas de registro fixadas às arcadas dentais por meio de um 
dispositivo de engate ou acoplador do pantógrafo. Segundo estes autores, diversos estudos com pantógrafos eletrônicos e computadorizados mostram que estes instrumentos são precisos e confiáveis em registrar os movimentos mandibulares.

Kolling et al. (1988) também analisaram a validade de um sistema computadorizado na pesquisa dos movimentos mandibulares $\mathrm{e}$ demonstraram tratar-se de um método efetivo e preciso para se detectar diferenças entre traçados pantográficos superiores a $0,1 \mathrm{~mm}$.

Hayashi et al. (1994) verificaram em seu estudo que é possível se reproduzir eletronicamente a oclusão do paciente, porém ainda é um método que consome muito tempo e muitas vezes pode perder a precisão para os métodos convencionais. Segundo estes autores, os métodos robotizados para se determinar eletronicamente a oclusão do paciente foram inicialmente desenvolvidos por Messerman (1967).

Leknius (1996) analisou e melhorou a utilização de um pantógrafo eletrônico que, segundo o autor, simplificou grandemente o processo de transferência de informações para os articuladores totalmente ajustáveis. 


\section{PROPOSIÇÃO}

A proposta desta pesquisa é a de, a partir do estudo dos articuladores e das técnicas existentes para montagem do modelo de gesso da arcada superior do paciente, procurar identificar e solucionar as alterações verificadas na precisão de montagem dos modelos de gesso superior em articuladores semi-ajustáveis do tipo arcon, que utilizam o arco facial simples, analisando a amplitude do desposicionamento do modelo superior, sob o efeito do apoio do arco facial sobre a mesa incisal, durante os procedimentos de montagem do modelo no articulador.

Este estudo também procurará indicar a técnica mais segura e precisa para a montagem dos modelos de gesso superiores, por meio de um dispositivo especificamente desenvolvido para essa finalidade. 


\section{MATERIAIS E MÉTODO}

\subsection{Articuladores utilizados}

Para este estudo foram utilizados os articuladores semi-ajustáveis do tipo arcon, onde os elementos condilares (postes condilares) estão presentes no ramo inferior do instrumento, assim como os côndilos estão unidos à mandíbula (Fig. 1). Estes articuladores conseguem ajustar as guias condilares, guia incisal e ângulo de Bennett.

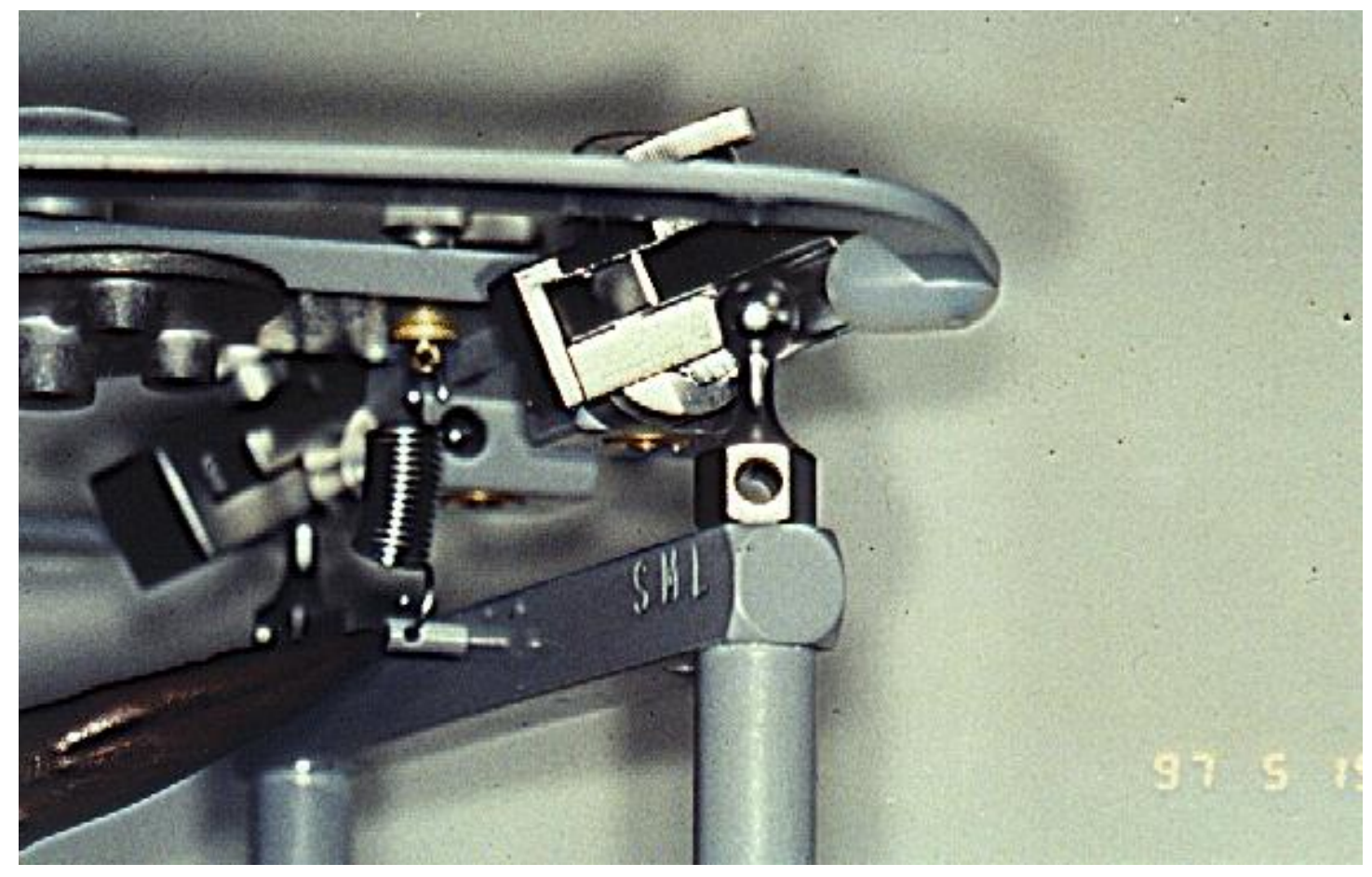

Figura 1 - Detalhe de um articulador do tipo arcon 
Para tanto foram escolhidos os seguintes articuladores semiajustáveis que possuem arco facial simples: Whip-Mix modelo $8500^{\circledR}$; Dent-Flex modelo $10600^{\circledR}$; Gnatus modelo $8600^{\circledR}$, e Bio Art modelo WM$\operatorname{LS}^{(4)}$ e $4000^{\circledR}$ (Fig. 2).
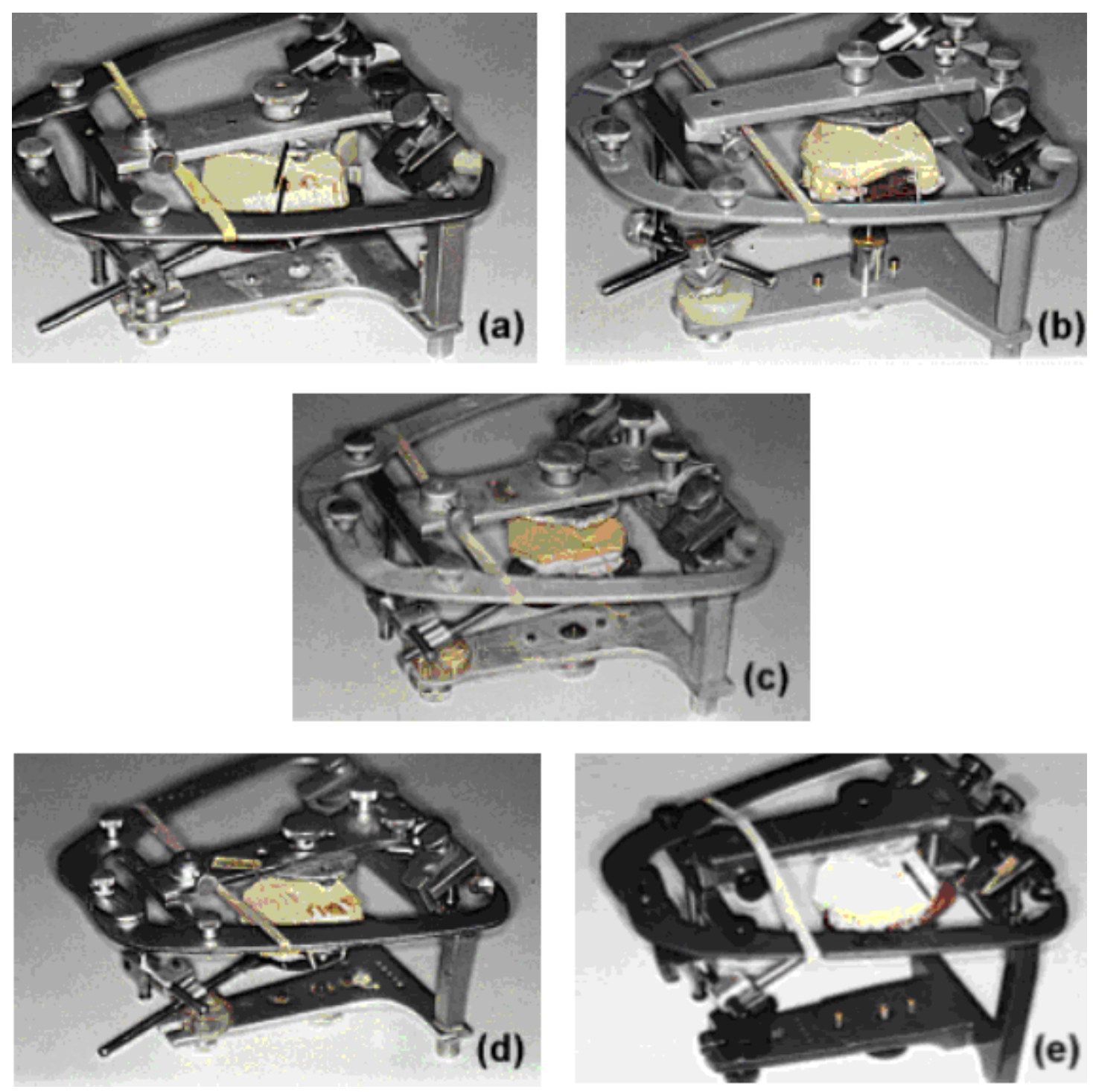

Figura 2 - Articuladores utilizados: (a) Whip-Mix 8500; (b) Dent-Flex 10600; (c) Gnatus; (d) Bio Art WMLS; (e) Bio Art 4000
(1) The Whip-Mix Corp., USA.
(2) Dent-Flex Ind. e Com. Ltda., Brasil.
(3) Gnatus Equip. Médico-Odontol. Ltda., Brasil.
(4) Bio Art Equip. Odontol., Brasil.
(5) Bio Art Equip. Odontol., Brasil. 


\subsection{Método de moldagem e obtenção dos modelos de gesso}

Utilizou-se 5 pacientes, um para cada articulador, sendo que foram moldados 2 vezes para obtenção de 2 modelos de gesso da arcada superior, um para avaliação na região do $1^{\circ}$ molar e outro para avaliação na região do $2^{\circ}$ molar, num total de 10 modelos.

Os pacientes foram moldados com a técnica de dupla moldagem, primeiramente com um material hidrofílico a base de vinil polisiloxano (silicone de adição) tipo $\mathrm{O}$, putty de presa normal, utilizado como material de base ${ }^{\circledR}$ e depois com um material automisturável hidrofílico a base de vinil polisiloxano (silicone de adição) tipo 3, de baixa viscosidade (fluida) e de presa normal ${ }^{\circledR}$, dentro da técnica preconizada pelo fabricante. Os moldes assim obtidos foram vazados sob vibração com gesso pedra Herodent ${ }^{(3)}$ de endurecimento rápido e, após a cristalização do gesso, os modelos foram recortados (em máquina própria para recortar gesso) e ajustados no espaço compreendido entre o garfo de mordida e a placa de montagem do ramo superior do articulador. 


\subsection{Método de registro do arco facial e montagem no articulador}

Para o registro das pontas de cúspides no garfo de mordida do arco facial, foi utilizado, como meio macio ou veículo de transferência, um material de moldagem termoplástico de média fusão e de baixa viscosidade $^{\circledR}$, que foi plastificado em água morna e adaptado ao garfo de mordida de modo uniforme.

Seguindo a técnica preconizada por Teteruck \& Lundeen (1966), Hickey et al. (1967), Parel (1972), Whitsett et al. (1977), Laing \& Wise (1978), Kotwal (1979), Hockel (1980), Wise (1982), Shillingburg et al. (1983), Carter (1984), Zuckerman (1985), Malone \& Koth (1991), Mohl et al. (1991), Ellis III et al. (1992), Todescan et al. (1996) e pelo manual de instruções do articulador Whip-Mix 8500, o garfo de mordida foi então colocado na boca do paciente, contra os dentes superiores. O cabo do garfo foi centralizado e uma pequena e uniforme pressão foi feita no mesmo, contra os dentes superiores, de modo a obter somente a impressão das pontas de cúspides. Tomou-se o cuidado de não deixar as pontas de cúspides penetrarem muito no material de modo a não tocar no metal do garfo. Após esse procedimento, o material do garfo foi resfriado com jato de água e depois removido da boca do paciente. Todo o excesso do material, das ameias e das áreas de tecidos moles impressas, foram cortados e removidos.

(1) Godibar Lysanda Prod. Odontol Ltda., São Paulo, Brasil. 
Para melhorar a precisão deste registro foi utilizada a pasta de óxido de zinco e eugenol, de alto escoamento ${ }^{\circledR}$, colocada somente nas impressões de cúspides e, assim, o garfo de mordida foi recolocado na boca do paciente.

Com o auxílio de uma assistente, o garfo foi mantido em posição na boca do paciente para o posicionamento do arco facial.

$\mathrm{O}$ arco facial foi assim posicionado na face do paciente tomando-se o cuidado para não tira-lo de posição durante os ajustes de seus parafusos de fixação. Para a fixação do arco nos pontos posteriores, pediu-se ao paciente para segurar ambas as metades do arco facial, introduzindo as olivas plásticas nos condutos auditivos externos, tal como faria com um estetoscópio. Ao mesmo tempo, foi introduzida a presilha inferior do arco facial no cabo do garfo de mordida, tomando-se o cuidado para que o suporte horizontal do arco, por onde percorre a presilha superior, fosse posicionado acima do cabo do garfo de mordida. Apertou-se então os três parafusos do arco facial, localizados sobre o mesmo. A seguir foi posicionado o anterior e terceiro ponto do arco, com auxílio do apoio nasal ou relator do nasion, com seu suporte fixado no suporte geral ou barra transversal do arco.

(1) Lysanda Prod. Odontol. Ltda., Brasil. 
Com a assistente mantendo firmemente o garfo de mordida em posição, a presilha do garfo foi deslocada para trás, deslizando-a pelo cabo do garfo, até ficar perto dos lábios, porém sem tocá-los. O parafuso que transfixa as duas presilhas foi então apertado firmemente com a chave hexagonal. A seguir a presilha da haste vertical foi também fixada. Todo o cuidado foi tomado para que, durante esses procedimentos de fixação dos parafusos do arco facial, o mesmo não se desviasse de sua posição correta.

Nesta etapa, a distância intercondilar aproximada do paciente foi anotada, para posterior ajuste dos postes condilares do articulador.

Após o término de todos os ajustes necessários, o arco facial foi cuidadosamente removido da boca do paciente e colocado sobre a mesa de trabalho com o garfo de mordida para cima. Nesta fase foi colocada a banda elástica ao redor do arco facial, com a finalidade de auxiliar nos procedimentos de montagem seguintes (Fig. 3).

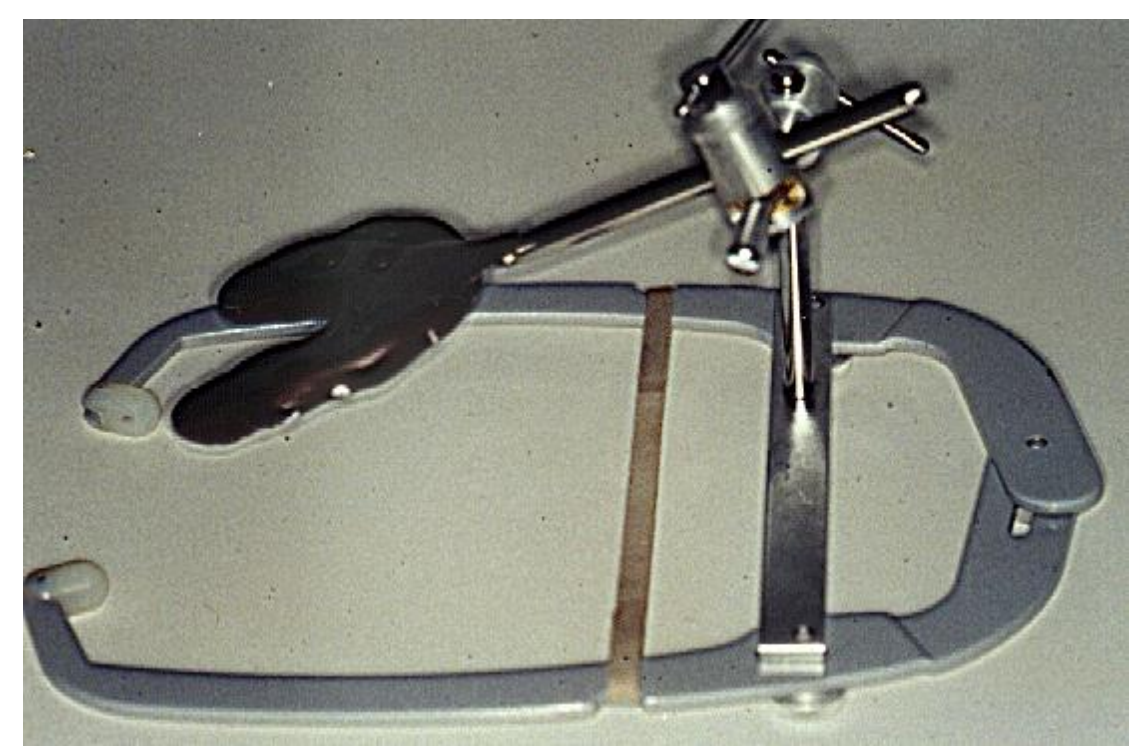

Figura 3 - Observar a correta posição de descanso do arco facial sobre a mesa de trabalho, enquanto se prepara o articulador para recebê-lo. A banda elástica é colocada nesta fase 
O articulador foi então preparado para receber o arco facial. Os elementos condilares do ramo inferior do articulador foram parafusados nos orifícios correspondentes à distância intercondilar do paciente. Estabeleceu-se a mesma distância intercondilar no ramo superior, acrescentando-se ou removendo-se os espaçadores nas hastes das guias condilares, dependendo de cada paciente. As guias condilares foram ajustadas numa angulação média de $30^{\circ}$, previamente a colocação do arco facial, para que os pinos de fixação das olivas do arco facial, localizados nas laterais destas guias, fiquem no mesmo plano horizontal do ramo superior do articulador. As placas de montagem do ramo superior foram firmemente fixadas. As inferiores não foram necessárias para esse estudo. Embora os autores consultados e, mesmo no manual do articulador WhipMix 8500, não tenham feito menção, ou mesmo terem mencionado ser irrelevante o ajuste da guia do movimento lateral (ângulo de Bennett), o ajuste desta guia, nesta fase, com uma angulação negativa irá travar as guias condilares e, por conseqüência, o ramo superior do articulador em posição evitando seu deslocamento posterior (Fig. 4).

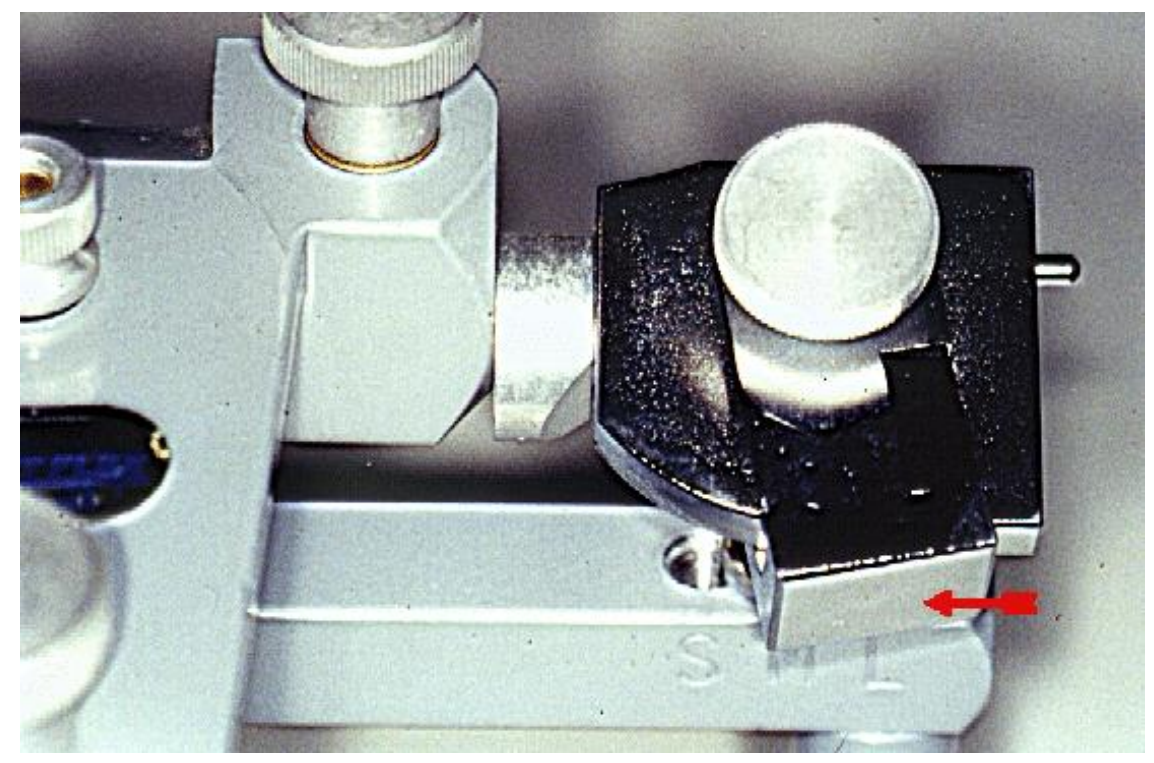

Figura 4 - Ajuste das guias do movimento lateral com angulação negativa para facilitar o manuseio do ramo superior do articulador (seta) 
Em seguida, o arco facial foi posicionado no ramo superior do articulador por meio da fixação dos orifícios de montagem das olivas de plástico nos pinos situados externamente às guias condilares, apertando-se firmemente os três parafusos da parte superior do arco facial e, segundo os autores consultados, com o ramo superior apoiado sobre o suporte geral do arco facial e este apoiado sobre o ramo inferior em 3 pontos, a saber: 2 pontos posteriores, representados pelos postes condilares e 1 ponto anterior representado pelo apoio das presilhas que fixam o cabo do garfo de mordida do arco facial sobre a mesa incisal do articulador (Fig. 5).

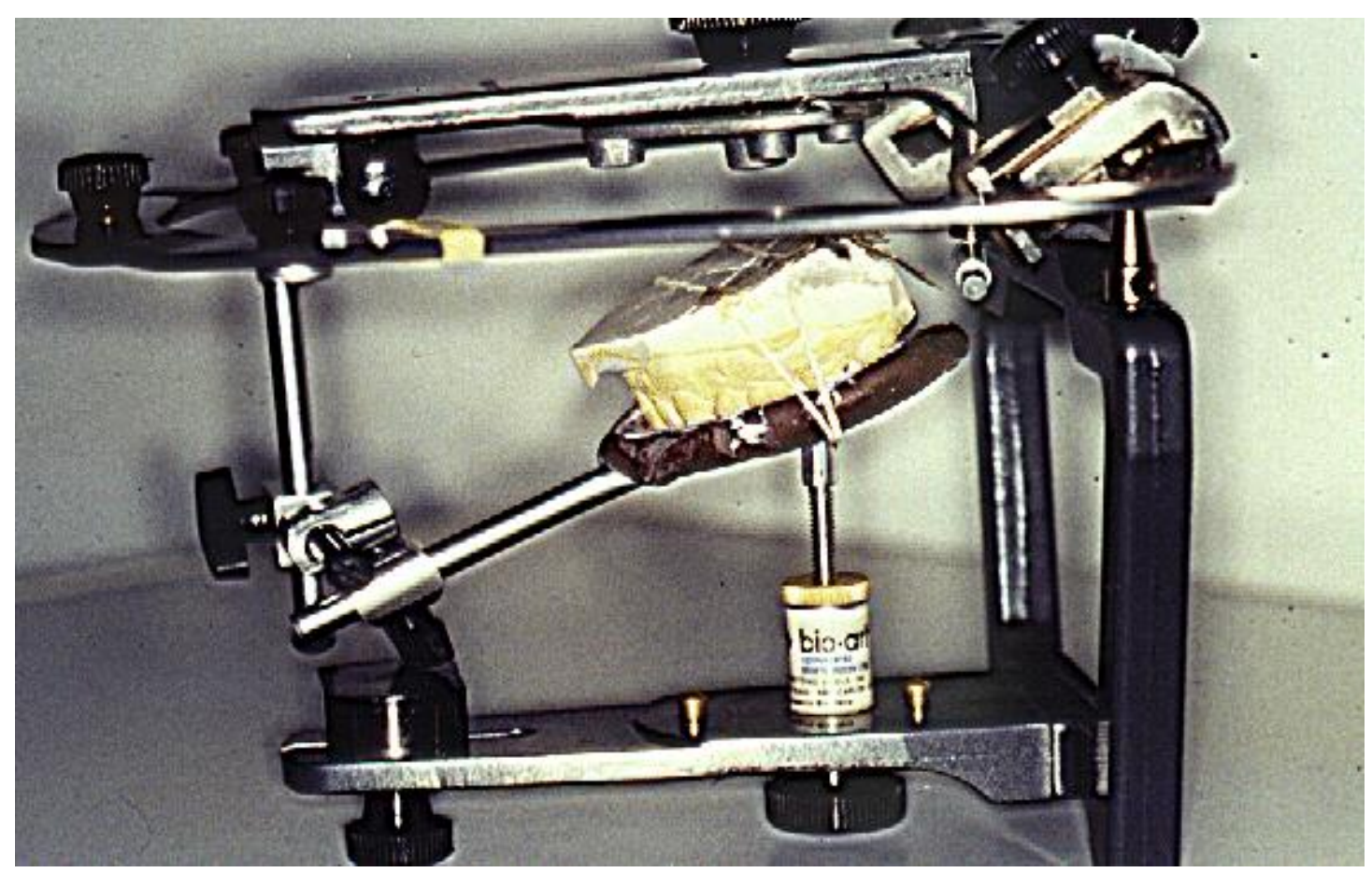

Figura 5 - Arco facial montado no ramo superior e apoiado sobre o ramo inferior do articulador

Existe uma observação no manual de instruções do articulador Whip-Mix 8500, informando que "a relação entre o ramo superior do articulador e seu arco facial com o ramo inferior do mesmo e seus elementos condilares não tem importância nesta etapa da montagem, 
pois o ramo inferior serve meramente como um conveniente meio de suporte durante a montagem do modelo superior."

No entender de Todescan et al. (1996), para fixar o modelo de gesso ao ramo superior, os autores preconizam que o mesmo deva estar paralelo à mesa de trabalho, o que é feito calçando-se o garfo de mordida com qualquer objeto. Será demonstrado posteriormente a inconveniência deste procedimento.

Como o objetivo deste estudo foi o de especificamente avaliar o método de montagem do arco facial no articulador e verificar possíveis alterações posicionais do modelo quando as presilhas do arco facial são apoiadas sobre a mesa incisal localizada no ramo inferior do articulador, a fixação com gesso do modelo à placa de montagem do ramo superior do articulador não foi efetivada.

\subsection{Método de avaliação da montagem do arco facial no articulador}

Foram colados 2 pinos metálicos na base de cada modelo de gesso e paralelos à mesa de trabalho, sendo que 5 foram na região do $1^{\circ}$ molar superior direito e esquerdo e, os 5 restantes, na região do $2^{\circ}$ molar superior direito e esquerdo. Outros 2 pinos foram colados sobre a superfície da placa de montagem do ramo superior do articulador de modo a ficarem paralelos com os pinos direito e esquerdo da base do modelo. Este último procedimento foi realizado em todos os articuladores de forma idêntica, alternando entre as regiões do $1^{\circ}$ e $2^{\circ}$ molares (Figs. 6 e 7). 


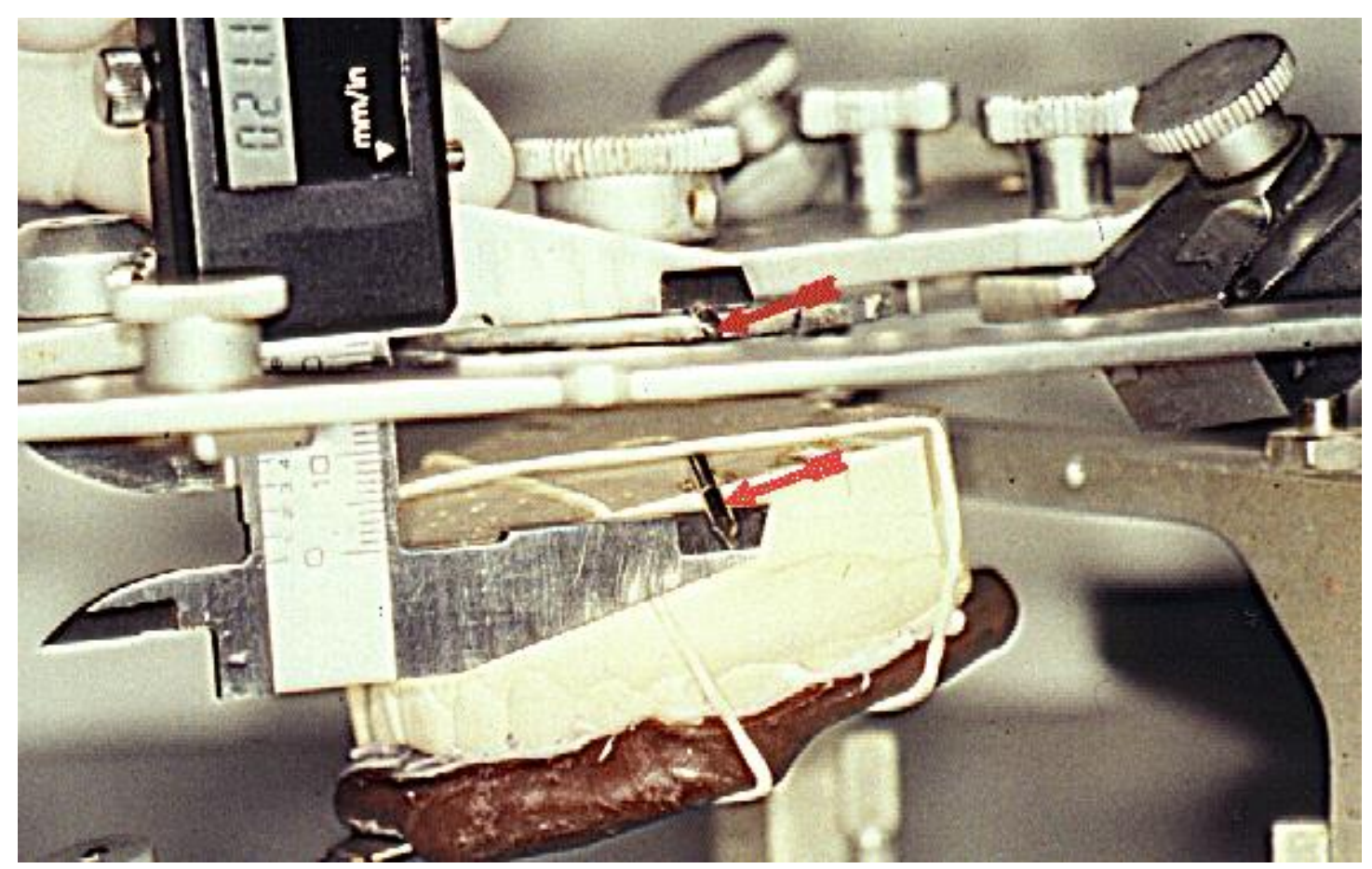

Figura 6 - Localização dos pinos metálicos utilizados para a mensuração na região do $1^{\circ}$ molar superior esquerdo. Observar os pinos metálicos utilizados neste procedimento (setas)

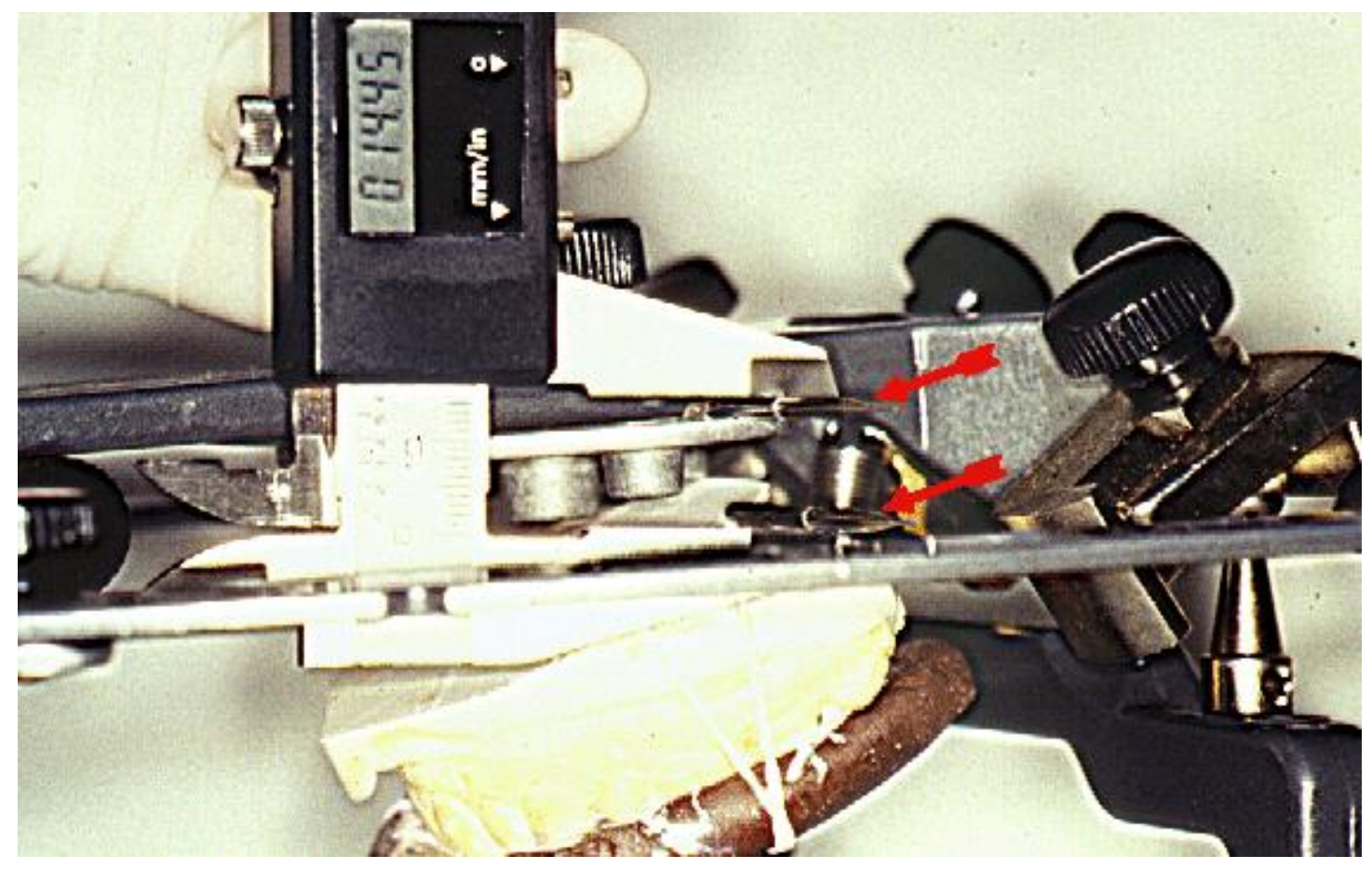

Figura 7 - Localização dos pinos metálicos utilizados para a mensuração na região do $2^{\circ}$ molar superior esquerdo. Observar os pinos metálicos utilizados neste procedimento (setas) 
Utilizando estes dois pinos metálicos, foram realizadas todas as medições, por meio de um paquímetro digital ${ }^{\circledR}$, em todos os articuladores com e sem o apoio do arco facial sobre a mesa incisal (Fig. 8).

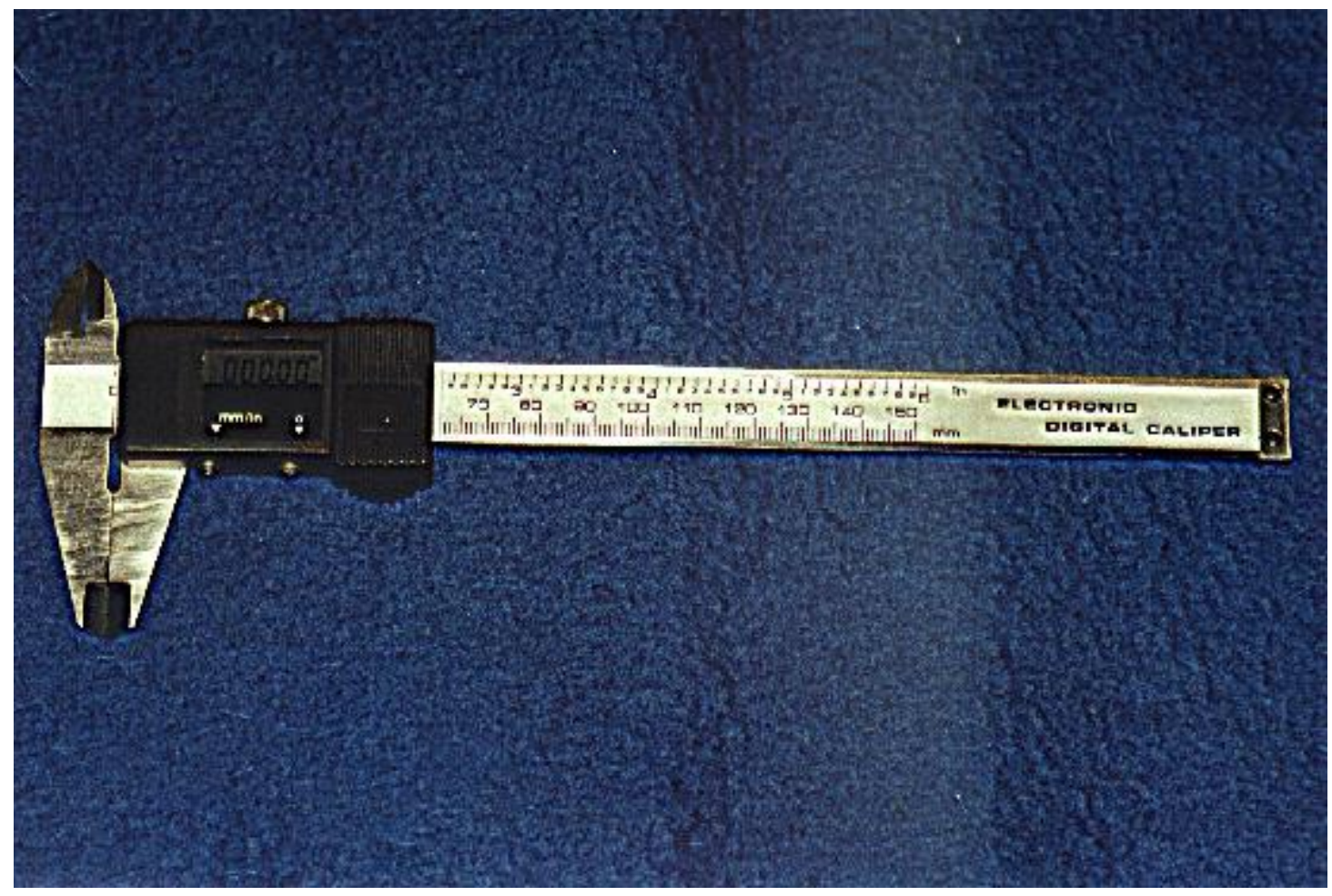

Figura 8 - Detalhe do paquímetro digital

Foram realizadas 436 montagens, distribuídas entre os 5 articuladores analisados, conforme mostram as tabelas de 5.1.a a 5.4 (As montagens apresentadas nas tabelas de 5.1.a a 5.3 foram realizadas com o recorte da presilha inferior voltado para o lado direito do paciente, o que faz com que as presilhas fiquem mais próximas da haste vertical do suporte geral do arco facial. As montagens da tabela 5.4 comparam as duas posições possíveis). 
Deste total, 200 montagens foram realizadas analisando-se a região do $1^{\circ}$ molar superior esquerdo e depois na região do $2^{\circ}$ molar superior esquerdo (Tabela 5.1.a e 5.1.b).

Posteriormente foram realizadas mais 200 montagens, para analisar a região do $2^{\circ}$ molar superior direito e esquerdo (Tabelas 5.2.a e 5.2.b).

Foram realizadas também 20 montagens para comparar algumas técnicas de colocação de elástico, utilizado para o controle da expansão de presa (alteração dimensional) do gesso que fixa os modelos no articulador.

No articulador Whip-Mix 8500 foi utilizado 1 elástico passando ao redor das duas metades do arco facial e pela haste vertical do suporte geral do arco (Fig. 9). Essa mesma técnica pode ser observada no próprio manual da Whip-Mix e no livro texto de Todescan et al. (1996).

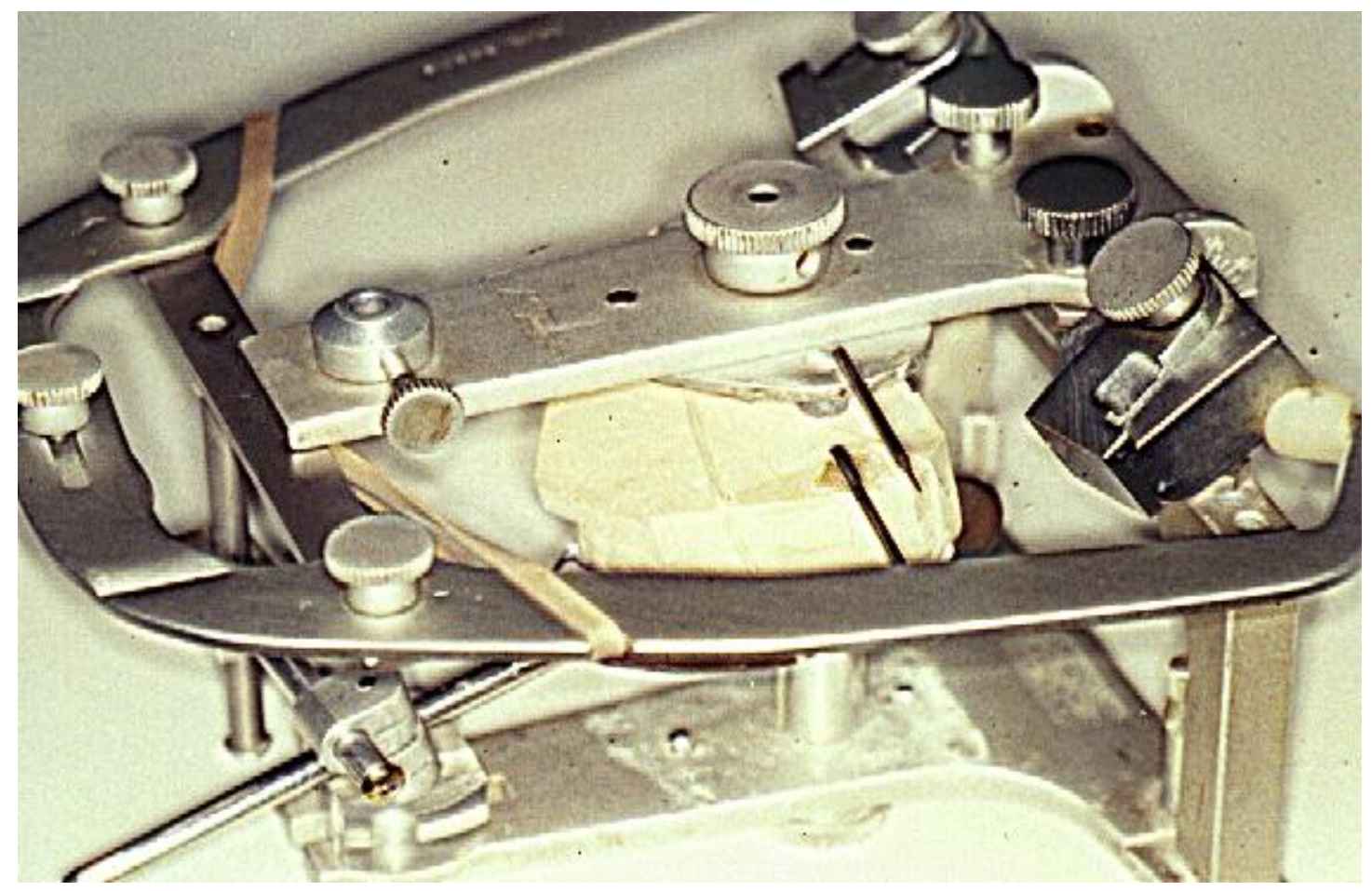

Figura 9 - Colocação de 1 elástico passando ao redor das duas metades do arco facial e pela haste vertical do suporte geral do arco facial do articulador Whip-Mix 8500 
No articulador Dent-Flex 10600, foi utilizado 1 elástico passando pelos ramos superior e inferior do articulador, conforme mostra a figura 10 .

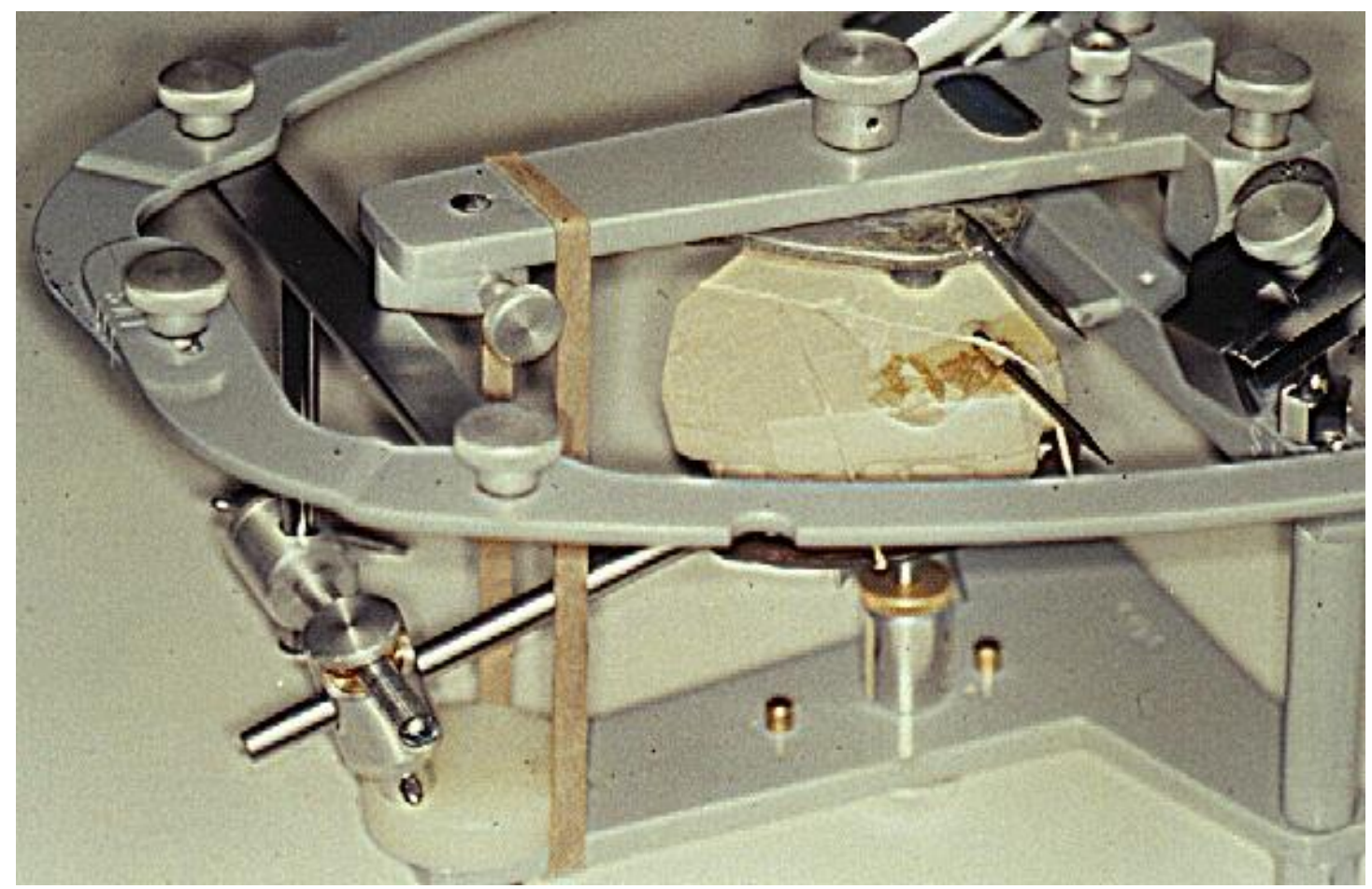

Figura 10 - Colocação de 1 elástico passando pelos ramos superior e inferior do articulador Dent-Flex 10600

No Gnatus 8600, foram utilizados 3 elásticos, 2 deles passando pelo pino incisal no ramo superior e pelo parafuso da mesa incisal no ramo inferior (pelo lado direito e esquerdo) e outro passando pelos parafusos de aperto condilar direito e esquerdo, localizados na parte de cima do ramo superior e pelos apoios laterais ("pés" de apoio) localizados na parte debaixo e posterior do ramo inferior do articulador (Fig. 11). 


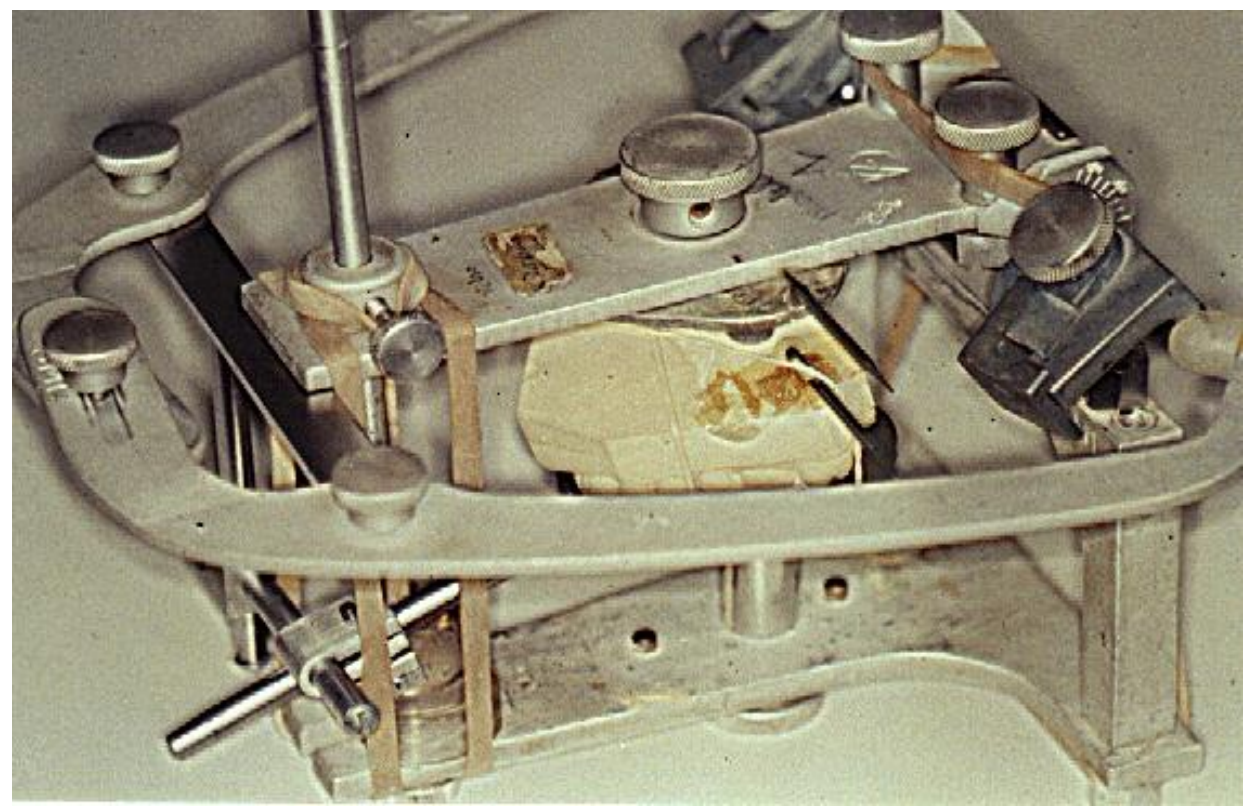

Figura 11 - Colocação de 3 elásticos no articulador Gnatus 8600, sendo 2 passando pelo lado direito e esquerdo do pino incisal no ramo superior e pelo parafuso da mesa incisal no ramo inferior e outro passando pelos parafusos de aperto condilar direito e esquerdo

No Bio Art WM-LS foi utilizado o elástico de maneira semelhante ao Gnatus 8600, só que apenas 1 anterior pelo lado esquerdo e outro posterior (Fig. 12).

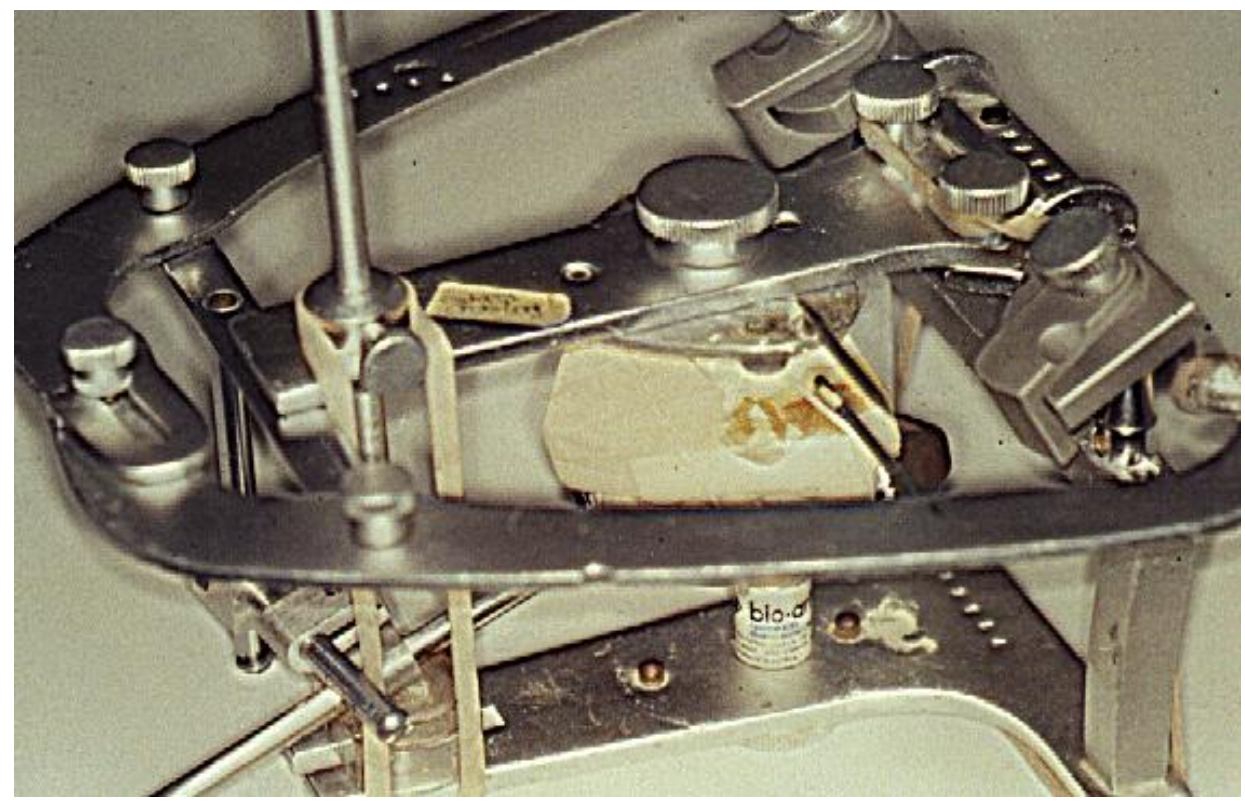

Figura 12 - Colocação de 2 elásticos no articulador Bio Art WM-LS, sendo 1 pelo lado esquerdo do pino incisal e parafuso da mesa incisal e outro passando pelos parafusos de aperto condilar direito e esquerdo 
E, finalmente no Bio Art 4000, foi utilizado 1 elástico passando pelo arco e pelo ramo inferior do articulador (Fig. 13).

Na tabela 5.4 são apresentadas 16 montagens para comparar as realizadas com e sem apoio das presilhas na mesa incisal e com a fenda da presilha inferior voltada para a direita e depois para a esquerda.

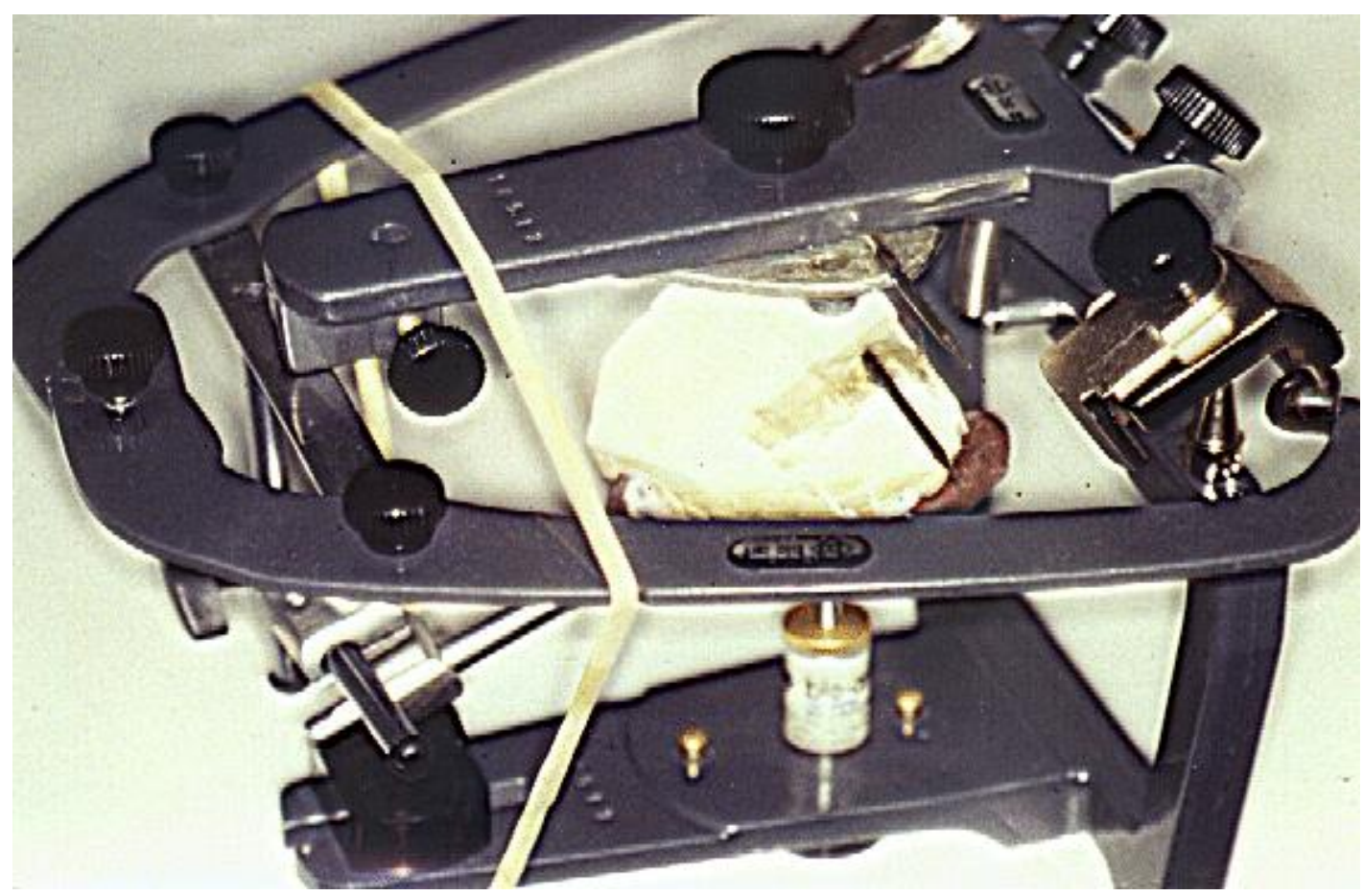

Figura 13 - Colocação de 1 elástico no articulador Bio Art 4000, passando pelo arco facial e pelo ramo inferior do mesmo

Do total de montagens, um grupo controle foi formado com a participação de 10 professores de prótese dental, os quais realizaram uma montagem padrão de um mesmo modelo no articulador Whip-Mix 8500 com o apoio das presilhas, somente na avaliação da região do $1^{\circ}$ molar superior esquerdo (ver Tabela 5.1.a. “*”). Todos eles empregaram, com pequenas variações, a técnica convencional de montagem encontrada na literatura e nos manuais dos articuladores, portanto, todos apoiaram as 
presilhas de fixação do garfo de mordida do arco facial na mesa incisal do articulador. Neste grupo, após a montagem realizada pelo professor, foi realizada a montagem sem o apoio das presilhas, com a finalidade de se avaliar as diferenças entre as montagens com e sem o apoio das presilhas.

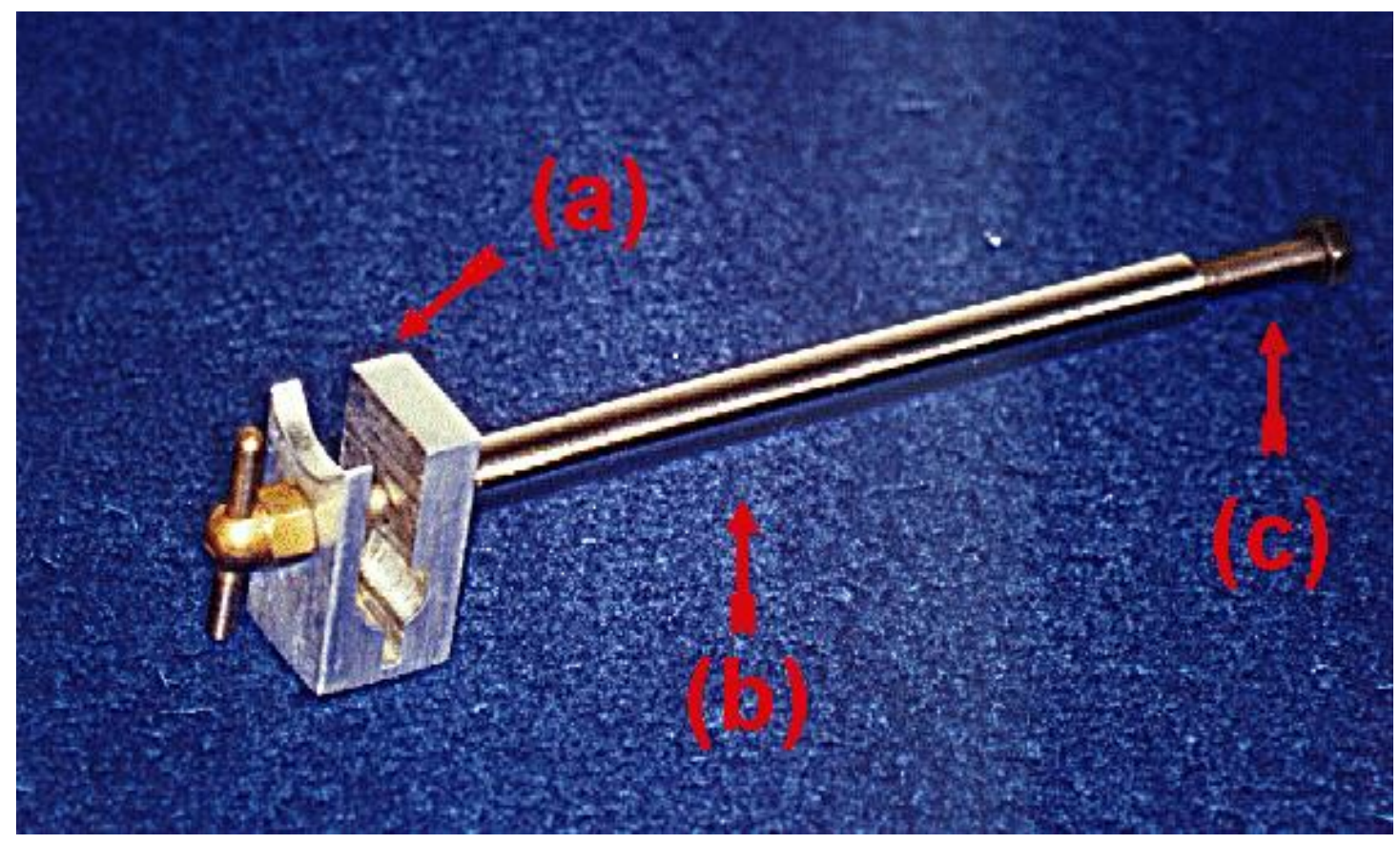

Figura 14 - Detalhe do suporte anterior do arco facial: (a) presilha em alumínio com parafuso de pressão; (b) haste oca com rosca interna; (c) parafuso extensor com rosca sem fim

Para a montagem sem o apoio das presilhas sobre a mesa incisal, foi desenvolvido um suporte anterior do arco facial que deve ser fixado na linha mediana da borda anterior do mesmo, para se obter um perfeito equilíbrio também entre as duas metades do arco facial. Esse dispositivo é constituído pelas seguintes partes: (1) uma presilha em alumínio com um parafuso de pressão em forma de borboleta para a fixação da mesma; (2) uma haste oca com rosca interna soldada à presilha e (3) um parafuso extensor com rosca sem-fim, que proporcionará a altura adequada ao arco 
facial para que a parte posterior do mesmo fique apoiado nos postes condilares do ramo inferior do articulador e sobre esse novo dispositivo em sua parte anterior, sem que haja contato do arco facial sobre a mesa incisal ou qualquer outra parte do articulador, garantindo assim, a manutenção da posição do modelo obtida com o arco facial (Figs. 14 a $18)$.

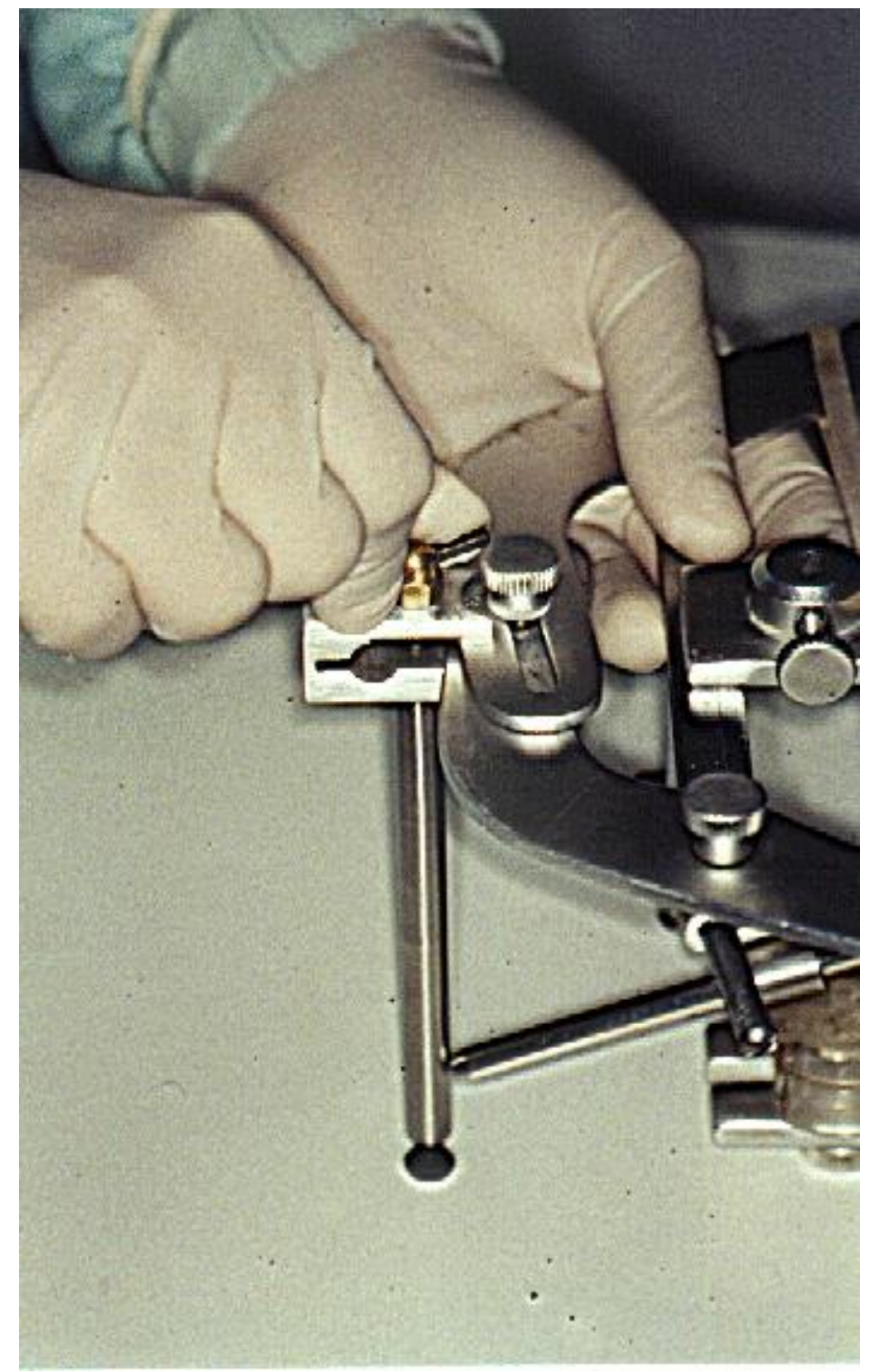

Figura 15 - Colocação do suporte do arco facial na linha mediana da borda anterior do mesmo 


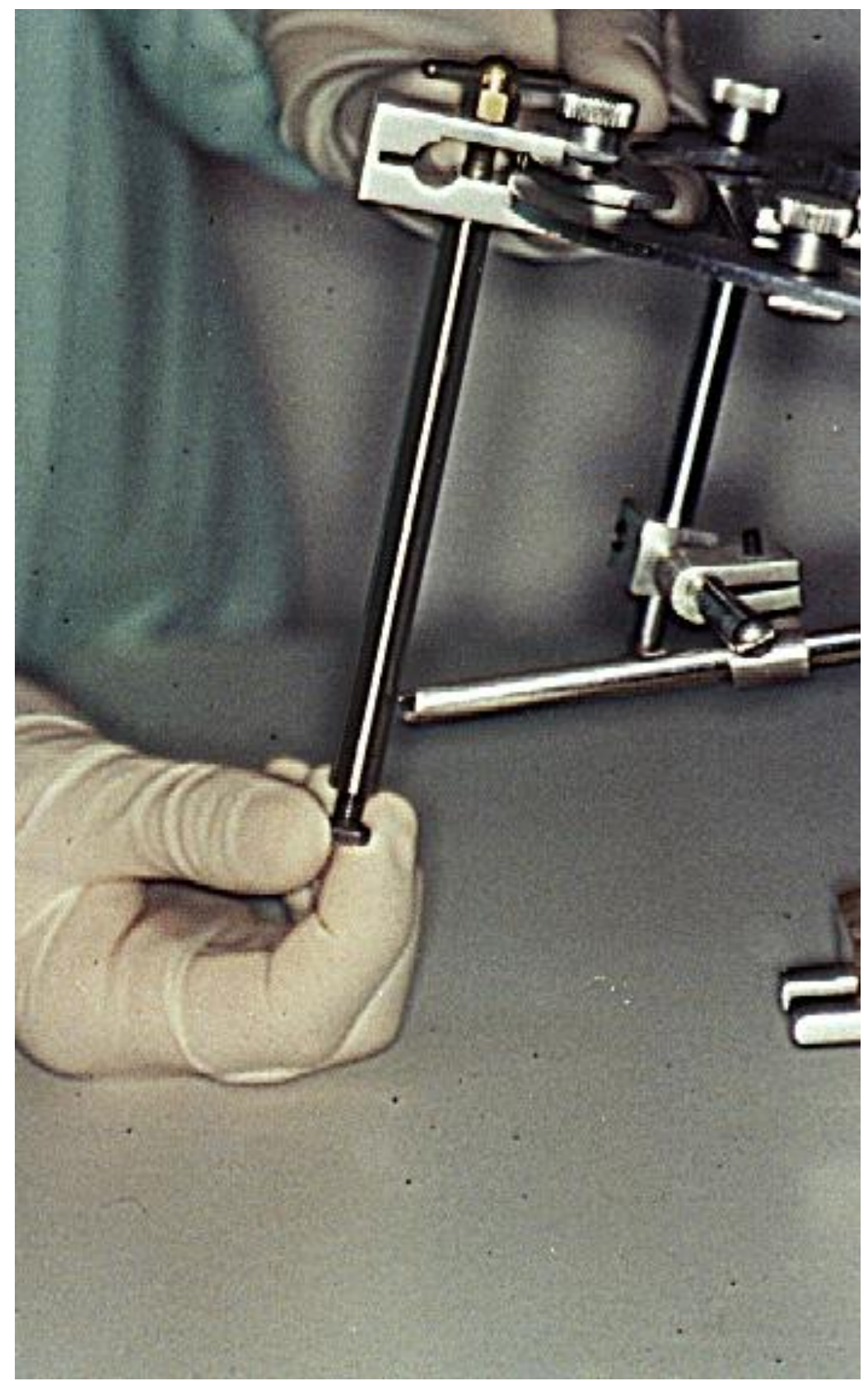

Figura 16 - Ajuste da altura do suporte anterior do arco facial 


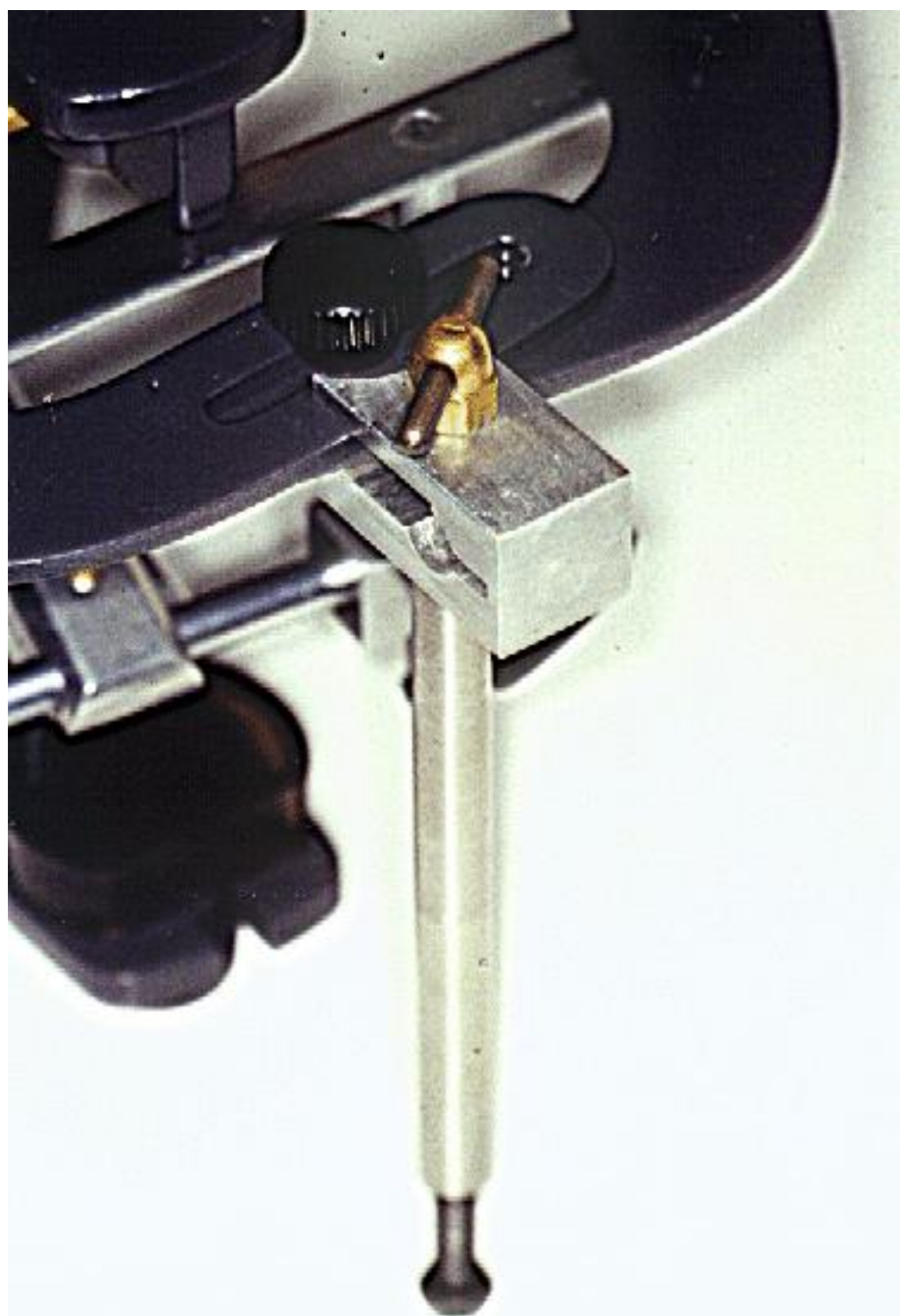

Figura 17 - Suporte anterior do arco facial instalado 


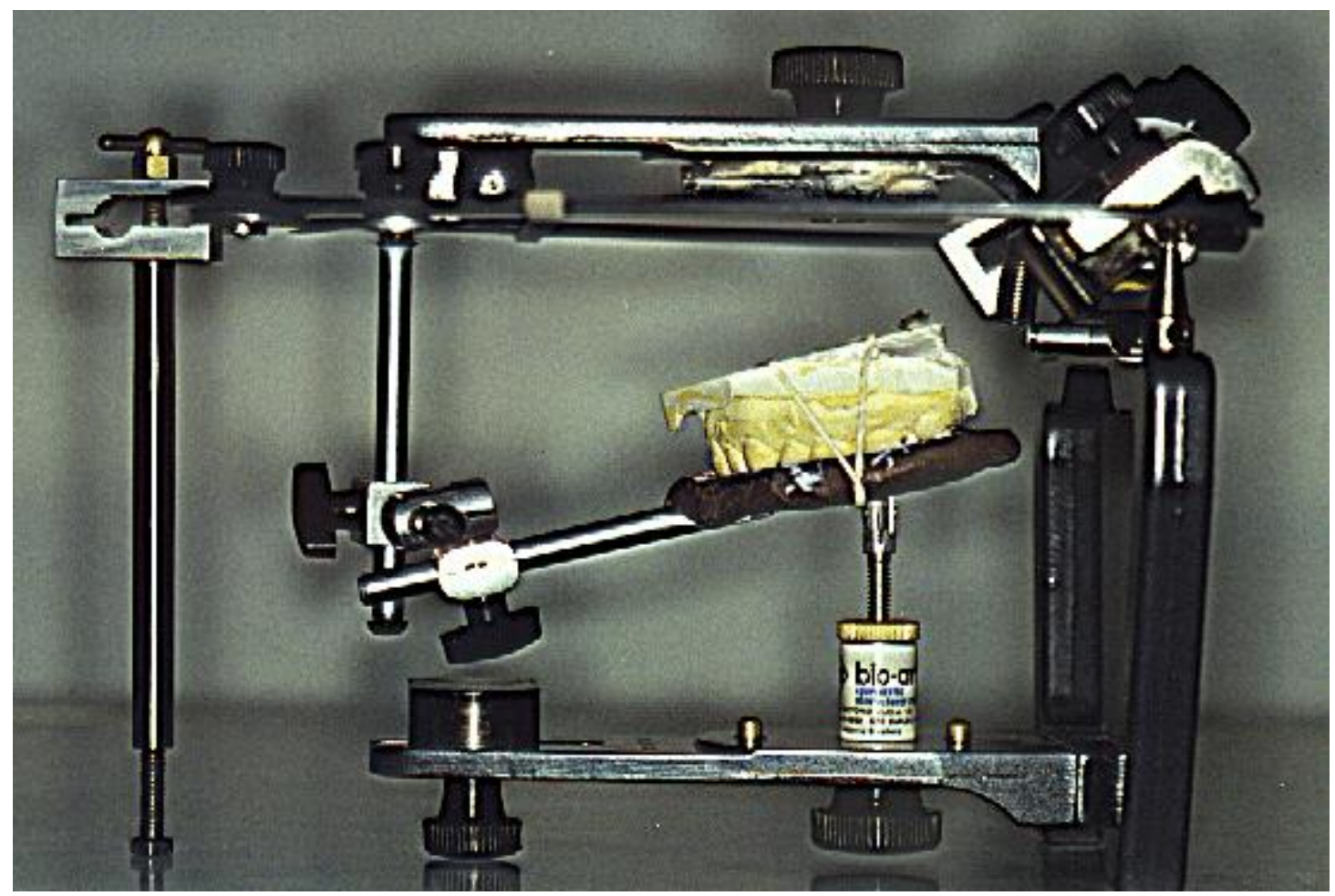

Figura 18 - O suporte anterior do arco facial deve ser ajustado de modo que nenhuma parte do arco encoste no ramo inferior do articulador 


\section{RESULTADOS}

Os resultados são mostrados nas tabelas numeradas de 5.1.a a 5.4.

Neste estudo os 5 articuladores avaliados quanto a habilidade de transferência do registro da arcada superior do paciente com a técnica convencional de montagem no articulador, apresentaram um erro no posicionamento do modelo de gesso em relação ao ramo superior do articulador, representado por um deslocamento do modelo de gesso para cima.

Nas montagens realizadas para a análise nas regiões do $1^{\circ}$ molar superior esquerdo e depois na região do $2^{\circ}$ molar superior do mesmo lado, verificou-se um aumento da amplitude do momento de rotação na região mais posterior. Observou-se, na análise dos resultados, que quanto mais posterior maior é o deslocamento. Conseqüentemente, o deslocamento do modelo de gesso para cima foi maior na região dos $2^{\circ}$ molares (v. tabelas 5.1.a e 5.1.b).

Nas montagens realizadas para se comparar as regiões do $2^{\circ}$ molar direito e esquerdo, ou seja, para se analisar as diferenças do momento de rotação de ambos os lados do modelo, verificou-se um desvio maior do modelo para a esquerda do mesmo, causado pela posição da haste vertical para o lado direito do paciente e pela posição (inclinação) da presilha inferior do arco facial quando apoiada na mesa incisal (Fig. 19 e tabelas 5.2.a e 5.2.b). 


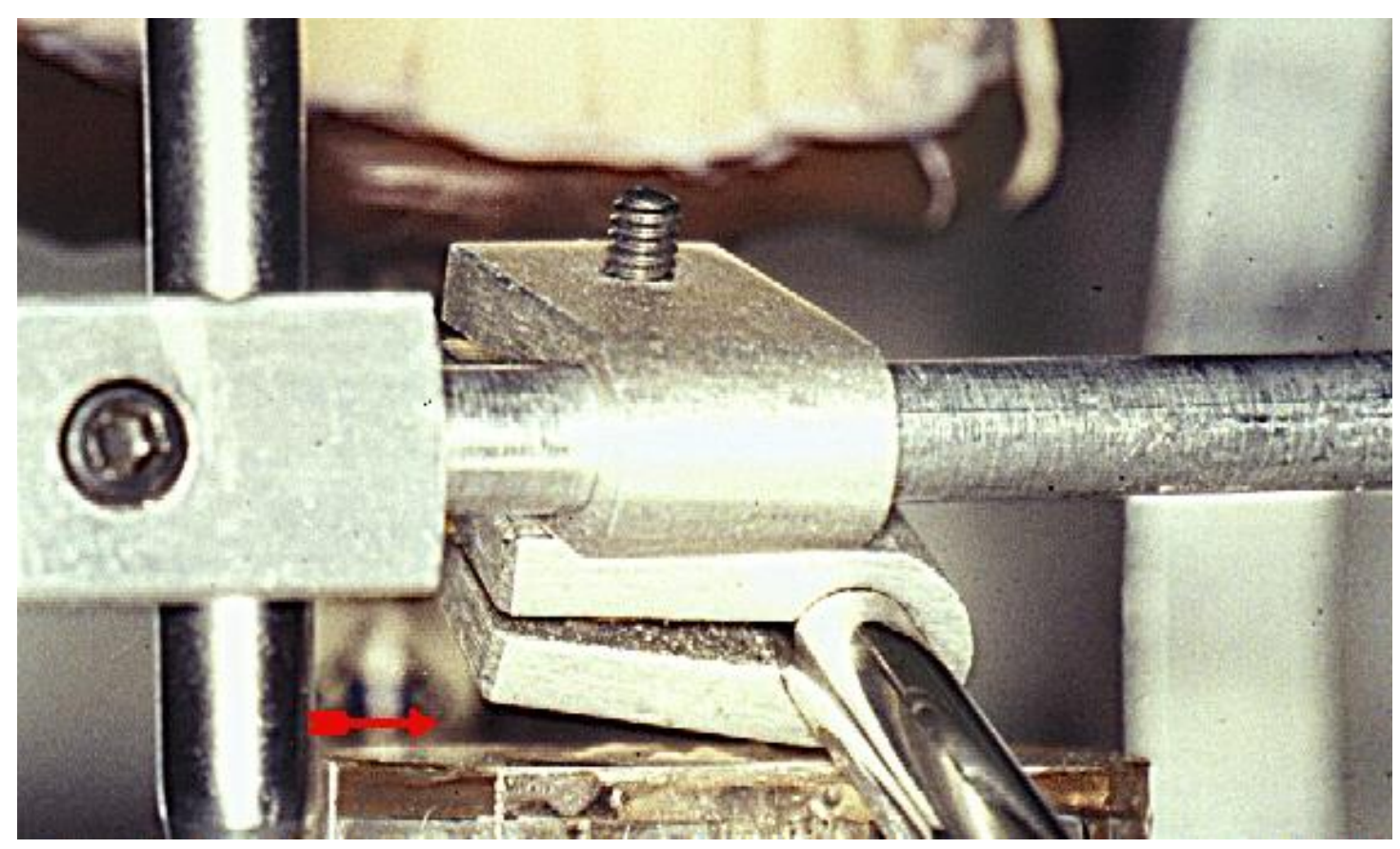

Figura 19 - Inclinação da presilha inferior favorecendo o aumento do efeito de alavanca (seta)

Nas montagens apresentadas na tabela 5.3, para se analisar as montagens com e sem a utilização da banda elástica que acompanha os articuladores, pode-se verificar que houve uma diminuição do espaço compreendido entre o modelo e a placa de montagem do ramo superior do articulador, em todos os casos onde foi utilizado elástico para controlar a alteração dimensional do gesso de fixação do modelo, indicando que o uso do elástico aumenta o momento de rotação do modelo.

A tabela 5.4 apresenta uma análise entre os articuladores que possuem presilhas para fixação do garfo de mordida ao arco facial. Os resultados demonstram que houve um maior aumento do momento de rotação do modelo com a fenda da presilha voltada para a esquerda do paciente, devido ao posicionamento mais distante das presilhas em relação a haste vertical do suporte geral do articulador. 
TABELA 5.1.a: Comparação (em $\mathrm{mm}$ ) entre a montagem do modelo de gesso com e sem apoio das presilhas sobre a mesa incisal, na região do $1^{\circ}$ molar superior esquerdo, para análise da amplitude do momento de rotação do modelo

\begin{tabular}{|c|c|c|c|c|c|c|c|c|c|c|}
\hline \multirow[b]{2}{*}{ SEQÜÊENCIA } & \multicolumn{2}{|c|}{$\begin{array}{l}\text { WHIP-MIX } \\
\quad 8500\end{array}$} & \multicolumn{2}{|c|}{$\begin{array}{c}\text { DENT-FLEX } \\
10600\end{array}$} & \multicolumn{2}{|c|}{$\begin{array}{c}\text { GNATUS } \\
8600\end{array}$} & \multicolumn{2}{|c|}{$\begin{array}{r}\text { BIO ART } \\
\text { WM-LS }\end{array}$} & \multicolumn{2}{|c|}{$\begin{array}{c}\text { BIO ART } \\
4000\end{array}$} \\
\hline & $\operatorname{com}\left({ }^{*}\right)$ & SEM & COM & SEM & COM & SEM & COM & SEM & COM & SEM \\
\hline 1 & 24,10 & 24,31 & 26,53 & 26,98 & 26,06 & 26,35 & 22,47 & 22,66 & 31,79 & 32,12 \\
\hline 2 & 24,08 & 24,41 & 26,67 & 26,87 & 26,08 & 26,40 & 26,39 & 26,67 & 31,66 & 32,14 \\
\hline 3 & 24,13 & 24,46 & 26,62 & 27,08 & 26,07 & 26,38 & 26,41 & 26,53 & 31,60 & 32,08 \\
\hline 4 & 24,00 & 24,36 & 26,79 & 27,15 & 26,11 & 26,35 & 26,37 & 26,74 & 31,62 & 32,00 \\
\hline 5 & 24,15 & 24,46 & 26,73 & 27,06 & 26,10 & 26,37 & 22,45 & 22,81 & 31,67 & 32,14 \\
\hline 6 & 24,19 & 24,42 & 26,76 & 27,01 & 26,04 & 26,34 & 22,49 & 22,84 & 31,59 & 32,24 \\
\hline 7 & 24,16 & 24,46 & 26,75 & 26,97 & 26,02 & 26,34 & 22,46 & 22,80 & 31,62 & 32,17 \\
\hline 8 & 24,15 & 24,42 & 26,78 & 27,00 & 26,12 & 26,38 & 22,45 & 22,88 & 31,72 & 32,18 \\
\hline 9 & 24,18 & 24,49 & 26,68 & 27,01 & 26,13 & 26,37 & 22,49 & 22,87 & 31,69 & 32,10 \\
\hline 10 & 24,19 & 24,40 & 26,65 & 27,03 & 26,06 & 26,41 & 22,42 & 22,80 & 31,71 & 32,13 \\
\hline média & 24,13 & 24,41 & 26,69 & 27,01 & 26,07 & 26,36 & 22,49 & 23,96 & 31,66 & 32,13 \\
\hline DIFERENÇA & \multicolumn{2}{|c|}{0,28} & \multicolumn{2}{|c|}{0,32} & \multicolumn{2}{|c|}{0,29} & \multicolumn{2}{|c|}{0,32} & \multicolumn{2}{|c|}{0,47} \\
\hline
\end{tabular}

Nota: (*) Grupo controle 
TABELA 5.1.b: Comparação (em $\mathrm{mm}$ ) entre a montagem do modelo de gesso com e sem apoio das presilhas sobre a mesa incisal, na região do $2^{\circ}$ molar superior esquerdo, para análise da amplitude do momento de rotação do modelo

\begin{tabular}{|c|c|c|c|c|c|c|c|c|c|c|}
\hline \multirow[b]{2}{*}{ SEQÜÊENCIA } & \multicolumn{2}{|c|}{$\begin{array}{c}\text { WHIP-MIX } \\
8500\end{array}$} & \multicolumn{2}{|c|}{$\begin{array}{c}\text { DENT-FLEX } \\
10600\end{array}$} & \multicolumn{2}{|c|}{$\begin{array}{c}\text { GNATUS } \\
\mathbf{8 6 0 0}\end{array}$} & \multicolumn{2}{|c|}{$\begin{array}{r}\text { BIO ART } \\
\text { WM-LS }\end{array}$} & \multicolumn{2}{|c|}{$\begin{array}{l}\text { BIO ART } \\
\quad 4000\end{array}$} \\
\hline & COM & SEM & COM & SEM & COM & SEM & COM & SEM & COM & SEM \\
\hline 1 & 28,71 & 29,07 & 23,98 & 24,34 & 22,82 & 23,14 & 19,32 & 19,72 & 31,06 & 31,85 \\
\hline 2 & 28,65 & 29,09 & 24,01 & 24,23 & 22,85 & 23,29 & 19,28 & 19,70 & 30,94 & 31,65 \\
\hline 3 & 28,68 & 28,99 & 23,89 & 24,28 & 22,81 & 23,28 & 19,30 & 19,69 & 31,00 & 31,83 \\
\hline 4 & 28,70 & 29,14 & 23,80 & 24,32 & 22,87 & 23,26 & 19,34 & 19,75 & 31,08 & 31,72 \\
\hline 5 & 28,78 & 29,07 & 23,90 & 24,33 & 22,71 & 23,21 & 19,23 & 19,76 & 31,13 & 31,88 \\
\hline 6 & 28,73 & 29,09 & 24,06 & 24,31 & 22,86 & 23,27 & 19,36 & 19,60 & 31,11 & 31,71 \\
\hline 7 & 28,75 & 29,15 & 23,95 & 24,25 & 22,88 & 23,24 & 19,30 & 19,63 & 31,09 & 31,87 \\
\hline 8 & 28,64 & 29,05 & 23,96 & 24,28 & 22,87 & 23,17 & 19,33 & 19,58 & 31,07 & 31,72 \\
\hline 9 & 28,61 & 29,00 & 23,94 & 24,38 & 22,91 & 23,12 & 19,32 & 19,70 & 31,01 & 31,70 \\
\hline 10 & 28,66 & 29,07 & 24,00 & 24,35 & 22,82 & 23,14 & 19,34 & 19,75 & 31,17 & 31,83 \\
\hline média & 28,69 & 29,07 & 23,94 & 24,30 & 22,84 & 23,31 & 19,31 & 19,68 & 31,06 & 31,77 \\
\hline DIFERENÇA & & & & & & & & & & \\
\hline
\end{tabular}


TABELA 5.2.a: Comparação (em $\mathrm{mm}$ ) entre a montagem do modelo de gesso com e sem apoio das presilhas sobre a mesa incisal na região do $2^{\circ}$ molar superior direito, para analisar a diferença de deslocamento do modelo em ambos os lados

\begin{tabular}{|c|c|c|c|c|c|c|c|c|c|c|}
\hline \multirow[b]{2}{*}{ SEQÜÊENCIA } & \multicolumn{2}{|c|}{$\begin{array}{c}\text { WHIP-MIX } \\
8500\end{array}$} & \multicolumn{2}{|c|}{$\begin{array}{c}\text { DENT-FLEX } \\
10600\end{array}$} & \multicolumn{2}{|c|}{$\begin{array}{c}\text { GNATUS } \\
\mathbf{8 6 0 0}\end{array}$} & \multicolumn{2}{|c|}{$\begin{array}{r}\text { BIO ART } \\
\text { WM-LS }\end{array}$} & \multicolumn{2}{|c|}{$\begin{array}{l}\text { BIO ART } \\
\quad 4000\end{array}$} \\
\hline & COM & SEM & COM & SEM & COM & SEM & COM & SEM & COM & SEM \\
\hline 1 & 18,87 & 19,08 & 16,98 & 17,65 & 17,26 & 17,28 & 17,34 & 17,65 & 12,57 & 12,96 \\
\hline 2 & 18,84 & 19,05 & 16,85 & 17,60 & 17,31 & 17,40 & 17,30 & 17,59 & 12,54 & 12,92 \\
\hline 3 & 18,86 & 19,02 & 16,97 & 17,53 & 17,30 & 17,43 & 17,48 & 17,58 & 12,52 & 12,94 \\
\hline 4 & 18,87 & 19,07 & 16,94 & 17,54 & 17,33 & 17,54 & 17,36 & 17,59 & 12,53 & 12,95 \\
\hline 5 & 18,85 & 19,05 & 16,93 & 17,51 & 17,21 & 17,45 & 17,37 & 17,62 & 12,54 & 12,94 \\
\hline 6 & 18,90 & 19,11 & 16,82 & 17,50 & 17,26 & 17,56 & 17,43 & 17,65 & 12,60 & 12,96 \\
\hline 7 & 18,80 & 19,04 & 16,99 & 17,52 & 17,00 & 17,29 & 17,38 & 17,46 & 12,47 & 12,94 \\
\hline 8 & 18,87 & 19,09 & 16,92 & 17,49 & 17,07 & 17,23 & 17,31 & 17,63 & 12,57 & 12,93 \\
\hline 9 & 18,79 & 19,07 & 16,87 & 17,55 & 16,85 & 17,13 & 17,29 & 17,62 & 12,58 & 12,91 \\
\hline 10 & 18,83 & 19,00 & 16,85 & 17,62 & 16,82 & 17,08 & 17,33 & 17,59 & 12,54 & 12,93 \\
\hline média & 18,84 & 19,05 & 16,91 & 17,55 & 17,14 & 17,33 & 17,35 & 17,59 & 12,53 & 12,93 \\
\hline DIFERENÇA & & & & & & & 0 , & & & \\
\hline
\end{tabular}


TABELA 5.2.b: Comparação (em $\mathrm{mm}$ ) entre a montagem do modelo de gesso com e sem apoio das presilhas sobre a mesa incisal, na região do $2^{\circ}$ molar superior esquerdo, para analisar a diferença de deslocamento do modelo em ambos os lados

\begin{tabular}{|c|c|c|c|c|c|c|c|c|c|c|}
\hline \multirow[b]{2}{*}{ SEQÜÊNCIA } & \multicolumn{2}{|c|}{$\begin{array}{c}\text { WHIP-MIX } \\
8500\end{array}$} & \multicolumn{2}{|c|}{$\begin{array}{c}\text { DENT-FLEX } \\
10600\end{array}$} & \multicolumn{2}{|c|}{$\begin{array}{c}\text { GNATUS } \\
8600\end{array}$} & \multicolumn{2}{|c|}{$\begin{array}{r}\text { BIO ART } \\
\text { WM-LS }\end{array}$} & \multicolumn{2}{|c|}{$\begin{array}{c}\text { BIO ART } \\
4000\end{array}$} \\
\hline & COM & SEM & COM & SEM & COM & SEM & COM & SEM & COM & SEM \\
\hline $\mathbf{1}$ & 17,34 & 17,79 & 13,57 & 14,37 & 15,74 & 16,00 & 19,08 & 19,35 & 15,28 & 15,94 \\
\hline 2 & 17,28 & 17,75 & 13,42 & 14,46 & 15,72 & 15,94 & 19,01 & 19,33 & 15,41 & 15,86 \\
\hline 3 & 17,22 & 17,82 & 13,49 & 14,31 & 15,68 & 16,13 & 19,03 & 19,29 & 15,40 & 15,82 \\
\hline 4 & 17,28 & 17,72 & 13,43 & 14,37 & 15,63 & 16,01 & 19,08 & 19,34 & 15,34 & 15,73 \\
\hline 5 & 17,30 & 17,81 & 13,52 & 14,36 & 15,70 & 16,10 & 18,98 & 19,28 & 15,44 & 15,81 \\
\hline 6 & 17,22 & 17,76 & 13,60 & 14,37 & 15,62 & 16,14 & 19,05 & 19,27 & 15,42 & 15,93 \\
\hline 7 & 17,29 & 17,80 & 13,38 & 14,32 & 15,73 & 16,19 & 19,04 & 19,35 & 15,39 & 15,86 \\
\hline 8 & 17,25 & 17,80 & 13,57 & 14,34 & 15,79 & 16,20 & 19,08 & 19,37 & 15,35 & 15,81 \\
\hline 9 & 17,33 & 17,73 & 13,37 & 14,32 & 15,76 & 16,17 & 19,03 & 19,28 & 15,43 & 15,87 \\
\hline 10 & 17,31 & 17,76 & 13,54 & 14,36 & 15,75 & 16,16 & 19,04 & 19,30 & 15,36 & 15,85 \\
\hline média & 17,28 & 17,77 & 13,50 & 14,35 & 15,71 & 16,14 & 19,04 & 19,31 & 15,37 & 15,85 \\
\hline DIFERENÇA & & & & & & & & & & \\
\hline
\end{tabular}


TABELA 5.3: Comparação (em $\mathrm{mm}$ ) entre a montagem com apoio das presilhas na mesa incisal, sem e com elástico para a contenção do ramo superior. A região analisada é a do $2^{\circ}$ molar superior direito e esquerdo

\begin{tabular}{|c|c|c|c|c|c|c||}
\hline \multirow{2}{*}{} & \multicolumn{3}{|c|}{ LADO DIREITO } & \multicolumn{3}{c||}{ LADO ESQUERDO } \\
\cline { 2 - 7 } & \multicolumn{2}{|l|}{ SEM ELÁSTICO COM ELÁSTICO MÉDIA } & \multicolumn{2}{l||}{ SEM ELÁSTICO COM ELÁSTICO MÉDIA } \\
\hline $\begin{array}{c}\text { WHIP-MIX } \\
\mathbf{8 5 0 0}\end{array}$ & 18,94 & 18,68 & $\mathbf{0 , 2 6}$ & 17,69 & 17,16 & $\mathbf{0 , 5 3}$ \\
\hline $\begin{array}{c}\text { DENT-FLEX } \\
\mathbf{1 0 6 0 0}\end{array}$ & 17,99 & 16,33 & $\mathbf{1 , 6 6}$ & 14,89 & 12,49 & $\mathbf{2 , 4 0}$ \\
\hline $\begin{array}{c}\text { GNATUS } \\
\mathbf{8 6 0 0}\end{array}$ & 17,17 & 15,78 & $\mathbf{1 , 3 9}$ & 15,81 & 14,14 & $\mathbf{1 , 6 7}$ \\
\hline $\begin{array}{c}\text { BIO ART } \\
\text { WM-LS }\end{array}$ & 19,61 & 18,88 & $\mathbf{0 , 7 3}$ & 19,66 & 18,60 & $\mathbf{1 , 0 6}$ \\
\hline BIO ART & 15,89 & 15,01 & $\mathbf{0 , 8 8}$ & 12,80 & 11,90 & $\mathbf{0 , 9 0}$ \\
$\mathbf{4 0 0 0}$ & & & & & & \\
\hline
\end{tabular}


TABELA 5.4: Comparação (em $\mathrm{mm}$ ) entre a montagem sem o apoio das presilhas na mesa incisal e com o apoio da presilha inferior com a fenda voltada para a direita e, depois, com a mesma voltada para a esquerda do paciente

\begin{tabular}{|c|c|c|c|c|c|c|}
\hline & \multicolumn{3}{|c|}{$\begin{array}{l}\text { COM A FENDA VOLTADA PARA DIREITA } \\
\text { DO PACIENTE }\end{array}$} & \multicolumn{3}{|c|}{$\begin{array}{l}\text { COM A FENDA VOLTADA PARA ESQUERDA } \\
\text { DO PACIENTE }\end{array}$} \\
\hline & SEM APOIO & СОM АРОIO & MÉDIA & SEM APOIO & СOM APOIO & MÉDIA \\
\hline $\begin{array}{l}\text { WHIP-MIX } \\
8500\end{array}$ & 22,57 & 22,28 & 0,28 & 17,65 & 17,09 & 0,56 \\
\hline $\begin{array}{c}\text { GNATUS } \\
8600\end{array}$ & 20,89 & 20,43 & 0,46 & 20,22 & 19,51 & 0,71 \\
\hline $\begin{array}{l}\text { BIO ART } \\
\text { WM-LS }\end{array}$ & 21,62 & 21,34 & 0,28 & 20,91 & 20,15 & 0,36 \\
\hline $\begin{array}{l}\text { BIO ART } \\
4000\end{array}$ & 13,85 & 13,55 & 0,30 & 23,14 & 22,48 & 0,66 \\
\hline
\end{tabular}




\section{DISCUSSÃO}

Em relação a montagem do modelo de gesso superior em articulador semi-ajustável, utilizando o método arbitrário com o arco facial simples de posicionamento no meato acústico externo e, em particular, entre todos os modelos que seguem o padrão do articulador Whip-Mix 8500, a revisão da literatura apresentou uma similaridade muito grande entre os pesquisadores (Weinberg, 1961; Weinberg, 1963ª 1963b; Teteruck \& Lundeen, 1966; Tamaki, 1971; Tanaka et al., 1975; Whitsett et al., 1977; Hockel et al., 1980; Walker, 1980; Hart et al., 1983; Shillingburg et al., 1983; Gordon et al., 1984; Todescan et al., 1996).

Especificamente no que se refere ao uso dos articuladores semiajustáveis do tipo arcon, que utilizam o método arbitrário de localização do eixo terminal de rotação dos côndilos da mandíbula, por meio do arco facial simples de posicionamento no meato acústico externo, os quais foram analisados na presente pesquisa, a revisão da literatura demonstrou que estes aparelhos, mesmo apresentando certas limitações mecânicas (Aull, 1965; Hickey et al., 1967; Bellanti, 1973; Whitsett et al., 1977; Shillingburg et al., 1983; Whitbeck \& Ivanhoe, 1985; Desplats, 1986; Johnson \& Stratton, 1988; Malone \& Koth, 1991; Mohl et al., 1991; Todescan et al., 1996), são importantes para a análise oclusal, diagnóstico, plano de tratamento e execução da prótese dental, conseguindo reproduzir padrões aproximados de alguns movimentos mandibulares, numa relação modelo-articulação temporomandibular semelhante à que existe no paciente (Pruden, 1960; Weinberg, 1963b; Teteruck \& Lundeen, 1966; Tanaka et al., 1975; Tanaka \& Finger, 1978; Celenza, 1979; Kotwal, 1979; Henderson \& Steffel, 1979; Hockel, 1980; Gibbs \& Lundeen, 1982; 
Drago \& Rugh, 1982; Mongini, 1982; Wise, 1982; Barnett, 1984; Carter, 1984; Piehslinger et al., 1985; Zuckerman, 1985; Goska \& Christensen, 1988; Strohaver \& Ryan, 1988; Elledge, 1989; Wright, Jr., 1989; Pitchford, 1991; Ellis III et al., 1992; Hayashi et al., 1994).

Apesar das controvérsias existentes sobre o grau de falha destes instrumentos em reproduzir os movimentos mandibulares verdadeiros, os articuladores semi-ajustáveis são os mais utilizados na prática clínica e, entre seus diversos tipos, o mais largamente utilizado é o Whip-Mix (Hickey et al., 1967; Whitsett et al., 1977; Walker, 1980; Gross \& Gazil, 1985; Smith, 1985; Gross et al., 1990 e Mohl et al., 1991).

Segundo vários autores, a precisão do uso dos articuladores está na dependência do método utilizado para localizar o eixo terminal de rotação da mandíbula, da precisão do arco facial usado para registrar esta posição e transferi-la para o articulador e, ainda, da habilidade e experiência do profissional no manuseio destes instrumentos (Teteruck \& Lundeen, 1966; Zuckerman, 1985).

Das técnicas existentes para a localização do eixo de rotação, vários trabalhos na literatura, como por exemplo o de Laing \& Wise (1978), analisaram o uso dos arcos faciais arbitrários de posicionamento no meato acústico externo e demonstraram ser de razoável precisão e, dependendo do tipo utilizado, consegue-se uma eficiência de 75,5\% (Teteruck \& Lundeen, 1966; Parel, 1972; Whitsett et al., 1977; Shillingburg et al., 1983). Verificou-se ainda que é importante esta localização a fim de capacitar a precisa reprodução do relacionamento oclusal (Thorp et al., 1978; Kotwal, 1979; Beard \& Clayton, 1981; Chow et al., 1985), 
essencial para planejar, registrar, avaliar, verificar e corrigir problemas oclusais (Hockel, 1980).

Quando este registro e a montagem são acompanhados de precisão, os modelos montados permanecerão na posição de relação central, mesmo que a dimensão vertical seja alterada no articulador (Henderson \& Steffel, 1979; Shillingburg et al., 1983; Zuckerman, 1985; Pitchford, 1991; Ellis III et al., 1992). É um passo significativo para a construção de próteses dentais que requeiram um mínimo de ajuste oclusal (Weinberg, 1961). Foi também demonstrado, que é importante que o ângulo formado entre o plano oclusal e o plano de Frankfort no paciente, seja o mesmo que o formado pelo plano oclusal do modelo de gesso superior em relação ao ramo superior do articulador (Ellis III et al., 1992).

Se os modelos forem montados de tal forma que o articulador feche ao redor de um eixo diferente daquele da mandíbula do paciente, os dentes ocluirão no articulador em posição diferente daquela que ocorre na boca do paciente (Weinberg, 1959; Weinberg, 1961; Weinberg, 1963a; Weinberg, 1963b; Whitsett et al., 1977; Thorp et al., 1978; Beard \& Clayton, 1981; Shillingburg et al., 1983; Chow et al., 1985; Zuckerman, 1985; Bowley \& Bowman, 1992).

O eixo de rotação da mandíbula transferido incorretamente para o articulador, fará com que o espaço interoclusal utilizado para se fazer os registros maxilo-mandibulares induza a erros quando o articulador ocluir, ou seja, os erros encontrados numa prótese dental assim construída, serão atribuídos à montagem incorreta dos modelos de gesso do paciente. Podem afetar, por isso, a colocação das pontas de cúspides, fazendo com que as 
vertentes de restaurações na região posterior contactem ou batam primeiro, quando o paciente fechar a boca e os dentes ocluírem (Thorp et al., 1978; Weinberg, 1961; Hart et al., 1983; Gordon et al., 1984; Palik et al., 1985; Strohaver \& Ryan, 1988; Malone \& Koth, 1991; Bowley \& Bowman, 1992; Mohl et al., 1991),

Um erro verificado no funcionamento de um articulador pode ser definido como um "desvio da verdade" e verdade como "de acordo com a realidade". Portanto, um erro produzido na oclusão é considerado como um desvio de todos os registros que foram efetuados, tal como os recomendados para uma determinada técnica. Existem trabalhos na literatura que demonstram que diferenças de $3 \mathrm{~mm}$ em espessura na região $\operatorname{dos} 2^{\text {os }}$ molares, causam um erro horizontal de $0,1934 \mathrm{~mm}$ nesta região (Weinberg, 1959; Weinberg, 1963b). Outro trabalho afirma que o limite para este erro oclusal em prótese fixa está entre 0,05mm e 0,075mm (Fox, 1965). Um outro ainda, demonstra que este limite não deve exceder a 0,1mm (Piehslinger et al., 1985).

Estes resultados mostram, portanto, que qualquer erro acima destes limites estará desviando o objetivo pelo qual os articuladores foram desenvolvidos, qual seja, a de transferir de maneira precisa o modelo de gesso para o articulador, de acordo com a posição espacial tridimensional que a arcada superior ocupa em relação ao crânio e ao eixo terminal de rotação da mandíbula do paciente.

Estudando-se um novo método para simplificação e maior precisão de montagem do modelo de gesso da arcada superior em articuladores, por meio de moldeiras de transferência, Zanetti \& Ribas (1997) utilizaram 
vários articuladores do tipo semi-ajustável e verificaram a existência de alterações posicionais durante os procedimentos para montagem do modelo de gesso no articulador.

Por esta razão, o presente estudo analisou estes desvios de posição do modelo de gesso superior fixado ao garfo de mordida, que foi causado pelo apoio do arco facial sobre a mesa incisal do ramo inferior dos articuladores semi-ajustáveis do tipo arcon, que utilizam o arco facial arbitrário simples, com o objetivo de procurar corrigi-los fazendo com que os articuladores possam ser utilizados de acordo com a finalidade para a qual foram construídos.

De acordo com os autores consultados, a técnica descrita para a montagem do modelo de gesso superior neste tipo de articulador, preconiza o apoio do arco facial fixado ao ramo superior sobre o ramo inferior por meio de 3 pontos, dois posteriores e um anterior, sendo este último, representado pelo apoio das presilhas que fixam o cabo do garfo de mordida ao arco facial sobre a mesa incisal localizada no ramo inferior do articulador (Teteruck \& Lundeen, 1966; Hickey et al., 1967; Parel, 1972; Whitsett et al., 1977; Laing \& Wise, 1978; Kotwal, 1979; Hockel, 1980; Wise, 1982; Shillingburg et al., 1983; Carter, 1984; Zuckerman, 1985; Malone \& Koth, 1991; Mohl et al., 1991; Ellis III et al., 1992; Todescan et al., 1996; Manual de Instruções do articulador Whip-Mix).

Foi demonstrado, de acordo com os resultados obtidos, que este apoio do arco facial sobre o ramo inferior do articulador causa um erro posicional, isto é, um deslocamento do modelo de gesso para cima, 
alterando sua posição espacial no articulador em relação ao eixo terminal de rotação da mandíbula.

Este erro foi causado por uma alavanca de terceira classe formada entre o garfo de mordida e o suporte geral do arco facial, onde o fulcro se dá na haste vertical do suporte geral, a força é representada pelo apoio do sistema de presilhas do arco facial (que fixam o garfo ao arco) na mesa incisal do articulador e a resistência como sendo o modelo de gesso, que é deslocado para cima quando o arco é apoiado sobre o ramo inferior do articulador.

Se o ponto de apoio ou fulcro se achar situado fora da linha de ação da força, esta tenderá a produzir um giro do corpo e, este efeito será tanto mais pronunciado, quanto maior for a força (que, em nosso estudo, dependerá, além de outras variáveis, do peso total do arco facial juntamente com o modelo) e quanto maior for a distância do ponto fixo ou fulcro (Kneip et al., 1951). (Fig. 20).

Os resultados da tabela 5.1.a, que analisou a região do $1^{\circ}$ molar superior esquerdo, demonstraram que o apoio das presilhas do arco facial sobre a mesa incisal causam uma alavanca de terceira classe, ocasionando um desvio do modelo de gesso para cima, aproximando-o da placa de montagem do ramo superior.

Os resultados da tabela 5.1.b, que analisou a região do $2^{\circ}$ molar superior esquerdo, demonstraram um aumento da amplitude do momento de rotação nesta região mais posterior, em relação ao fulcro localizado onde a haste vertical é soldada ao suporte geral do arco facial. Portanto, o 
deslocamento do modelo para cima será mais exacerbado na região posterior das arcadas.

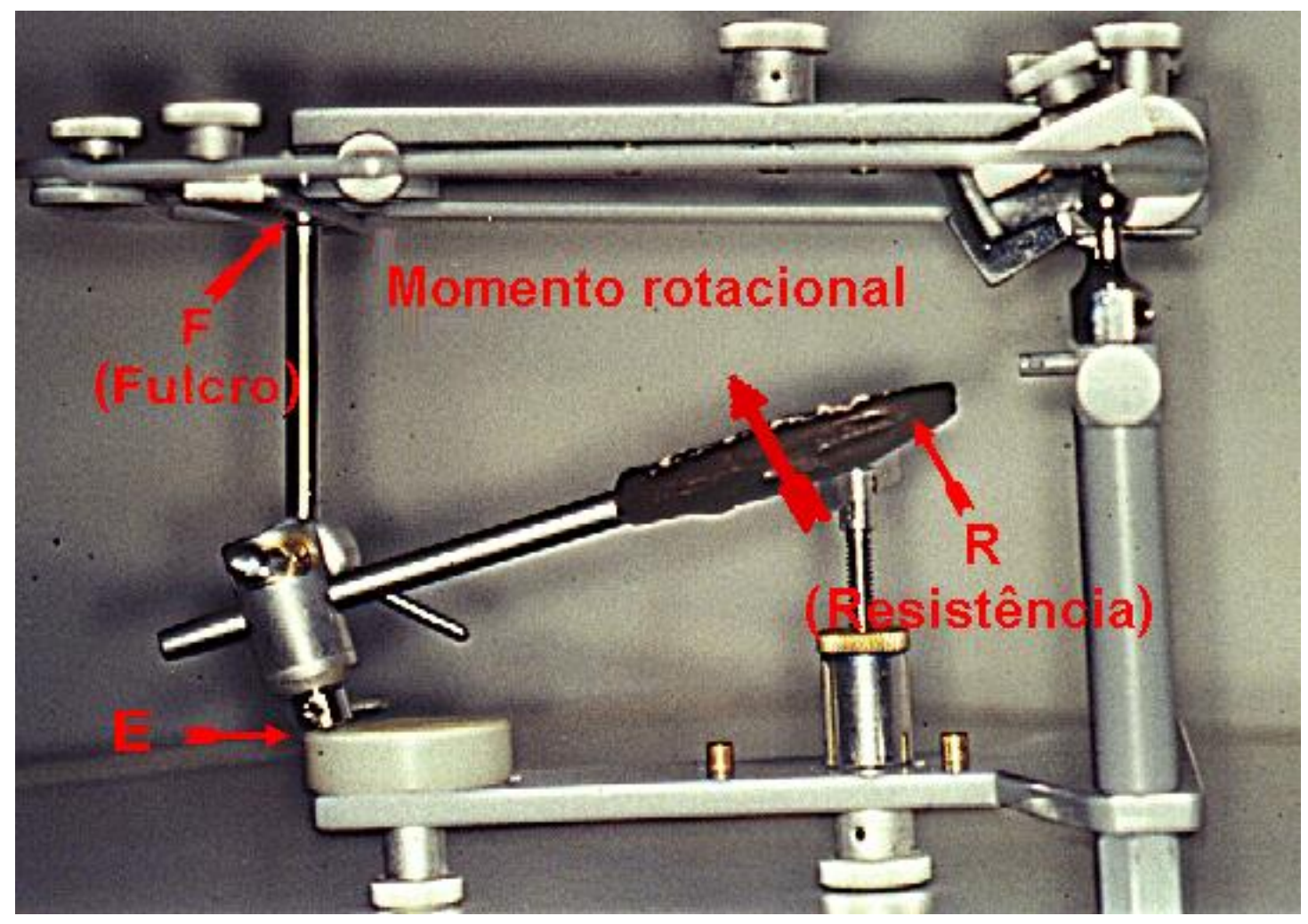

Figura 20 - Efeito de alavanca ocasionado pelo apoio das presilhas do arco facial sobre a mesa incisal do articulador

Os resultados das tabelas 5.2.a. e 5.2.b, que analisaram a montagem com e sem apoio das presilhas na região do $2^{\circ}$ molar direito e esquerdo, demonstraram que o deslocamento do modelo é maior do lado esquerdo, causado pela posição da haste vertical para o lado direito do paciente, que faz com que haja um desequilíbrio do peso do arco facial, sendo maior do lado oposto à haste vertical. A posição (inclinação) da presilha em relação à mesa incisal também favorece este desvio maior para o lado esquerdo. 
Particularmente no articulador Bio Art 4000, existe um sistema de fixação de presilhas por meio de um parafuso com aleta do tipo "borboleta". Esta aleta, pelo desenho da presilha inferior, acha-se deslocada para o lado oposto ao orifício por onde passa o cabo do garfo de mordida. Este posicionamento excêntrico da aleta, ou seja, fora do eixo do cabo do garfo de mordida, faz com que o garfo de mordida, juntamente com o modelo, sofra um desvio para direita ou para esquerda, dependendo do lado que esteja a presilha (com a fenda voltada para a direita ou para esquerda) e, dependendo da posição que a aleta fique após ser apertada para a fixação do garfo de mordida (Fig. 21).

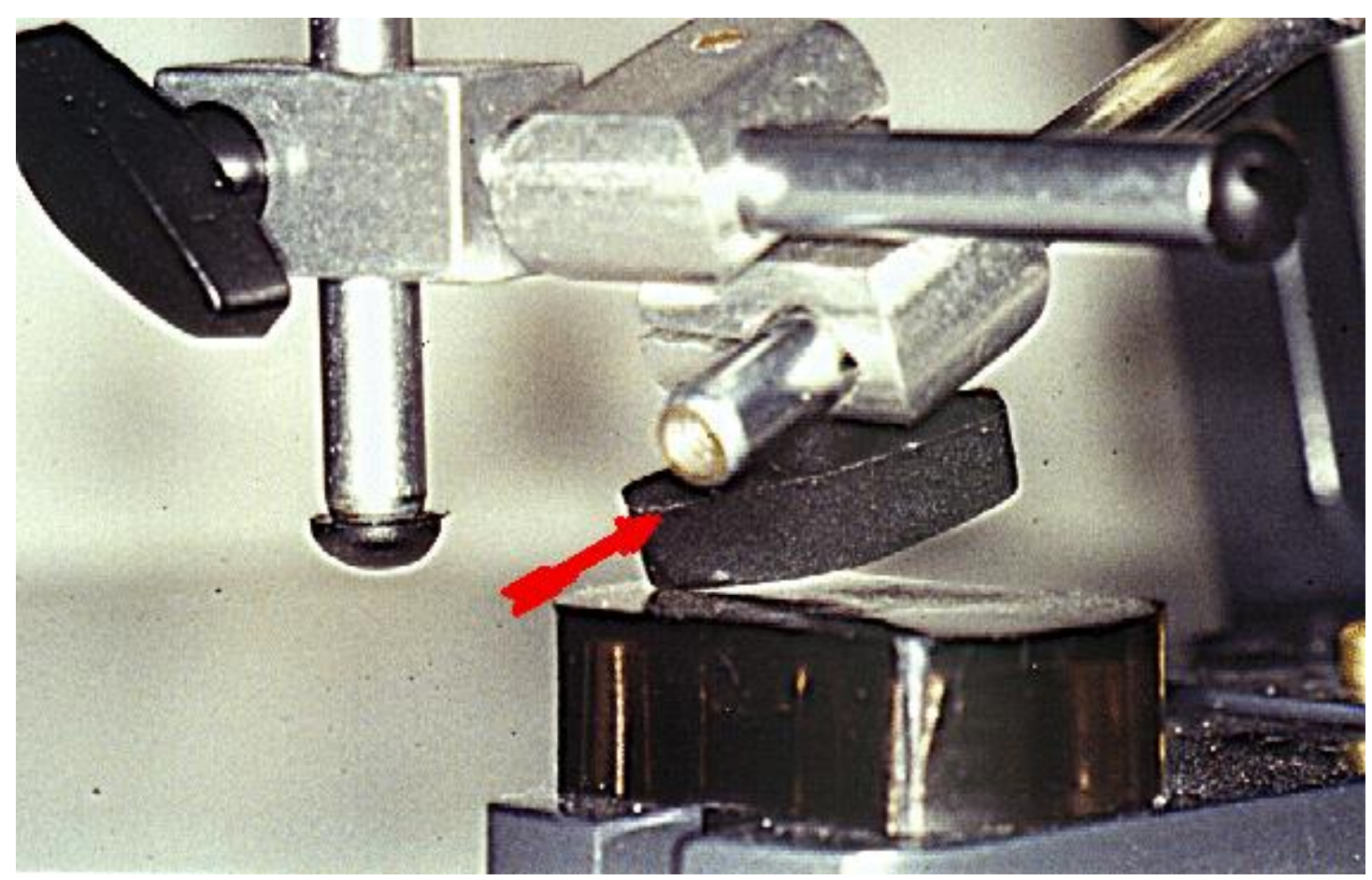

Figura 21 - O desenho da aleta e a posição em que é apoiada sobre a mesa incisal, favorece o aumento do efeito de alavanca no articulador Bio Art 4000 (seta)

Os resultados da tabela 5.3, que analisou a montagem com elástico para se controlar a expansão dimensional do gesso, demonstraram que 
dependendo da posição e do modo como é colocado no articulador e/ou arco facial, ele exacerbará o desvio de posição do modelo de gesso.

Os resultados da tabela 5.4, que analisou a posição da presilha em relação a sua fenda, para direita e para esquerda, mostrou que a posição da mesma pode exacerbar o momento de rotação do modelo, pois, como foi verificado, quando a fenda estiver posicionada para a esquerda do modelo, irá fazer com que as presilhas se afastem da haste vertical, aumentando desta maneira o braço de alavanca.

Não foi encontrado na literatura alguma indicação de qual lado a presilha deve estar posicionada. Ao contrário, pôde-se encontrar muita confusão, inclusive no próprio manual do articulador Whip-Mix 8500, onde uma fotografia mostra o arco facial montado na face do paciente, com a fenda da presilha voltada para a direita do mesmo. Este posicionamento faz as presilhas se aproximarem da haste vertical do suporte geral do arco facial (Fig. 22). Noutra fotografia, a que mostra o caso sendo montado no articulador, a fenda da presilha aparece voltada para a esquerda do modelo, o que faz as presilhas se afastarem da haste vertical aumentando o braço de alavanca (Fig. 23). Obviamente não se trata de uma mesma sequiência de montagem do modelo de gesso de um mesmo paciente. Fato semelhante foi encontrado em alguns livros-texto e trabalhos de pesquisa. 


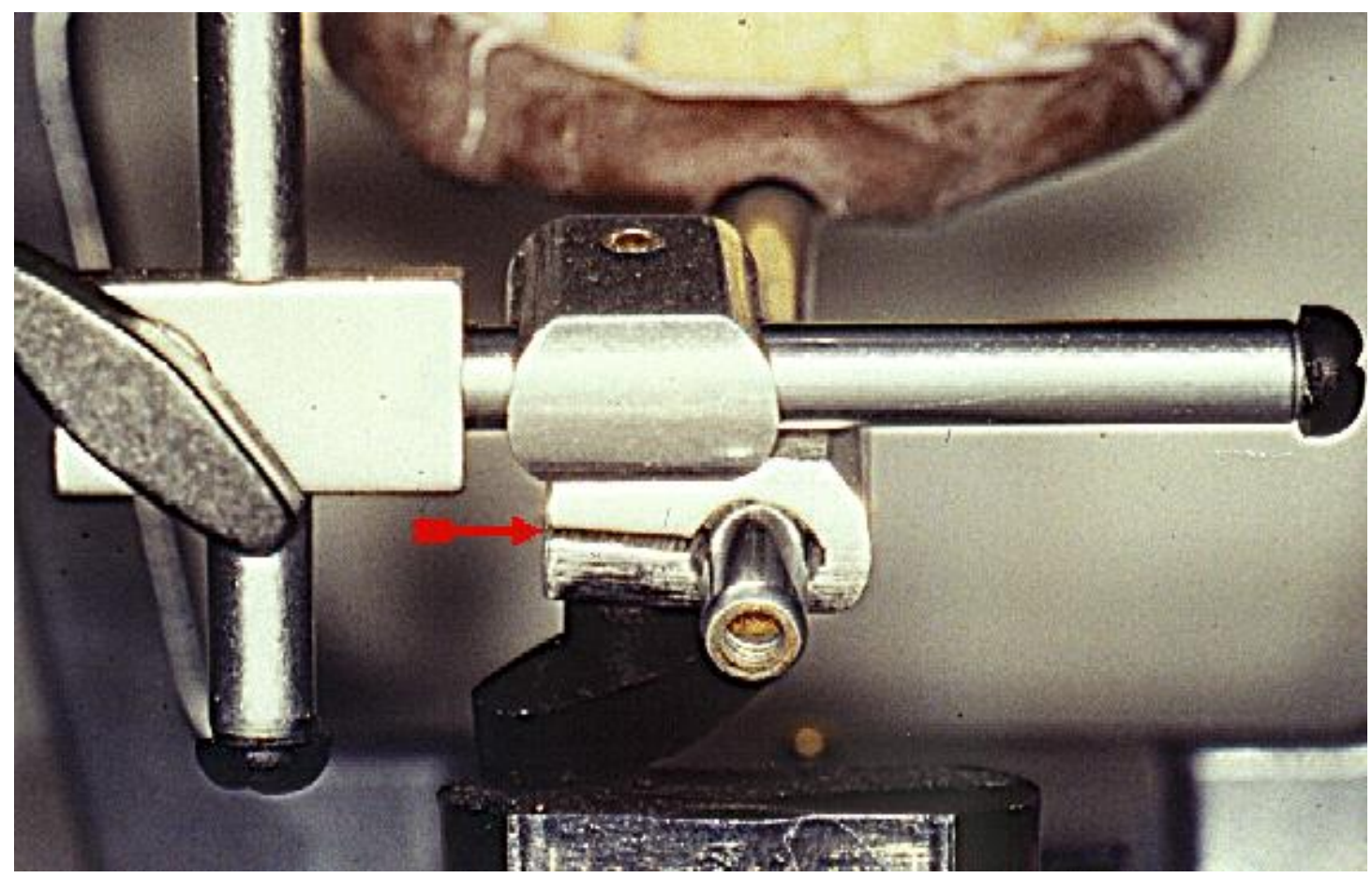

Figura 22 - Fenda da presilha inferior voltada para a direita do paciente. Neste caso as presilhas se aproximam da haste vertical do arco facial (seta)

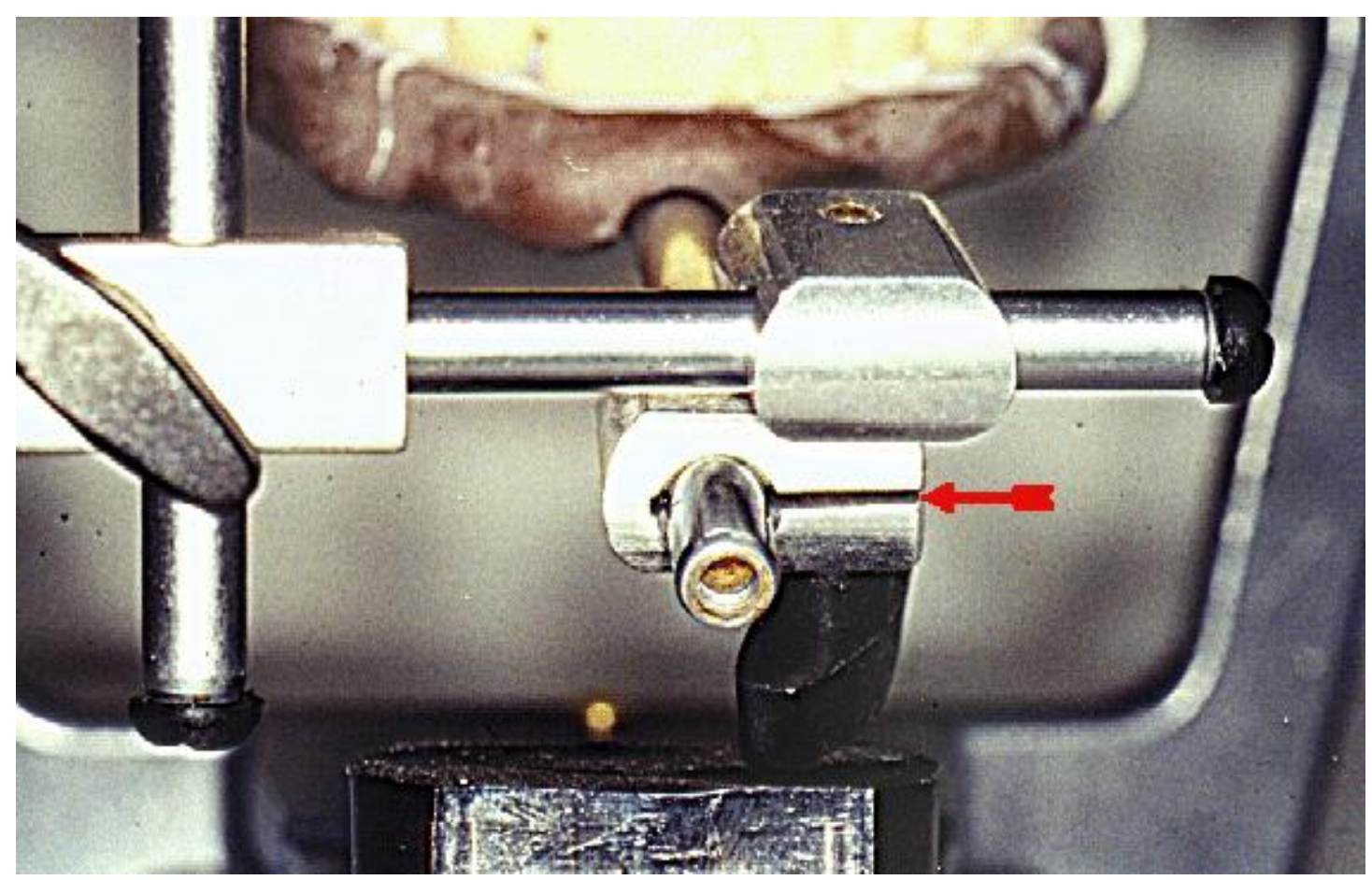

Figura 23 - Fenda da presilha inferior voltada para a esquerda do paciente. Neste caso as presilhas se afastam da haste vertical do arco facial, aumentando o efeito de alavanca (seta) 
Como pôde ser também verificado na tabela 5.4, o articulador DentFlex 10600 não foi analisado quanto a esse desvio dependente do lado em que esteja posicionado o recorte da presilha, justamente porque seu arco facial possui um sistema de fixação do garfo de mordida por meio de uma junta universal, cujo parafuso, com cabeça em forma de disco com borda serrilhada, encontra-se no centro do cruzamento desse sistema com o cabo do garfo de mordida. Esse sistema possui apenas uma posição possível para o encaixe no garfo, sendo que este, diferentemente de todos os outros articuladores analisados, fica posicionado acima do suporte horizontal (Fig. 24).

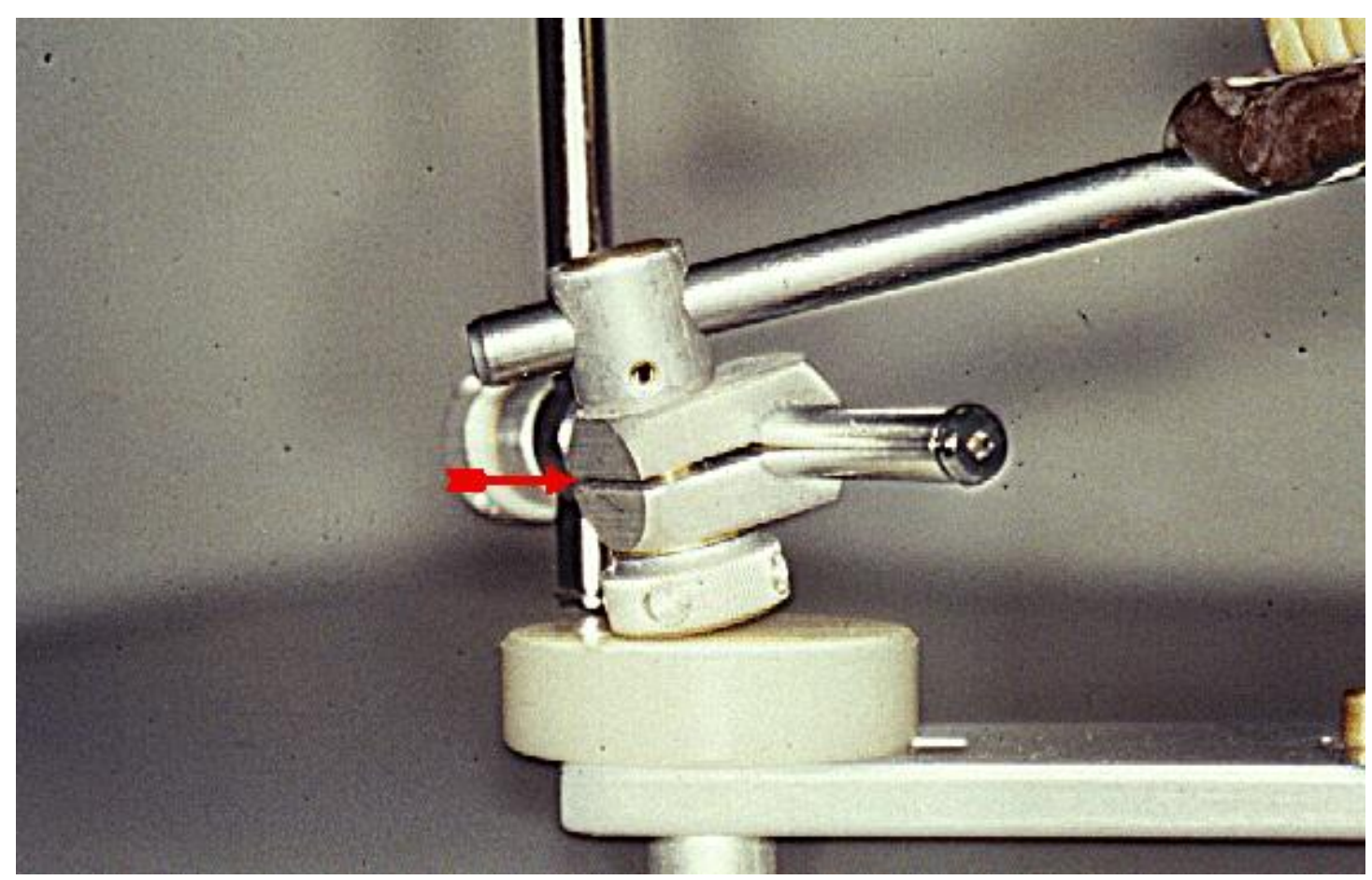

Figura 24 - Detalhe da junta universal do articulador Dent-Flex 10600 (seta) e do posicionamento do cabo do garfo de mordida acima do suporte horizontal do arco facial, diferentemente dos demais articuladores analisados

Como já foi descrito anteriormente, no capítulo referente à técnica de montagem utilizada para esta pesquisa, nos outros articuladores as 
presilhas (qualquer que seja o lado da fenda da presilha inferior) fazem com que o cabo do garfo de mordida seja posicionado abaixo do suporte horizontal (Fig. 25). Nos dois casos, este posicionamento do cabo do garfo em relação ao suporte horizontal, se deve ao fato de que os parafusos que fixam esse cabo, tanto no sistema de presilhas como no sistema de junta universal, devem ficar para baixo a fim de possibilitar seu manuseio.

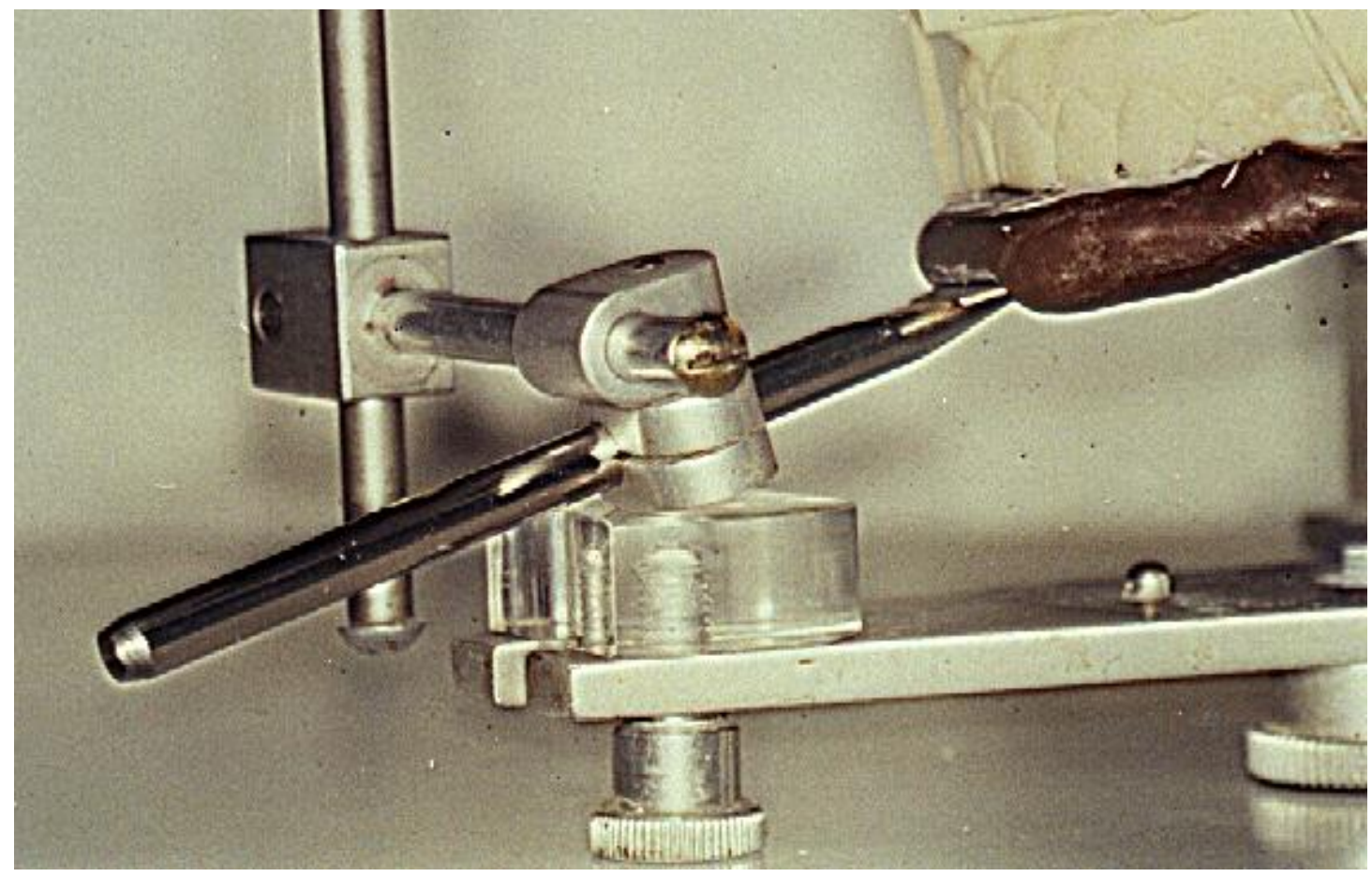

Figura 25 - Detalhe do posicionamento do cabo do garfo de mordida abaixo do suporte horizontal do arco facial, encontrado na maioria dos articuladores analisados

Fundamentado nestas constatações, sugerimos que novas pesquisas sejam realizadas neste campo, abrangendo outras funções deste tipo de articulador, com a finalidade de melhorar a precisão de montagem dos modelos de gesso nos mesmos. 


\section{CONCLUSÕES}

Com referência a técnica de montagem em articuladores semiajustáveis do tipo arcon, que utilizam o arco facial simples adaptado ao meato acústico externo, diferentemente daquilo que foi encontrado na literatura, os resultados obtidos em nosso estudo demonstram que é de extrema importância o modo pelo qual o arco facial é apoiado sobre o ramo inferior do articulador.

Os resultados mostraram claramente que na montagem do modelo de gesso superior no articulador, se o apoio anterior do arco facial for feito por meio das presilhas sobre a mesa incisal, originará uma resultante de força ou momento de rotação, provocando um erro de posicionamento do modelo de gesso em relação ao eixo terminal de rotação da mandíbula.

Estes desvios de posição do modelo apresentaram alterações dependendo de algumas variáveis, tais como:

1) da região em que foi analisado o desvio. A região mais posterior $\left(2^{\circ}\right.$ molar) apresentou uma maior amplitude do momento de rotação. A presença de parafuso de pressão com aleta do tipo "borboleta", parece exacerbar, devido ao seu desenho, o momento de rotação do modelo, principalmente quando o apoio é feito numa das arestas da referida aleta.

2) do ângulo e posição da presilha inferior em relação à mesa incisal.

3) da posição lateral (lado direito do arco facial em relação ao paciente) da haste vertical do suporte geral do arco, fazendo com que haja um 
desequilíbrio na distribuição do peso de todo o conjunto suportado pelo arco.

4) da posição que as presilhas que fixam o cabo do garfo de mordida se encontram no eixo do suporte horizontal do arco facial, ou seja, quanto mais distante as presilhas estiverem da haste vertical do suporte geral, maior será o momento de rotação do modelo de gesso. A própria posição da fenda da presilha inferior para a direita, aumenta o braço de alavanca, pois afasta o ponto de fixação da presilha inferior para longe da haste vertical.

5) dependendo do modo de utilização das bandas elásticas que acompanham os articuladores, estas podem exacerbar o momento de rotação do modelo de gesso. Portanto sua utilização, para auxiliar nos procedimentos de montagem dos modelos no articulador e, também para melhor controlar a expansão de presa do gesso utilizado para a fixação dos modelos às placas de montagem, deverá ser feita com critérios.

6) da marca de articulador avaliado, provavelmente em função dos materiais que são utilizados em sua construção.

Na presença destes desvios, concordamos com Weinberg (1963b) quando afirmou que, mesmo supondo que estes erros sejam tão pequenos que possam ser completamente absorvidos pelas variações biológicas ou por meio de ajustes oclusais na boca do paciente, é plenamente justificável a verificação e correção de erros durante os procedimentos de montagem 
dos modelos para a manutenção da viabilidade clínica desses instrumentos, a medida que esses erros, além de serem cumulativos e não auto-corretivos, são freqüentemente negativos por causarem um posicionamento no articulador de vertentes de cúspides posteriores mais planas do que o necessário na boca. $\mathrm{Na}$ verdade este tipo de erro não pode ser corrigido clinicamente por desgaste ou ajuste oclusal, pois não são contatos prematuros e sim um posicionamento errado da inclinação das cúspides.

Quanto menor for a necessidade de ajustes posteriores das restaurações dentais ou qualquer outro procedimento clínico, mais precisa terá sido a técnica utilizada para a transferência dos registros da arcada superior do paciente para o articulador.

Para se manter a exata posição do modelo de gesso obtida com a utilização do arco facial, além de proceder a um criterioso método de montagem do modelo de gesso, a porção anterior do arco não poderá ser apoiada sobre o articulador, pois, se as presilhas ou a haste do garfo de mordida forem apoiadas ou calçadas, como preconizam os autores consultados, ocorrerá uma alteração posicional do garfo de mordida do arco facial, conseqüentemente alterando o posicionamento do modelo de gesso no articulador em relação a posição da arcada superior do paciente.

Conclui-se, portanto, que medidas devam ser tomadas para que os modelos não sofram alterações posicionais decorrentes desse erro verificado, procurando aplicar técnicas mais apuradas de utilização do articulador e do arco facial, permitindo assim, que os mesmos possam cumprir a finalidade para a qual foram construídos. 
Por este motivo, o suporte anterior do arco facial foi desenvolvido com a finalidade de impedir os efeitos deletérios que o apoio das presilhas sobre a mesa incisal poderiam causar, devendo ser posicionado na linha mediana da borda anterior do arco para se obter um perfeito equilíbrio entre as duas metades do mesmo, razão pela qual, não se poderia lançar mão do aumento do comprimento da haste vertical do suporte geral do arco. 


\section{REFERÊNCIAS BIBLIOGRÁFICAS*}

1. Anderson, G. C.; SCHUlTE, J. K.; ARNOLD, T. G. An in vitro study of an electronic pantograph. J Prosth Dent, v. 57, n. 5, p. 57780, may. 1987.

2. AULL, A. E. Condylar determinants of occlusal patterns. J Prosth Dent, v. 15, n. 5, p. 826-46, sept./oct. 1965.

3. BARNETT, F. C. Articulator mounting and adjustments. Aust Ortho J, v. 8, n. 4, p. 128-30, oct. 1984.

4. BEARD, C. C.; CLAYTON, J. A. Studies on the validity of the terminal hinge axis. J Prosth Dent, v. 46, n. 2, p. 185-91, aug. 1981.

5. BECK, H. O. Choosing the articulator. J Am Dent Ass, v. 64, p. 46875, 1962. In: RIHANI, A. Classification of articulators. J Prosth Dent, v. 43, n. 3, p. 344-47, mar. 1980.

6. BELLANTI, N. D. The significance of articular capabilities. Part I: Adjustable vs. Semiadjustable articulators. J Prosth Dent, v. 29, n. 3, p. 269-75, mar. 1973.

\footnotetext{
* De acordo com NBR-6023 da Associação Brasileira de Normas Técnicas, 1989, Abreviatura de periódicos segundo "Index to Dental Literature".
} 
7. BERGSTROM, C. On the reproduction of dental articulation by means of articulators. A kinematic investigation. Orebo, Sweden, A. B. Littorin Ryden, 1950.

8. BOUCHER, C. O. Methods of recording functional movements of full denture bases in three dimensions. J Dent Res, v. 14, p. 39, 1934. In: RIHANI, A. Classification of articulators. J Prosth Dent, v. 43, n. 3, p. 344-47, mar. 1980.

9. BOWLEY, J. F.; BOWMAN, H. C. Evaluation of variables associated with transverse horizontal axis. J Prosth Dent, v. 68, n. 3, p. 537-41, sept. 1992.

10. CARTER, R. N. Quick-mounted diagnostic study models. J Clin Ortho, v. 18, n. 6, p. 423-26, jun. 1984.

11. CelenZA, F. V. Un analisis de los articuladores. Clin Odont Am N, v. 2, n. 1, p. 305-26, 1979.

12. CHOW, T. W.; CLARK, R. K. F.; COOKE, M. S. Errors in mounting maxillary casts using face-bow records as a result of an anatomical variation. J Dent, v. 13, n. 4, p. 277-82, dec. 1985.

13. DAWSON, P. E. New definition for relating occlusion to varying conditions of the temporomandibular joint. J Prosth Dent, v. 74, n. 6, p. 619-27, dec. 1995. 
14. DESPLATS, E. M. La protesis parcial removible en la practica diaria. Labor, Barcelona, 1986. p. 263-302.

15. DRAGO, C. J.; RUGH, J. D. Measurement of vertical jaw relationship. In: LUNDEEN, H. C.; GIBBS, C. H. Advances in occlusion. Bristol: John Wright-PSG Inc., 1982. p. 174-81.

16. ElLEDGE, D. A.; THEISEN, F. C.; AMET, E. M.; HART, W. K. Secure mounting of diagnosis casts. J Prosth Dent, v. 61, n. 4, p. 51920, apr. 1989.

17. ELLIS III, E.; THARANON, W.; GAMBRELL, K. Accuracy of Face-Bow Transfer: Effect on Surgical Prediction and Postsurgical Result. J Oral Maxillo Surg, v. 50, n. 6, p. 562-67, jun. 1992.

18. FERREIRA, A. B. H. Novo dicionário Aurélio da Língua Portuguesa. $2^{\text {a }}$ ed. São Paulo: Ed. Nova Fronteira, 1994.1838p.

19. FOX, S. S. The significance of errors in hinge axis location. J Am Dent Ass, v. 74, p. 1268-72, 1967. In: PIEHSLINGER, E.; BAUER, W.; SCHMIEDMAYER, H. B. Computer simulation of occlusal discrepancies resulting from different mounting techniques. J Prosth Dent, v. 74, n. 3, p. 279-83, sept. 1985.

20. GALVÃO FILHO, S. Dicionário Odonto-Médico InglêsPortuguês. $1^{\text {a }}$ ed. São Paulo: Livr. Ed. Santos, 1998. 952p. 
21. GIBBS, C. H.; LUNDEEN, H. C. Jaw movements and forces during chewing and swallowing and their clinical significance. In: LUNDEEN, H. C.; GIBBS, C. H. Advances in occlusion. Bristol: John Wright-PSG Inc., 1982. p. 2-29.

22. GILLIS, R. R. Articulator development and the importance of observing the condyle paths in full denture prosthesis. J Am Dent Ass, v. 13, p. 3, 1926. In: RIHANI, A. Classification of articulators. J Prosth Dent, v. 43, n. 3, p. 344-47, mar. 1980.

23. GORDON, S. R.; STOFFER, W. M.; CONNOR, S. A. Location of the terminal hinge axis and its effect on the second molar cusp position. J Prosth Dent, v. 52, n. 1, p. 99-105. 1984.

24. GOSKA, J. R.; CHRISTENSEN, L. V. comparision of cast positions by using four face-bows. J Prosth Dent, v. 59, n. 1, p. 42-4, jan. 1988.

25. GROSS, M. D.; GAZIL, E. Articulators used in North american dental schools. J Dent Ed, v. 49,n. 10, p. 710-11, oct. 1985.

26. GROSS, M. D.; NEMCOVSKY, C.; FRIEDLANDER, L. D. comparative study of condylar settings of three semiadjustable articulators. The Int J Prosth, v. 3, n. 2, p. 135-41, mar./apr. 1990.

27. HART, T. D.; MALONE, W. F.; SANDRICK, J.; BOWMAN, D.; BALTHAZAR, Y. M. A proposed format for mandibular displacement analysis in fixed prosthodontics. J Prosth Dent, v. 50, n.1, p. 54-61. 1983. 
28. HAYASHI, T.; SAITOH, A.; ISHIOKA, K.; MIYAKAWA, M. A computerized system for analyzing occlusal relations during mandibular movements. Int J Prosth, v. 7, n. 2, p. 108-14, mar./apr. 1994.

29. HEARTWELL, C. M; RAHN, A. O. Syllabus of complete dentures. $2^{\mathrm{a}}$ ed. Lea \& Febiger, Publishers, Philadelphia, 1974. p. 47, 77, 202.

30. HENDERSON, D., STEFFEL, V. L. Prótese parcial removível de McCracken. Artes Médicas, São Paulo, 1979. p. 15-8; 105-20; 165 201; 273-321.

31. HICKEY, J. C.; LUNDEEN, H. C.; BOHANNAN, H. M. A new articulator for use in teaching and general practice. J Prosth Dent, v. 18, n. 5, p. 425-37, nov. 1967.

32. HOCKEL, J. L. The face bow: A primary diagnostic aid to gaining an organic occlusion, the goal of orthopedic gnathology. Int J Ortho, v. 18, n. 2, p. 13-16, jun. 1980.

33. HUGGETT, R.; HARRISON, A. Antagonizers 1805 to articulators 1977. The Dent Tech, v. 30, n. 7, p. 4-7, jul. 1977.

34. JOHNSON, D. L.; STRATTON, R. J. Fundamentos da prótese removível. Quintessence, Rio de Janeiro, 1988. p. 167-90, 245-8.

35. JONES, G. L. A method of teaching face-bow transfer. J Dent Educ, v. 38 , n. 10 , p. 558-60, oct. 1974. 
36. KNEIP, K.; WINZER, G.; KILLMANN, P. La escuela del técnico mecánico. Tomo III: Mecánica resistencia de materiales grafostática. $3^{\mathrm{a}}$ ed. Barcelona, Espanã: Labor, 1951. p.78-90 e 166-71.

37. KOLLING, J. N.; PRICE, R. B.; MILLER, R. L.; CLAYTON, J. A. Evaluation of a digitizer and computer system designed to analyze articulator-generated occlusal tracings. J Prosth Dent, v. 59, n. 4, p. 499-503, apr. 1988.

38. KOTWAL, K. R. The need to use an arbitrary face-bow when remounting complete dentures with interoclusal records. J Prosth Dent, v. 42, n. 2, p. 224-27, aug. 1979.

39. LAING, D. P.; WISE, M. D. Split cast discrepancies and arbitrary axis dental cast articulator mounting. J Oral Rehab, v. 5, n. 3, p. 24959, jul. 1978.

40. LEKNIUS, C. Structural improvement of an electronic pantograph stylus assembly. J Prosth Dent, v. 76, n. 3, p. 339, sept. 1996.

41. Malone, W. F.; KOTH, D. Teoria e Prática de Prótese Fixa de Tylman. $8^{\text {a }}$ ed. São Paulo. Artes Médicas, São Paulo, 1991. p. 371-79.

42. McCOLLUM, B. B. Fundamentals involved in prescribing restorative dental remedies. D Items Interest, v. 61, n. 9, p. 641-48; 724-36; 85263; 942-50, 1939. 
43. MESSERMAN, T. A means for studying mandibular movements. J Prosth Dent, v. 17, p. 36-43, 1967. In: HAYASHI, T.; SAITOH, A.; ISHIOKA, K.; MIYAKAWA, M. A computerized system for analyzing occlusal relations during mandibular movements. Int J Prosth, v. 7, n. 2, p. 108-14, mar./apr. 1994.

44. MITCHELL, D. L.; WILKIE, N. D. Articulators through the years. Part I. Up to 1940. J Prosth Dent, v. 30, n. 3, p. 330-8, mar. 1978.

45. MOBERG, C. T.; YODER, J. L.; THAYER, K. E. The pantograph as a face-bow transfer instrument. J Prosth Dent, v. 29, n. 2, p. 139-45, feb. 1973.

46. MOHAMED, S. E.; SCHIDT, J. R.; HARRISON, J. D. Articulators in dental education and practice. J Prosth Dent, v. 36, n. 3, p. 319-25, sept. 1976.

47. MOHL, N. D.; ZARB, G. A.; CARLSSON, G. E.; RUGH, J. D. Fundamentos de Oclusão. $2^{\text {a }}$ ed. Quintessence Edit. Ltda., Rio de Janeiro, 1991. p. 154-59.

48. MONGINI, F. Occlusion and the temporomandibular joint. In: LUNDEEN, H. C.; GIBBS, C. H. Advances in occlusion. Bristol: John Wright-PSG Inc., 1982. p. 100-3.

49. PALIK, J. F.; NELSON, D. R.; WHITE, J. T. Accuracy of an earpiece face-bow. J Prosth Dent, v. 53, n. 6, . 800-04, jun. 1985. 
50. PAREL, S. M. Using the Whip-Mix face-bow with condylar articulators. J Prosth Dent, v. 28, n. 2, p. 200-4, aug. 1972.

51. PIEHSLINGER, E.; BAUER, W.; SCHMIEDMAYER, H. B. Computer simulation of occlusal discrepancies resulting from different mounting techniques. J Prosth Dent, v. 74, n. 3, p. 279-83, sept. 1985.

52. PITCHFORD, J. H. A reevaluation of the axis-orbital plane and the use of orbitale in facebow transfer record. J Prosth Dent, v. 66, n. 3, p. 349-55, sept. 1991.

53. POSSELT, U. Physiology of occlusion, $2^{\mathrm{a}}$ ed., Blackwell Scientific Publications, Oxford, 1968. p. 108.

54. PRUDEN, W.H. The Role of Study Casts in Diagnosis and Treatment Planning. J Prosth Dent, v.10, n.4, p.707-10, jul. 1960.

55. RAMFJORD, S.; ASH, M. M. Oclusão. $1^{\text {a }}$ ed. Ed. Guanabara S.A., Rio de Janeiro, 1983. p. 212-27.

56. RIHANI, A. Classification of articulators. J Prosth Dent, v. 43, n. 3 , p. 344-47, mar. 1980 .

57. SAIZAR, P. Prótesis a placa. Progental, Buenos Aires, 1958. p. 263.

58. SHARRY, J. J. Complete denture prosthodontics, $3^{\mathrm{a}}$ ed. McGrawHill Book Co., Inc., New York, 1974. p. 222-24. 
59. SHILlingBURG, H. T.; HOBO, S.; WHITSETT, L. D. Fundamentos de Prótese Fixa. $1^{\text {a }}$ ed. Livr. Ed. Santos, São Paulo, 1983. p. 207-28.

60. SMITH, D. E. Does one articulator meet the needs for both fixed and removable prosthodontics? J Prosth Dent, v. 54, n. 2, p. 296-302, aug. 1985.

61. STADE, E. H.; HANSON, J. G.; BAKER, C. L. Esthetic considerations in the use of face-bows. J Prosth Dent, v. 48, n. 3, p. 253-56, sept. 1982.

62. STROHAVER, R. A.; RYAN, J. R. New face-bow simplifies routine use and dental laboratory cooperation. J Prosth Dent, v. 60, n. 5, p. 638-41, nov. 1988.

63. TAMAKI, S. T. Calibragem do articulador. Estudo comparativo de 3 técnicas. Tese para Livre-Docência na disciplina de Prótese Total da FOUSP, São Paulo, 1976.

64. TAMAKI, T. ATM - Noções de interêsse protético. Ed. Sarvier, São Paulo. 1971.

65. TANAKA, H.; FINGER, I. M. A new semiadjustable articulator. Part IV: An investigation of three semiadjustable articulators. J Prosth Dent, v. 40, n. 3, p. 288-93, sept. 1978. 
66. TANAKA, H.; FINGER, I.; PORTER, M. M. J. A new semiadjustable articulator. Part II: Adjustment of a new-concept articulator. J Prosth Dent,. v. 33, n. 2, p. 158-67, feb. 1975.

67. TETERUCK, W. R.; LUNDEEN, H. C. The accuracy of an ear facebow. J Prosth Dent, v. 16, n. 6, p. 1039-46, nov./dec. 1966.

68. THOMAS, C. J. A classification of articulators. J Prosth Dent, v. 30, n. 1, p. 11-14, sept. /oct. 1973.

69. THORP, E. R.; SMITH, D. E.; NICHOLLS, J. I. Evaluation of the use of a face-bow in complete denture occlusion. J Prosth Dent, v. 39, v. 1, p. 5-15, jan. 1978.

70. TODESCAN, R.; SILVA, E. E. B.; SILVA, O. J. Atlas de Prótese Parcial Removível. $1^{\text {a }}$ ed., Livr. Ed. Santos, São Paulo, 1996. p. 27882

71. UNIVERSIDADE DE SÃO PAULO, FACULDADE DE ODONTOLOGIA, COMISSÃO DE PÓS-GRADUAÇÃO. Manual de Funcionamento do curso de Pós-Graduação em Odontologia da FOUSP (Níveis de Mestrado e Doutorado). São Paulo, 1997. Capítulos V-VII, p. 103-172.

72. WALKER, P. M. Discrepancies between arbitrary and true hinge axes. J Prosth Dent, v. 43, n. 3, p. 279-85, mar. 1980. 
73. WEINBERG, L. A. The transverse hinge axis: Real or imaginary. J Prosth Dent, v. 9, p. 775, 1959. In: THORP, E. R.; SMITH, D. E.; NICHOLLS, J. I. Evaluation of the use of a face-bow in complete denture occlusion. J Prosth Dent, v. 39, n. 1, p. 5-15, jan. 1978.

74. WEINBERG, L. A. An evaluation of of the face-bow mounting. $\mathbf{J}$ Prosth Dent, v. 11, p. 32-42. 1961.

75a. WEINBERG, L. A. An evaluation of basic articulators and their concepts. Part I: Basic Concepts. J Prosth Dent, v. 13, n. 4, p. 622-44. jul/aug. 1963.

75b. WEINBERG, L. A. An evaluation of basic articulators and their concepts. Part II: Arbitrary, Positional, Semiadjustable Articulators. J Prosth Dent, v. 13, n. 4, p. 645-63. jul/aug. 1963.

76. WHIP MIX Articulator and Quick Mount Face-Bow Instruction Manual. Whip-Mix Corporation, Kentucky, USA.

77. WHITBECK, P.; IVANHOE, J. R. Occlusal relationship. Dent Clin N Am, v. 29, n. 1, p. 149-62, jan. 1985.

78. WhitseTt, L. D.; ShILlingBURG, H. T.; KEENAN, M. P. Modifications of a new semi-ajustable for use with a caliper style ear facebow. J Cal Dent Ass, v. 5, n. 4, p. 32-38, apr. 1977.

79. WINSTANLEY, R. B. The hinge-axis: areview of the literature. J Oral Rehab v. 12, n. 2, p. 135-59, mar. 1985. 
80. WISE, M. D. Occlusion and restorative dentistry for the general practicioner. Br Dent J, v. 152, n. 8, p. 277-87, apr. 1982.

81. WRIGHT, Jr., W. J. A mathematical method for calculating the compensating anterior stop pin setting of a semiadjustable arcon articulator. J Prosth Dent, v. 61, n. 3, p. 362-67, mar. 1989.

82. ZANETTI, A. L.; RIBAS, R. A new method to simplify and increase the precision of maxillary cast mounting procedures in fully adjustable or semiadjustable articulators. J Prosth Dent, v. 77, n. 2, p. 219-24, feb. 1997.

83. ZUCKERMAN, G.R. Practical considerations for using the face-bow for complete denture prosthodontics. J Prosth Dent, v. 53, n. 2, p. 21921, feb. 1985. 


\section{SUMMARY}

\section{STUDY OF THE PRECISION CHANGES OF CAST MOUNTING PROCEDURES IN SEMIADJUSTABLE ARTICULATOR WITH THE ARBITRARY FACE-BOW TRANSFER.}

The articulator is one of the main instruments used in Dentistry for the diagnosis and treatment of the patient.

The factors associated with the choice of such instrument are multiple and perhaps the most important one is related to the philosophy of the development and correction of the occlusion, basic and fundamental principle that determines the construction of a dental prosthesis.

By means of a correct cast mounting procedure, the articulator represents the way in which the patient's maxillary cast is mounted in a similar way to the three-dimensional position of the patient's arches, in relation to the base of the cranium and to the terminal hinge axis of the condyles.

Zanetti \& Ribas (1997), studying a new method to simplify and increase the precision of maxillary cast mounting procedures in fully adjustable or semiadjustable articulators, by means of a transfer system in the simple arbitrary face-bow, they verified the existence of changes of the precision of the articulator when its upper frame with attached face-bow is replaced onto its lower frame allowing the fork toggle of the face-bow to rest on the plastic incisal guide block.

The present study analyzes the reasons of such precision changes in several articulators available in the Brazilian market and it presents a new device to be used with the simple arbitrary face-bow in order to avoid the deleterious effects that such positional errors could cause, from the occlusal analysis to the construction of a dental prosthesis. 


\section{$\underline{\text { AUTORIZACÃO }}$}

Autorizo a reprodução parcial ou total pelos interessados.

ROGÉRIO RIBAS DA COSTA

São Paulo, 08 de Maio de 1998.

Faculdade de Odontologia da Universidade de São Paulo.

Av. Lineu Prestes, 2227 - Cidade Universitária.

05508-900 São Paulo - Capital - Brasil.

e-mail: rogerio.ribas.cd@gmail.com 